\title{
Modelagem do Controle Gênico do Ciclo Celular por Redes Genéticas Probabilísticas
}

\author{
Nestor Walter Trepode \\ TESE APRESENTADA À UNIVERSIDADE DE SÃO PAULO PARA \\ A OBTENÇÃO DO TÍTULO DE DOUTOR EM BIOINFORMÁTICA
}

Orientador: Prof. Dr. Junior Barrera

Co-orientador: Prof. Dr. Hugo Aguirre Armelin

- O autor recebeu apoio financeiro da CAPES, da FAPESP, da Texas A\&M University e dos NIH. -

São Paulo, fevereiro de 2007. 
. 
Aos meus pais. 
. 


\section{Agradecimentos}

A meu orientador, Prof. Junior Barrera, por sua amizade, orientação, motivação, apoio em todo momento e atitude sempre construtiva, não só durante o doutorado, mas desde que o conheço, antes de começar o mestrado.

A meu co-orientador, Prof. Hugo Aguirre Armelim, por sua qualidade humana e profissional, atitude sempre positiva e alentadora, e pelo prazer de tê-lo conhecido e trabalhado com ele.

Ao Prof. Eduard Russell Dougherty, com quem tive a honra de trabalhar durante meu estágio de pesquisa na Texas A\&M University (TAMU), pelo decidido apoio recebido e por tudo o que aprendi dele, que vai desde o técnico até o que ele ensina com todo o que faz.

Às pessoas que colaboraram com meu trabalho, os Profs. Marco Dimas Gubitoso, Ronaldo Fumio Hashimoto do IME-USP e Michael L. Bittner de Translational Genomics Research Institute (TGen), e uma menção especial para meu amigo Marcel Brun em TGen, por tudo o que ajudou, ainda em momentos em que estava mais ocupado do que se pode imaginar.

A meus colegas do Laboratório de Processamento de Imagens de BIOINFO-USP no IME, especialmente a David da Silva Pires pelas suas inúmeras ajudas no uso da rede Linux. À CPG do Programa Interunidades em Bioinformática da USP, a Prof ${ }^{-}$Helaine Carrier, pela sua atitude aberta, e a Patricia Martorelli pela ampla colaboração nestes últimos anos.

A todo o pessoal do Genomic Signal Processing Laboratory da TAMU, pela sua amável colaboração e companheirismo no dia a dia, e em especial a meu amigo, o Prof. Ivan Ivanov, por toda sua ajuda durante minha estadia em College Station, Texas.

A todas as pessoas que me ajudaram durante este período, do doutorado e de minha vida, aquelas com quem troquei idéias e colaboraram de uma forma ou de outra, direta ou indiretamente, com o meu trabalho, e que certamente não poderei mencionar aqui.

E, finalmente, o mais importante, minha família, amor e apoio incondicional permanente, em especial meus pais, Ana Maria e Humberto, presentes em cada dia de minha vida pelo menos com uma mensagem de correio eletrônico, e a minha irmã Sonia, a quem, entre muitas outras coisas, devo a honra de estar na Universidade de São Paulo.

A todos eles, meu mais sincero agradecimento! 
. 


\section{Sumário}

1 Introdução $\quad 1$

2 Estado da Arte $\quad 9$

2.1 Modelos de Redes de Regulação Gênica . . . . . . . . . . . . . . . . . . . . 9

2.1 .1 Redes de Regulação Gênica . . . . . . . . . . . . . . . . . . . . . 9

2.1.2 Famílias de Modelos . . . . . . . . . . . . . . . . . 11

2.1.3 Sistemas Dinâmicos Discretos . . . . . . . . . . . . . . . . . 13

2.1.4 Redes Genéticas Probabilísticas (PGNs) . . . . . . . . . . . . . . 14

2.2 Biologia do Ciclo Celular . . . . . . . . . . . . . . . . . . . . 19

2.2.1 Sistema de Controle do Ciclo Celular . . . . . . . . . . . . . . . 20

2.3 Modelos Recentes de Ciclo Celular . . . . . . . . . . . . . . . . . . 23

2.3.1 Modelo de Li et al. do Ciclo Celular da Levedura . . . . . . . . . . . . . . 23

3 Modelagem do Ciclo Celular $\quad 27$

3.1 Modelo PGN do Ciclo Celular da Levedura . . . . . . . . . . . . . . . . 27

3.1 Caso Determinístico de Três Níveis . . . . . . . . . . . . . . . 27

3.1.2 Especificação da PGN . . . . . . . . . . . . . . . . . . . . . . . . 29

3.1.3 Simulações do Modelo PGN de Três Níveis do Ciclo Celular da Levedura na Presença de $1 \%$ de Ruído . . . . . . . . . . . . . . . . . 31

3.2 Nosso Modelo de Controle da Progressão Ciclo Celular . . . . . . . . . . . . . . . 34

3.2.1 Especificação Completa da PGN . . . . . . . . . . . . . . . . . 38

3.2.2 Resultados Experimentais . . . . . . . . . . . . . . . . . . 39

3.3 Modelo do Ciclo Celular com Atrasos Aleatórios . . . . . . . . . . . . . . . . 45

3.3 .1 Especificação da PGN . . . . . . . . . . . . . . . . . 45

3.3.2 Resultados Experimentais . . . . . . . . . . . . . . 47

3.4 Modelo do Ciclo Celular com Realimentação Positiva . . . . . . . . . . . . . . . . 51

3.4.1 Resultados Experimentais . . . . . . . . . . . . . . . . . 51 
4 Conclusão $\quad 53$

A Simulações do Sistema de Controle do Ciclo Celular $\quad 59$

A.1 Modelo de Li et al. do Ciclo Celular da Levedura . . . . . . . . . . . . . . . . . . 61

A.1.1 Modelo PGN de Três Níveis . . . . . . . . . . . . . . . . . . . . . . 61

A.1.2 Modelo Binário com Ruido Decrescente . . . . . . . . . . . . . . . 66

A.2 Nosso Modelo PGN do Ciclo Celular . . . . . . . . . . . . . . . . . . . . 71

A.2.1 Modelo PGN de Três Níveis . . . . . . . . . . . . . . . . . . . . 71

A.2.2 Modelo PGN de Três Níveis com ruido crescente . . . . . . . . . . . . . 76

A.2.3 Modelo PGN de Três Níveis com Atrasos Aleatórios . . . . . . . . . . . . 80

A.2.4 Testes Exaustivos de Estabilidade e Robustez . . . . . . . . . . . . . . . . 87

B Publicações e Apresentações em Eventos Científicos 101 


\title{
Resumo
}

O ciclo de divisão celular compreende uma seqüência de fenômenos controlados por una complexa rede de regulação gênica muito estável e robusta. Aplicamos as Redes Genéticas Probabilísticas (PGNs) para construir um modelo cuja dinâmica e robustez se assemelham às observadas no ciclo celular biológico. A estrutura de nosso modelo PGN foi inspirada em fatos biológicos bem estabelecidos tais como a existência de subsistemas integradores, realimentação negativa e positiva e caminhos de sinalização redundantes. Nosso modelo representa as interações entre genes como processos estocásticos e apresenta uma forte robustez na presença de ruido e variações moderadas dos parâmetros. Um modelo determinístico recentemente publicado do ciclo celular da levedura não resiste a condições de ruido que nosso modelo suporta bem. A adição de mecanismos de auto excitação, permite a nosso modelo apresentar uma atividade oscilatória similar à observada no ciclo celular embrionário. Nossa abordagem de modelar e simular o comportamento observado usando mecanismos de controle biológico conhecidos fornece hipóteses plausíveis de como a regulação subjacente pode ser realizada na célula. A pesquisa atualmente em curso procura identificar tais mecanismos de regulação no ciclo celular da levedura, usando dados de expressão gênica provenientes de medições seqüenciais de microarray.

\begin{abstract}
The cell division cycle comprises a sequence of phenomena controlled by a stable and robust genetic network. We applied a Probabilistic Genetic Network (PGN) to construct an hypothetical model with dynamical behaviour and robustness typical of the biological cell-cycle. The structure of our PGN model was inspired in well established biological facts such as the existence of integrator subsystems, negative and positive feedback loops and redundant signaling pathways. Our model represents genes' interactions as stochastic processes and presents strong robustness in the presence of moderate noise and parameters fluctuations. A recently published deterministic yeast cell-cycle model collapses upon noise conditions that our PGN model supports well. In addition, self stimulatory mechanisms can give our PGN model the possibility of having a pacemaker activity similar to the observed in the oscillatory embryonic cell cycle. Our approach of modeling and simulating the observed behavior by known biological control mechanisms provides plausible hypotheses of how the underlying regulation may be performed in the cell. The ongoing research is lead to identify such regulation mechanisms in the yeast cell-cycle from time-series microarray gene expression data.
\end{abstract}


. 


\section{Capítulo 1}

\section{Introdução}

A Ciência tenta entender e explicar a natureza. Para atingir esse objetivo é necessário desenvolver linguagens adequadas para descrever os fenômenos naturais. Os fenômenos que apresentam grandezas que podem ser medidas são chamados quantitativos. A linguagem mais adequada para descrever este tipo de fenômenos é a matemática. A descrição de um fenômeno quantitativo por meio de fórmulas matemáticas constitue um modelo matemático. Ele se distingue de uma simples fórmula matemática porque ele é validado experimentalmente, i.e., os resultados previstos pelo modelo coincidem com os medidos no laboratório. Os modelos dinâmicos representam a evolução temporal do sistema real. A análise de simulações computacionais de modelos dinâmicos pode sugerir novos modelos e hipóteses, os quais, quando são validados experimentalmente, aumentam nosso conhecimento do sistema real.

Dado que a modelagem depende de medidas quantitativas, as técnicas de modelagem passaram a ser adotadas em Biologia a medida que instrumentos de medida de fenômenos biológicos

foram se tornando disponíveis. Os recentes desenvolvimentos de tecnologias para a medição das 
quantias envolvidas em fenômenos moleculares, como seqüenciamento de DNA e proteínas, medida massiva de expressão gênica e outras, abrem caminho para a modelagem desses fenômenos.

Na pesquisa desta tese de doutorado propomos um modelo para o sistema de controle do ciclo de duplicação e divisão celular, ou ciclo celular. A modelagem de sistemas bioquímicos é uma tarefa multidisciplinar que combina pesquisas em áreas tais como biologia molecular, ciência da computação, matemática, química, física, etc.. A escolha do tipo de modelo deve considerar determinadas limitações práticas que afetam sua utilidade. Em princípio, modelos preditivos com alto grau de detalhe seriam de grande interesse, mas os dados experimentais de que dispomos para grandes sistemas gênicos são incompletos. Por exemplo, extrapolar o modelo de equações diferenciais de um único gene - incluindo todos seus parâmetros cinéticos - a grandes sistemas faria o modelo proibitivamente complexo, dificultando, e até inviabilizando, a determinação de todos seus parâmetros, para que ele gere soluções consistentes com os dados observados (um exemplo deste tipo de abordagem em [1]). Uma alternativa para simplificar a modelagem é procurar uma descrição global das redes genéticas, focalizando no comportamento do sistema, e desprezando, sempre que possível, os detalhes moleculares [2]. A idéia seria escolher um modelo de complexidade relativamente pequena, de entre todos os modelos capazes de descrever o nível de regulação gênica sob estudo — sobretudo no referente à capacidade preditiva do modelo. Assim, a adequação do modelo é determinada por um balanço entre dados disponíveis e complexidade tratável.

Recentes validações de modelos de redes gênicas por dados de células vivas mostram que modelos simples de redes, tais como os que representam a um gene como uma chave binária (ligado/desligado), são suficientes para predizer a dinâmica global de um circuito genético biológico $[3,4]$. Adicionalmente, estudos que realizaram a comparação formal entre modelos 
contínuos e discretos mostram que o comportamento qualitativo dessas duas classes de sistemas é equivalente [5]. Na construção do modelo simplificado, a consideração mais importante parece ser caracterizar a estrutura de sinalização global da rede como um todo — sua arquitetura — [6], e, no referente à dinâmica, a parte mais delicada parece ser a escolha inteligente dos detalhes a serem deixados fora [2].

O ciclo celular é o fenômeno básico pelo qual todas as células se reproduzem, dando origem a duas células filhas. Consta de quatro fases seqüenciais rigidamente coordenadas: fase $G_{1}$ (G de "gap"), durante o qual a célula cresce e se prepara para a seguinte; fase $S$ (S de síntese), envolvendo a replicação do DNA; fase $G_{2}$, também de crescimento e preparo para a mitose $(M)$ isto é, a fase da divisão celular propriamente dita, que gera duas células filhas. Uma complexa rede genética centraliza o controle da progressão $G_{1} \rightarrow S \rightarrow G_{2} \rightarrow M$. Este sistema central de controle apresenta uma grande adaptabilidade a diferentes condições ambientais e tipos de célula específicos, é estável ante a variação — ou excesso - de estímulos, robusto frente a flutuações de parâmetros e tolerante a falhas graças à replicação de estruturas e mecanismos na sua rede. Ele recebe, monitora e integra sinais extra-celulares e pode deter o ciclo em determinados pontos de controle ("checkpoints") se alguns eventos ainda não foram devidamente completados. Esta importante ação reguladora é realizada através de sinais de realimentação negativa $[7,8]$. O ciclo celular é um dos processos biológicos mais intensamente estudados, apesar disso, muito fica ainda por ser descoberto, como por exemplo, como ele é controlado por alguns de seus reguladores mais importantes [9].

Estudamos dois modelos recentemente propostos para descrever este sistema de controle. Li et al. propuseram um modelo determinístico binário do sistema de controle do ciclo celular da levedura, completamente baseado em informação biológica documentada na literatura [3]. 
Eles analisaram a propagação da onda de sinal gerada pelo modelo, a qual passa através de todas as fases consecutivas do ciclo celular, verificando, mediante simulação, que quase todas as transições convergem para uma trajetória única no espaço de estados, mostrando estabilidade ante diferentes formas de onda do sinal de ativação. Pomerening et al., em base a dados experimentais, propuseram um modelo contínuo determinístico para o ciclo celular embrionário (de sapo-Xenopus laevis), cuja progressão é auto-estimulada e reduzida, realizando uma nova divisão (M) imediatamente após finalizar a fase S (replicação do DNA), sem esperar a célula crescer (G1 e G2 não ocorrem) e sem necessidade de estímulo externo [10].

Simulamos o modelo de Li sob condições de ruído e observamos que ele não tolera nem mesmo perturbações de intensidade média e instantâneas muito baixas. Assim, decidimos propor um novo modelo do sistema de controle do ciclo celular, que representa a interação entrada-saída entre genes, e é descrito por um processo estocástico discreto. A arquitetura do sistema e o comportamento esperado foram idealizados a partir de observações qualitativas de sistemas biológicos estudados. A descrição do modelo em termos de expressão gênica simplifica a elaboração da arquitetura, assim como, a validação, pois estes dados são mais simples de medir do que outras variáveis, tais como concentrações de proteína. Ainda, no novo modelo os sinais são descritos com três níveis de intensidade, que permite representar os tipos de regulação ativadora, inibidora e neutra, além de fornecer uma descrição mais detalhada da dinâmica do que o modelo binário.

Recentemente, definimos uma família de processos estocásticos para representar a interação entrada-saída de genes em uma rede gênica: as Redes Genéticas Probabilísticas (PGN: "Probabilistic Genetic Network"). Uma PGN é uma família particular de Cadeias de Markov com algumas propriedades adicionais — axiomas - inspirados em fenômenos biológicos. Algumas implicações 
destes axiomas são: estacionariedade; todos os estados são alcançáveis; a transição de uma variável é condicionalmente independente das transições das outras variáveis; a probabilidade da trajetória de estados mais provável é muito maior que as probabilidades das outras trajetórias possíveis -i.e., o sistema é quase determinístico - ; um gene é modelado como uma porta não linear estocástica cuja expressão depende de uma combinação linear de sinais ativadores e inibidores; e, o sistema é construído por combinação destas portas elementares. Este modelo PGN foi aplicado com sucesso na descrição de redes genéticas do parasita da malária [11, 12].

No presente trabalho, a definição do modelo PGN foi estendida para sistemas de memória $m$ onde uma nova transição na evolução temporal depende dos $m$ instantes de tempo discreto anteriores ao momento atual. Utilizamos a PGN para construir um modelo PGN hipotético estrutural do sistema de controle da progressão do ciclo celular nos eucariotos, procurando reproduzir o comportamento dinâmico com um grau de robustez similar ao tipicamente observado num sistema biológico real. Estruturas de controle inspiradas em fatos biológicos bem conhecidos, tais como a existência de integradores, realimentações negativas e positivas e redundâncias biológicas, foram as partes constitutivas da arquitetura do modelo. Depois de ajustar seus parâmetros heuristicamente, o modelo foi capaz de representar propriedades do sistema biológico real, tais como propagação seqüencial de ondas de expressão gênica, estabilidade na presença de excitação variável e robustez na presença de ruído e ante a flutuação aleatória de seus parâmetros $[13,14]$.

O análise da estabilidade e robustez do modelo proposto, foi feito mediante numerosas simulações realizadas em diferentes condições de excitação e ruído. Comparamos estas simulações com outras similares para o modelo de Li et al. [3]. Ao contrário do modelo de Li, notamos que o nosso modelo apresenta características de robustez notáveis. Inferimos que o novo modelo 
possui características estruturais responsáveis pela sua robustez, as quais não estão presentes no modelo de Li e que, possivelmente, existam no ciclo celular biológico. Para emular ainda mais as condições reais do ambiente celular, incluímos em nosso modelo atrasos aleatórios nos sinais de regulação. O novo modelo foi ajustado de forma de não degradar sua estabilidade e robustez na presença de tais atrasos. Finalmente, mediante a adição de realimentação positiva, obtivemos um modelo auto estimulado, com um comportamento oscilatório similar ao observado no ciclo celular embrionário [10].

Entre os modelos conhecidos, o nosso modelo é o que apresenta maior corroboração qualitativa com os fenômenos biológicos. A validação quantitativa desse modelo é um trabalho que ainda está em andamento. Os dados adotados para validação são medições seqüenciais por microarray da dinâmica de expressão dos genes do ciclo celular da levedura $[15,16]$. Técnicas de identificação da arquitetura de redes gênicas estão sendo aplicadas para inferir segmentos da arquitetura do sistema de controle do ciclo celular da levedura. A arquitetura inferida a partir dos dados será comparada com a arquitetura proposta. Este trabalho, que está em estágio avançado de desenvolvimento, está sendo conduzido em cooperação com o grupo do Dr. Edward R. Dougherty da Texas A\&M University.

Após a presente introdução, o Capítulo 2 apresenta uma breve descrição do estado da arte na biologia do controle do ciclo celular, modelagem de redes genéticas e modelos anteriores do ciclo celular. O Capítulo 3 descreve nossa modelagem e simulação do sistema de controle da progressão do ciclo celular — em suas três versões-, suas simulações, comparação com o modelo de Li et al. e análise dos resultados obtidos. O Capítulo 4, Conclusão, explica a contribuição realizada na modelagem de redes genéticas, no entendimento do controle gênico da progressão do ciclo celular, as hipóteses geradas e a conseqüente continuidade das pesquisas. 
No Apêndice A são apresentadas simulações adicionais dos modelos de Li et al. e do nosso, sob diferentes condições de ruído e excitação, como também testes exaustivos de estabilidade e robustez realizados em nosso modelo de controle da progressão do ciclo celular. No Apêndice B são listadas as publicações e trabalhos apresentados em eventos durante o período do curso de doutorado. 


\section{Capítulo 2}

\section{Estado da Arte}

\subsection{Modelos de Redes de Regulação Gênica}

\subsubsection{Redes de Regulação Gênica}

O mecanismo de regulação do ciclo celular é um sistema muito complexo formado por sinais que atuam em momentos específicos, muitas vezes através de laços de realimentação. Tais sinais controlam a atividade celular — vias metabólicas - principalmente por meio de sua ação reguladora dos padrões de expressão gênica. A Figura 2.1 é uma representação esquemática deste tipo de sistema, habitualmente chamado rede de regulação gênica. As proteínas, produzidas como conseqüência da expressão gênica (i.e., depois da transcrição e tradução), formam complexos multi-protéicos, que são os sinais atuantes no sistema de controle celular. Eles interagem com outros complexos multi-protéicos, tanto internos como externos à célula, controlam vias metabólicas - e recebem sinais de volta dos processos sendo controlados- (setas 3 e 4) e enviam sinais de realimentação para os níveis de transcrição e tradução (setas 1 e 2). Estes 


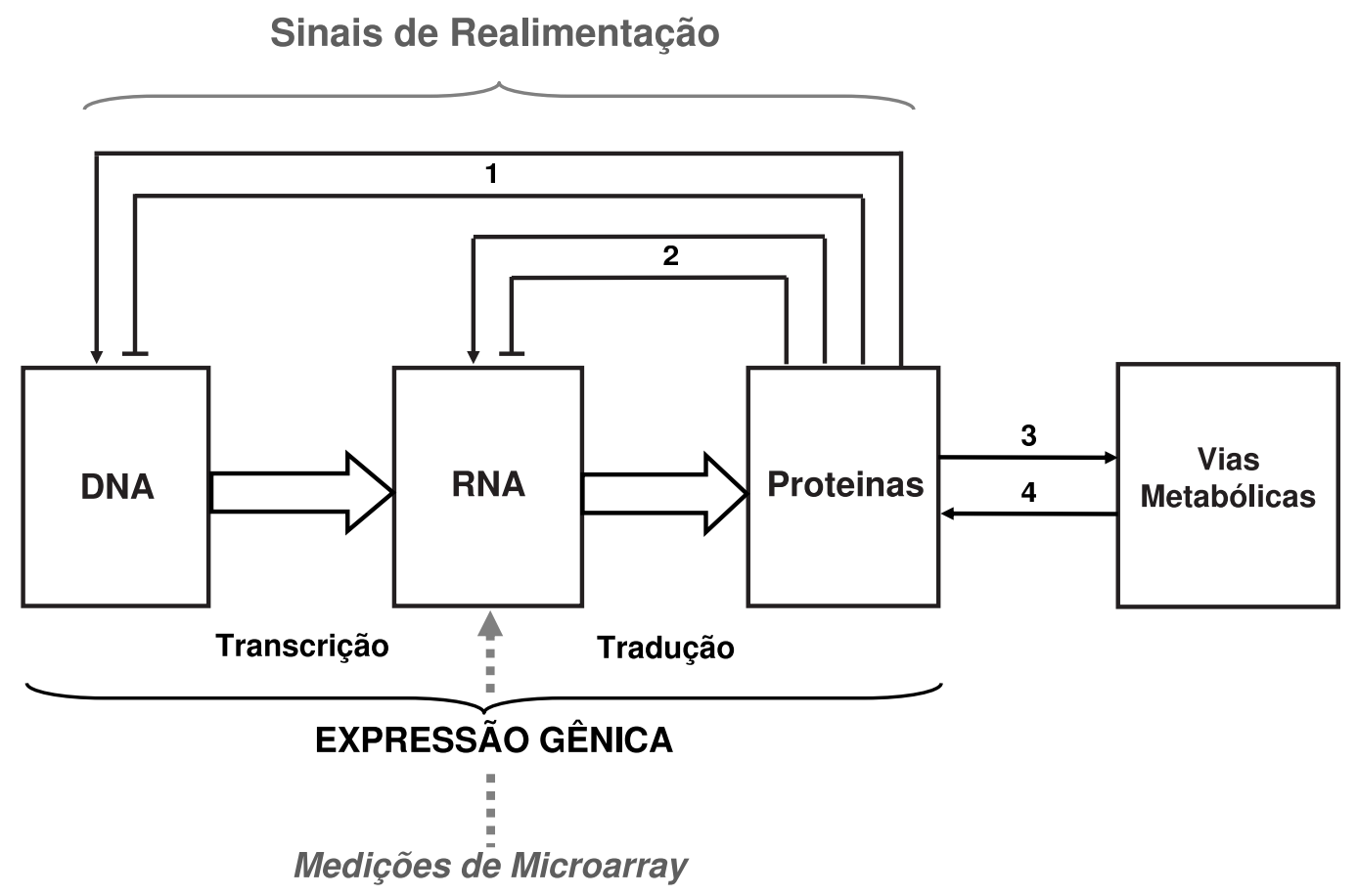

Figura 2.1: Rede de regulação gênica

sinais de realimentação modificam os padrões futuros de expressão gênica e, em conseqüência, a produção de novas proteínas. Desta forma, genes e os produtos de sua expressão formam uma rede de sinalização que controla as funções da célula, o ciclo de divisão celular e a morte celular programada. Fazendo uma analogia com um sistema típico de controle dos utilizados em engenharia (Figura 2.2), as vias metabólicas seriam a planta - o processo a ser controlado-, e o controlador estaria formado pelos níveis de transcrição e tradução — e de proteínas ${ }^{1}$ — os quais recebem sinais de realimentação dos processos sendo controlados.

Numa rede de regulação gênica, o nível de expressão de cada gene depende dos valores de

\footnotetext{
${ }^{1}$ Parte do controle é realizado inteiramente no nível de proteínas. As proteínas são ao mesmo tempo os sinais atuando no ambiente celular, portanto a distinção entre controlador e sinais, não é tão clara no sistema biológico.
} 


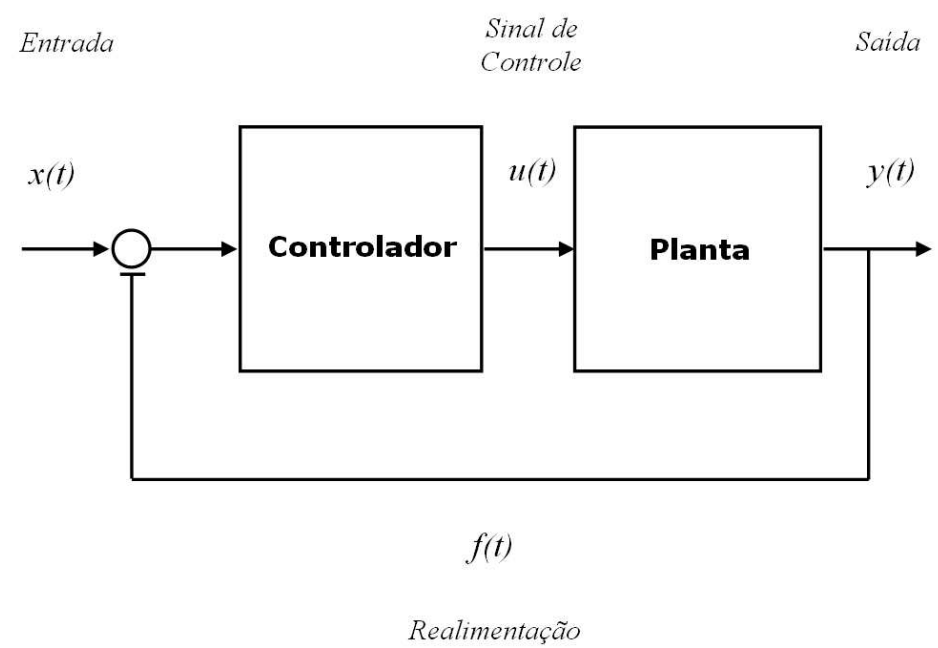

Figura 2.2: Sistema típico de controle.

expressão, próprios e de outros genes, em instantes prévios de tempo, como também de estímulos externos. Este tipo de dependência e evolução temporais permite modelar essa complexa rede de interações como um sistema dinâmico (nossa abordagem nas Subseções 2.1.3 e 2.1.4).

\subsubsection{Famílias de Modelos}

O vários tipos de modelos propostos de redes de regulação gênica existentes podem ser classificados, a grosso modo, em determinísticos ou estocásticos, ou em discretos ou contínuos.

Uma rede determinística é um sistema rígido onde o estado da expressão gênica — nível de expressão de todos os genes sendo considerados - em um tempo dado e as interações regulatórias entre eles determinam sem ambigüidades o estado da expressão gênica no tempo seguinte. Em tal rede, dada a história previa, há somente uma transição possível do estado presente da expressão da rede para o próximo.

Em um sistema estocástico, um estado dado de expressão gênica pode gerar mais de um estado seguinte, por exemplo, fazendo com que diferentes células da mesma população possam 
seguir um trajeto diferente de expressão gênica de um estado para o próximo. A estocacidade permite variações significativas na seqüência da ativação e inativação dos genes. A natureza estocástica de redes genéticas é suportada por considerações teóricas e por resultados experimentais. Os mecanismos que explicam esta estocacidade são, por exemplo, a degradação dos produtos do gene, a colisão espacial necessária antes que um reagente possa exercer sua influência, equações de reação reversível, etc.. Conseqüentemente, os modelos estocásticos descrevem a cinética da regulação gênica mais exatamente do que uma aproximação determinística. Em geral, os resultados experimentais podem ser melhor explicados e modelados por mecanismos estocásticos. Em compensação, os modelos determinísticos são mais simples que os estocásticos.

Uma rede Booleana é a rede discreta mais simples. Consiste de $n$ nós, representando os genes, que podem estar expressos ou não (estado 1 ou 0 , respectivamente). A dinâmica da rede é determinada por $n$ funções Booleanas (uma para cada nó). Uma função Booleana recebe $k$ nós de entrada, que determinam o estado seguinte desse nó a partir dos estados de todos os nós de entrada $[17,18]$. Este modelo é uma simplificação grosseira de uma rede genética, porque a expressão gênica tende a ser contínua (ou, ao menos, multi-valuada) antes que binária, e as relações possuem valores contínuos. Não obstante, muitos genes tem um comportamento biestável (muito expressos ou não expressos) e para eles o modelo binário constitui uma boa aproximação. Por outra parte, as redes Booleanas fornecem uma estrutura na qual os genes podem ter interações complexas e mostrar o comportamento comparável às características das redes genéticas biológicas (por exemplo: comportamento complexo global, auto-organização, etc. [19]). São um bom ponto de partida para uma modelagem realista das redes genéticas [20].

Em uma rede Booleana aleatória, cada nó - gene- pode ter um esquema diferente de entrada-saída, e um número diferente $k$ das entradas. Cada nó pode também ter diferentes 
funções Booleanas escolhidas aleatóriamente. São um refinamento probabilístico mais realista das redes Booleanas [21, 22].

No caso dos modelos contínuos, uma rede genética pode ser modelada como um conjunto de equações diferenciais [23]. Devem ser encontrados os parâmetros, que determinam a taxa de mudança da expressão de cada gene. A suposição de passos de tempo discretos para o próximo estado da rede, resulta aqui desnecessária.

\subsubsection{Sistemas Dinâmicos Discretos}

Os sistemas dinâmicos discretos — discretos em tempo e com escala de valores finita— são adequados para modelar o comportamento, descrito na Subseção 2.1.1, das redes de regulação gênica $[21,24,25,22,26]$. Neste modelo, um gene ou proteína é representado por uma variável cujo valor está dado pelo valor da expressão do gene ou da concentração da proteína. Tais variáveis, tomadas coletivamente, são as componentes de um vetor chamado estado do sistema, pelo qual são chamadas variáveis de estado. Cada variável de estado - i.e., gene ou proteínatem associada uma função que calcula seu próximo valor -i.e., nível de expressão ou concentração de proteína - a partir dos valores prévios do vetor de estado. Estas funções são as componentes de um vetor de funções, chamado função de transição do sistema, que define a transição para o próximo estado, modelando a ação conjunta dos mecanismos reais de regulação.

Seja $R$ a escala de valores que as componentes de estado podem assumir. Por exemplo: $R=\{0,1\}$, em sistemas binários; $R=\{-1,0,1\}$ ou $R=\{0,1,2\}$ em sistemas de três níveis. A função de transição $\phi$, de uma rede de $N$ variáveis e memória $m$, é uma função de $R^{m N}$ em $R^{N}$. Ou seja, a função de transição $\phi$ mapeia os $m$ estados prévios $x(t-1), x(t-2), \ldots, x(t-m)$ no estado $x(t)$, onde $x(t)=\left[x_{1}(t), x_{2}(t), \ldots, x_{N}(t)\right]^{T} \in R^{N}$. 
Um sistema dinâmico discreto é dado por

$$
x(t)=\phi[x(t-1), x(t-2), \ldots, x(t-m)],
$$

para todo tempo $t \geq 0$. Uma componente de $x$ é um valor $x_{i} \in R$. Os sistemas definidos desta forma são invariantes por translação no tempo, isto é, a função de transição é a mesma para todo tempo discreto $t$. A arquitetura - ou estrutura - do sistema é o diagrama de conexões que representa as dependências entre as variáveis componentes do vetor de estado. A dinâmica do sistema é a evolução temporal do vetor de estado — seqüência de valores - dada pela função de transição.

\subsubsection{Redes Genéticas Probabilísticas (PGNs)}

Quando a função de transição $\phi$ é uma função estocástica (isto é, para cada seqüência de estados $x(t-m), \ldots, x(t-2), x(t-1)$, o próximo estado $x(t)$ é uma realização de um vetor aleatório $)$ o sistema dinâmico é um processo estocástico. Aqui representamos as redes de regulação gênica por processos estocásticos nos quais a função de transição estocástica é uma família particular de cadeias de Markov, chamada redes genéticas probabilísticas.

Considere uma seqüência de vetores aleatórios $X_{0}, X_{1}, X_{2}, \ldots$ que toma valores em $R^{N}$, denotados, respectivamente, $x(0), x(1), x(2), \ldots$ Uma seqüência de estados aleatórios $\left(X_{t}\right)_{t=0}^{\infty}$ é chamada uma cadeia de Markov, se para cada $t \geq 1$,

$$
P\left[X_{t}=x(t) \mid X_{0}=x(0), \ldots, X_{t-1}=x(t-1)\right]=P\left[X_{t}=x(t) \mid X_{t-1}=x(t-1)\right]
$$

Ou seja, a probabilidade condicional do evento futuro, dada a história passada, só depende do 
instante de anterior. Seja $X$, com realização $x$, o estado antes da transição, e seja $Y$, com realização $y$, o primeiro estado depois da transição. Uma cadeia de Markov é completamente caracterizada por sua matriz de transição $\pi_{Y \mid X}$ de probabilidades condicionais entre estados — cujos elementos são denotados $p_{y \mid x}$ - e pela distribuição de probabilidades $\pi_{0}$ do vetor aleatório representando o estado inicial. A função de transição estocástica $\phi$ no tempo $t$, é dada por, para todo $t \geq 1$,

$$
\phi[x]=\phi[x(t-1)]=y
$$

onde $y$ é uma realização do vetor aleatório $Y \operatorname{com}$ distribuição $p_{\bullet} \mid x$.

Uma cadeia de Markov de ordem $m$ —a qual depende dos $m$ instantes de tempo anteriores à transição - é equivalente a uma cadeia de Markov com estados de dimensão $m \times N$.

Seja a seqüencia $\mathbf{X}=X_{t-1}, \ldots, X_{t-m}$, com realização $\mathbf{x}=x(t-1), \ldots, x(t-m)$, a seqüência de $m$ estados antes da transição. Uma Rede Genética Probabilística (ou PGN²) é uma cadeia de Markov de ordem $m\left(\pi_{Y \mid \mathbf{X}}, \pi_{0}\right)$, tal que

i) $\pi_{Y \mid \mathbf{X}}$ é homogênea, ou seja, $p_{y \mid \mathbf{x}}$ é independente de $t$.

ii) $p_{y \mid \mathbf{x}}>0$ para todos os estados $\mathbf{x} \in R^{m N}, y \in R^{N}$, i.e., a cadeia de Markov é ergódica.

iii) $\pi_{Y \mid \mathbf{X}}$ é condicionalmente independente, ou seja, para todos os estados $\mathbf{x} \in R^{m N}, y \in R^{N}$,

$$
p_{y \mid \mathbf{x}}=\Pi_{i=1}^{N} p\left(y_{i} \mid \mathbf{x}\right)
$$

iv) $\pi_{Y \mid \mathbf{X}}$ é quase determinística, ou seja, para toda seqüência de estados $\mathbf{x} \in R^{m N}$, existe um estado $y \in R^{N}$ tal que $p_{y \mid \mathbf{x}} \approx 1$.

\footnotetext{
2PGN: "Probabilistic Genetic Network"
} 
v) Para cada variável $i$ existe uma matriz $a_{i}$ e um vetor $b_{i}$ ambos de números reais, tal que para todo $\mathbf{x}, \mathbf{z} \in R^{m N}$ e $y_{i} \in R$, se

$$
\begin{gathered}
\sum_{j=1}^{N} \sum_{k=1}^{m} a_{j i}^{k} x_{j}(t-k)=\sum_{j=1}^{N} \sum_{k=1}^{m} a_{j i}^{k} z_{j}(t-k) \\
\text { e } \quad \sum_{k=1}^{p_{i}} b_{i}^{k} x_{i}(t-k)=\sum_{k=1}^{b_{i}} b_{i}^{k} z_{i}(t-k) \\
\text { então } \quad p\left(y_{i} \mid \mathbf{x}\right)=p\left(y_{i} \mid \mathbf{z}\right), \quad 0 \leq p_{i} \leq m .
\end{gathered}
$$

Estes axiomas implicam que cada variável $x_{i}$ está caracterizada por uma matriz e um vetor de coeficientes e uma função estocástica $g_{i}$ de $Z$ (um subconjunto de números inteiros) em $R$.

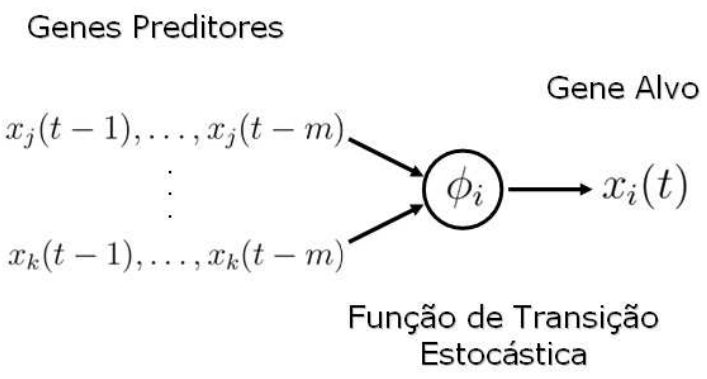

Figura 2.3: A PGN modela o comportamento de um gene como uma porta não linear estocástica.

Se $a_{j i}^{k}$ é positivo, então a variável alvo $x_{i}$ é ativada pela variável $x_{j}$ no tempo $t-k$, se $a_{j i}^{k}$ é negativo, então ela é inibida pela variável $x_{j}$ no tempo $t-k$, se $a_{j i}^{k}$ é zero, então não é afetada pela variável $x_{j}$ no tempo $t-k$. Dizemos que a variável $x_{i}$ é predita pela variável $x_{j}$ quando $\operatorname{algum} a_{j i}^{k}$ é diferente de zero. Similarmente, se $b_{i}^{k}$ é zero, o valor de $x_{i}$ no tempo $t$ não é afetado pelo seu valor prévio no tempo $t-k$. O parâmetro constante $p_{i}$, correspondente à variável $x_{i}$, representa o número de instantes prévios de tempo nos quais os valores anteriores de $x_{i}$ podem afetar o valor de $x_{i}(t)$. Se $p_{i}=0$, os valores prévios de $x_{i}$ não tem efeito nenhum sobre os valores 
de $x_{i}(t)$ e a somatória $\sum_{k=1}^{p_{i}} b_{i}^{k} x_{i}(t-k)$ é definida como zero.

A componente $i$ da função de transição estocástica $\phi$, denotada $\phi_{i}$, é construída pela composição de uma função estocástica $g_{i}$ com duas combinações lineares: i) $a_{i}$ e os estados prévios $x(t-1), \ldots, x(t-m)$, e ii) $b_{i}$ e os valores de $x_{i}(t-1), \ldots, x_{i}\left(t-p_{i}\right)$. Isto significa que, para todo $t \geq 1$,

$$
\phi_{i}[x(t-1), \ldots, x(t-m)]=g_{i}(\alpha, \beta)
$$

onde

$$
\alpha=\sum_{j=1}^{N} \sum_{k=1}^{m} a_{j i}^{k} x_{j}(t-k), \beta=\sum_{k=1}^{p_{i}} b_{i}^{k} x_{i}(t-k)
$$

e $g_{i}(\alpha, \beta)$ é uma realização de uma variável aleatória em $R$, com distribuição $p(\bullet \mid \alpha, \beta)$. Esta restrição sobre $g_{i}$ significa que as componentes do vetor função de transição da PGN são variáveis aleatórias com uma distribuição de probabilidade condicionada a duas combinações lineares, $\alpha$ e $\beta$, dadas pelo quinto axioma da PGN.

O modelo PGN representa as propriedades de um gene como uma porta não linear estocástica. Os sistemas são construídos combinando estas portas - Figura 2.3 - como elementos constitutivos.

\section{Justificativa biológica dos axiomas da PGN}

Os axiomas que definem o modelo PGN são inspirados em fenômenos biológicos. A estrutura de sistema dinâmico se justifica pela necessidade de representar um processo seqüencial. A representação discreta é suficiente dado que as interações entre genes e proteínas ocorrem no nível molecular [2]. Os aspectos estocásticos representam perturbações ou a falta de conhecimento detalhado sobre a dinâmica do sistema. O axioma i é simplesmente uma restrição para simplificar 
o modelo. Em geral, os sistemas reais não são homogêneos, mas podem ser homogêneos por partes, ou seja, em intervalos de tempo. O axioma ii impõe que todos os estados são alcançáveis, o seja que o ruido pode levar o sistema a qualquer estado. Trata-se de um modelo bastante geral que reflete nossa falta de conhecimento do tipo de ruido que pode afetar ao sistema. O axioma iii implica que a predição de cada gene pode ser computada independentemente da predição dos outros genes, o que representa um tipo de decomposição do sistema consistente com o que é observado na natureza. O Axioma iv significa que o sistema possui uma trajetória principal, ou seja, existe uma trajetória que é muito mais provável que as outras. O axioma v significa que os genes atuam como uma porta não linear disparada por um balanço entre entradas inibidoras e ativadoras, de forma análoga a como os neurônios são ativados. 


\subsection{Biologia do Ciclo Celular}

O ciclo celular é uma seqüência ordenada de eventos pela qual a célula se duplica e divide em duas células filhas. É o mecanismo básico pelo qual todos os seres vivos se reproduzem. A organização básica do ciclo e seu sistema de controle tem sido altamente conservados durante a evolução e são essencialmente os mesmos em todas as células eucariotas, particularmente no conjunto mínimo de processos que permitem realizar a tarefa mais fundamental: transmitir a informação genética para a próxima geração de células $[7,8]$.

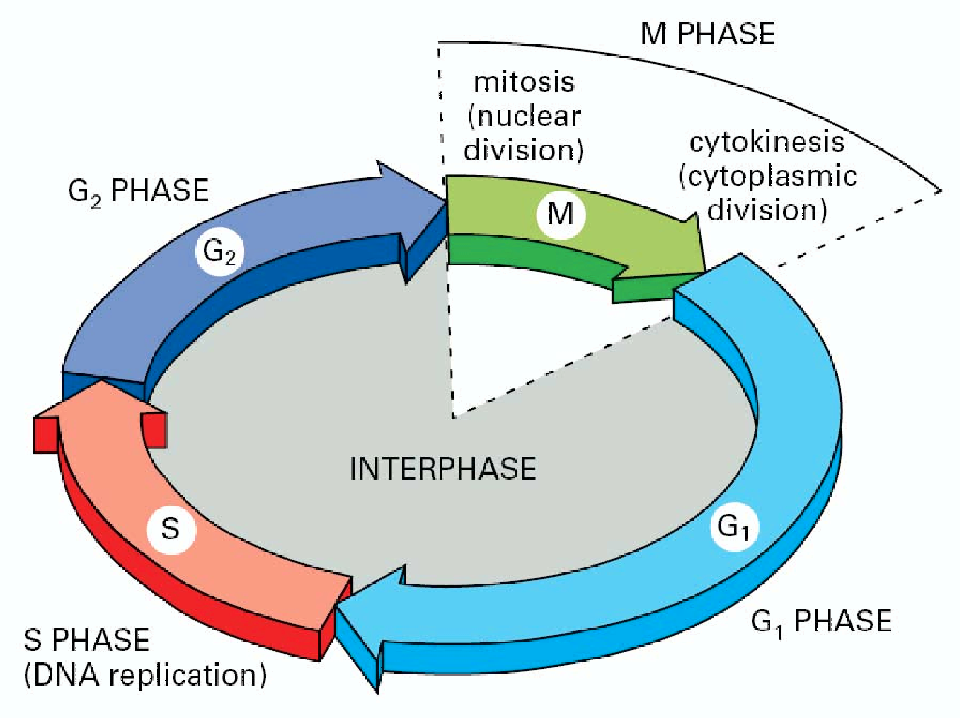

Figura 2.4: Fases do Ciclo Celular (extraída de [8]).

O ciclo celular eucarioto é tradicionalmente dividido em quatro fases seqüenciais: $G_{1}, S$, $G_{2}$ e $M$ (Figura 2.4). As fases $G_{1}, S$, e $G_{2}$, conjuntamente, são chamadas interfase. A célula cresce continuamente durante a interfase, onde o evento mais importante é a replicação dos cromossomos, isto é, síntese de DNA e principalmente histonas, proteínas básicas componentes essenciais da cromatina, que ocorre na fase $S$. A fase $S$ e a fase $M$ estão usualmente separadas por duas fases intermediárias ("Gap phases") chamadas $G_{1}$ e $G_{2}$. O comprimento da fase $G_{1}$ 
varia grandemente, dependendo do tipo celular e de condições externas ou sinais extracelulares provenientes de outras células, enquanto o comprimento das demais fases, $S, G_{2}$ e $M$, varia muito pouco, mesmo para diferentes espécies de organismos. Se as condições extracelulares são desfavoráveis desfavoráveis ou os sinais externos inibitórios prevalecem, as células atrasam a progressão para o estado $G_{1}$ ou mesmo regridem ao estado de repouso conhecido como $G_{0}(\mathrm{G}$ zero), onde podem permanecer por tempo indeterminado (horas, dias ou anos). Em condições extra celulares favoráveis e sob a ação de sinais externos estimulatórios, as células retornam ao ciclo, fazendo a transição $G_{0} G_{1}$ e progredindo através de $G_{1}$ até iniciar a replicação do DNA, a qual uma vez iniciada é irreversível, seguindo-se $G_{2}$ e mitose. Durante a fase $M$, os cromossomos replicados são separados em núcleos diferentes (mitose) e a célula se divide em duas (cytokinese).

\subsubsection{Sistema de Controle do Ciclo Celular}

O sistema de controle do ciclo celular está formado por uma rede complexa de proteínas reguladoras que governam a progressão através do ciclo. A parte central deste sistema está formada uma serie ordenada de comutadores biológicos que controlam os eventos principais. Outros níveis de regulação melhoram a fidelidade da divisão celular e permitem ao sistema de controle responder a sinais provenientes de dentro e fora da célula. O sistema de controle supervisiona a progressão ordenada pelo ciclo celular adiando determinados eventos quando outros anteriores precisam ainda ser completados. Também monitora e integra sinais de fora da célula — de outras células ou do ambiente intercelular - estimulando ou bloqueando a divisão celular dependendo da necessidade ou não de mais células.

Um controlador central dispara os principais eventos do ciclo celular em uma seqüência bem determinada. Algumas características que o sistema de controle possui são as seguintes: 
- Um temporizador - ou relógio interno - assegura que cada evento seja ativado em um momento específico, atribuindo a cada evento uma quantidade específica de tempo para ser completado.

- Os eventos sempre são iniciados na ordem correta.

- Cada evento é ativado somente uma vez por ciclo.

- Os eventos são ativados em uma forma completa e irreversível.

- Mecanismos paralelos (redundantes) fornecem robustez aumentando a tolerância a falhas de partes do sistema de controle.

- Adaptabilidade: o comportamento do sistema pode ser modificado para se adaptar a condições ambientais ou tipos de células específicas, sem que estes fatores afetem suas funções básicas (outra forma de robustez [27]).

- Robustez: o sistema mantém suas funções básicas apesar de perturbações externas ou internas.

O sistema de controle também recebe informação de volta dos processos que está controlando, na forma de sinais de realimentação. No caso de que alguns eventos não tenham sido completados, pode deter o ciclo celular em certos "checkpoints" — pontos de inspeção ou de controleespecíficos. Estes "checkpoints" operam geralmente através de sinais de realimentação negativa intracelulares.

As componentes moleculares centrais do sistema de controle do ciclo celular pertencem a uma família de proteínas kinases conhecidas como CDKs (Cyclin-Dependent Kinases), cuja atividade depende da associação com sub-unidades reguladoras chamadas ciclinas. Uma seqüência ordenada de atividades de complexos ciclina- $C D K$ dispara a maioria dos eventos do ciclo celular. Desta forma, a ativação dos complexos ciclina- $C D K$ da fase $S$ inicia a fase $S$, enquanto a ativação dos complexos ciclina- $C D K$ da fase $M$ dispara a mitose. As atividades dos complexos ciclina-CDK são influenciadas por vários mecanismos moleculares: fosforilização, ligação de 
proteínas inibidoras, proteólise de ciclinas, transcrição de genes que codificam reguladores das CDKs, etc.. Dois complexos de enzimas, $S C F$ e $A P C$ são também componentes cruciais do sistema de controle do ciclo celular. Eles, induzindo a degradação de reguladores específicos, disparam vários eventos críticos do ciclo celular. A progressão pelo ciclo celular é regulada com precisão por vários mecanismos de inibidores capazes de deter o ciclo celular em pontos de controle - checkpoints - específicos quando eventos não são completados com sucesso, quando existe dano de DNA, ou quando as condições extracelulares não são favoráveis. Apesar de que o ciclo celular tem sido extensamente estudado, muitos dos detalhes de como atuam os mecanismos, como assim certos mecanismos específicos, são ainda desconhecidos e motivo de pesquisa. 


\subsection{Modelos Recentes de Ciclo Celular}

Modelos de ciclo celular vem sendo desenvolvidos ao longo de décadas. Mas, recentemente destacam-se aqueles dirigidos à modelagem do ciclo celular de leveduras, pelo avançado conhecimento da biologia molecular e celular desses organismos. Existem tanto modelos contínuos como discretos. Entre os modelos contínuos, o desenvolvido pelo grupo de John J. Tyson é um dos mais completos $[28,29,30,1]$. Ele esta formado por mais de sessenta equações diferenciais determinísticas envolvendo as taxas de crescimento das concentrações de proteínas. O maior inconveniente deste tipo de modelos reside na grande quantidade de parâmetros a serem medidos ou estimados. Aqui, a disponibilidade de dados provenientes de medições e a qualidade da estimação dos que não se dispõe delas, devem ser consideradas.

Dentre os modelos discretos de ciclo celular, descreveremos em detalhe na seguinte subseção o de Li et al., o qual simulamos a fim de comparar seu desempenho com o nosso modelo do controle da progressão do ciclo celular (Seção 3.2). Tal modelo tem algumas similaridades com nossa abordagem, no sentido que se trata de um modelo discreto simplificado incluindo só os principais reguladores do ciclo celular, focalizando no comportamento dinâmico global da rede mais que nos detalhes moleculares $[2,5]$.

A estocacidade, tanto em modelos contínuos como discretos tem sido incluída em forma muito limitada (por exemplo em [31]).

\subsubsection{Modelo de Li et al. do Ciclo Celular da Levedura}

Realizamos estudos de estabilidade e robustez em um modelo binário determinístico do controle do ciclo celular da levedura de Li et al. [3]. O modelo foi inteiramente construído a partir de 
conhecimento biológico estabelecido, depois de realizar estudos extensivos da literatura. Dos $\approx 800$ genes envolvidos no processo do ciclo celular da levedura [16], foi selecionado um pequeno conjunto dos reguladores mais importantes — responsáveis pelo controle do ciclo celular — para construir um modelo com cada interação entre as variáveis devidamente documentada.

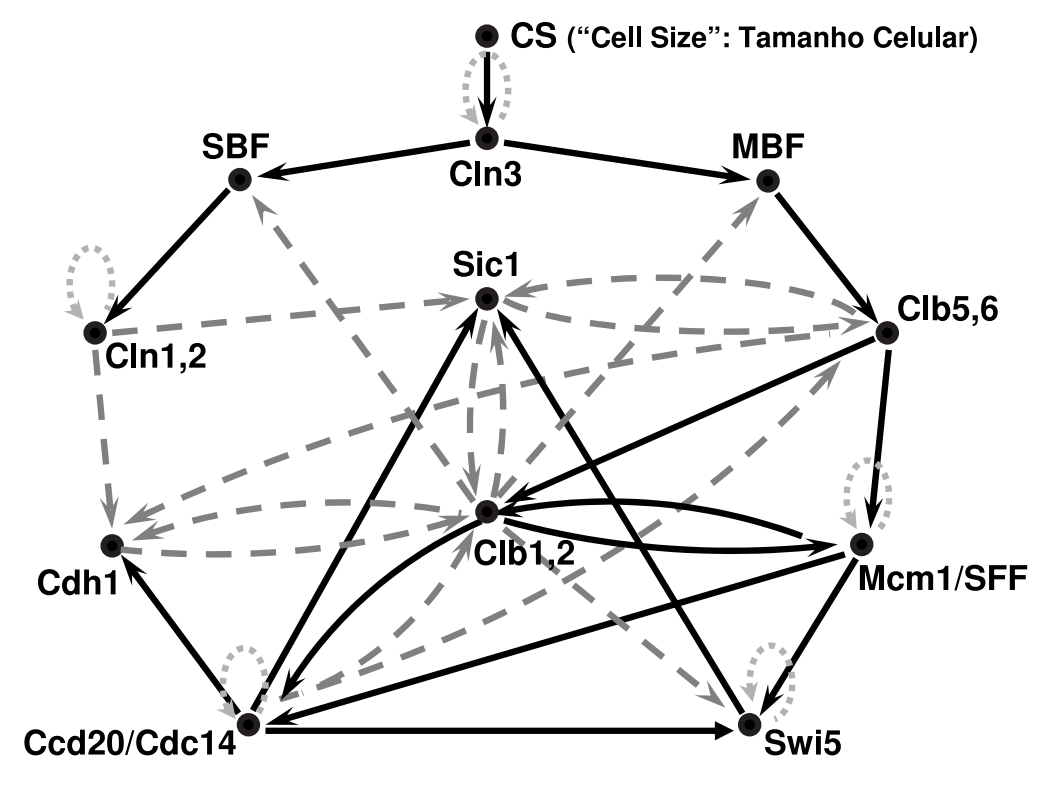

Figura 2.5: Arquitetura do modelo simplificado do ciclo celular da levedura (da Figura 1B de [3]).

A Figura 2.5 ilustra a arquitetura de rede da versão simplificada deste modelo. Nela, cada nó $i$ possui um estado binário $x_{i}=1$ ou $x_{i}=0$. Uma seta de linha cheia de $i$ para $j$ indica uma ação ativadora do nó $i$ sobre o nó $j$, a qual é quantificada por um peso $a_{i j}=1$ associado a essa seta. Uma seta de linha de traços de $i$ para $j$ indica que o nó $i$ tem um efeito inibidor sobre o nó $j$, representado por um peso $a_{i j}=-1$. Se não há nenhuma seta do nó $i$ para o nó $j$, o nó $i$ não influi no estado futuro do nó $j$, o que é representado por um peso $a_{i j}=0$.

O vetor função de transição determina a dinâmica do sistema, e possui uma componente 
associada a cada nó $i$ da rede:

$$
x_{i}(t)= \begin{cases}1 & \text { se } d_{i}(t-1)>0 \\ 0 & \text { se } d_{i}(t-1)<0 \\ x_{i}(t-1) & \text { se } d_{i}(t-1)=0\end{cases}
$$

onde $d_{i}(t-1)=\sum_{j} a_{j i}(t-1)$-função excitadora de $x_{i}$ - representa a entrada total sobre a variável $x_{i}$.

\begin{tabular}{|c|c|c|}
\hline Estado & Cln3 $\cdots$ McmSFF & Fase \\
\hline$S_{1}$ & 10001000100 & START \\
\hline$S_{2}$ & 01101000100 & $G_{1}$ \\
\hline$S_{3}$ & 01111000100 & $G_{1}$ \\
\hline$S_{4}$ & 01110000000 & $G_{1}$ \\
\hline$S_{5}$ & 01110001000 & $S$ \\
\hline$S_{6}$ & 01110001011 & $G_{2}$ \\
\hline$S_{7}$ & 00010011011 & $M$ \\
\hline$S_{8}$ & 00000110011 & $M$ \\
\hline$S_{9}$ & 00000110111 & $M$ \\
\hline$S_{10}$ & 00000110101 & $M$ \\
\hline$S_{11}$ & 00001110100 & $M$ \\
\hline$S_{12}$ & 00001100100 & $G_{1}$ \\
\hline$S_{S G_{1}}$ & 00001000100 & $G_{1}$ Estacionário \\
\hline
\end{tabular}

Tabela 2.1: Lista simplificada de estados da via biológica. As variáveis de estado são indicadas nesta ordem: Cln3, MBF, SBF, Cln12, Cdh1, Swi5, Cdc20Cdc14, Clb56, Sic1, Clb12, Mcm1SFF.

O processo de auto degradação é indicado na Figura 2.5 por laços de linha de pontos nos nós que não são negativamente regulados por outros nós. A auto degradação nestes nós é representada pela seguinte propriedade: se um nó $i$ com auto degradação tem valor $x_{i}(t)=1$ e 
sua entrada total de $t+1$ até $t+t_{d}$ é zero, então será degradado em $t+t_{d}$, ou seja $x_{i}\left(t+t_{d}\right)=0$. Os resultados apresentados no artigo [3], foram obtidos com $t_{d}=1$ e os pesos previamente indicados.

O ciclo celular começa quando o estado estacionário $G_{1}$ é ativado por $C S$ (Cell Size $\equiv$ tamanho da célula), ou seja quando a célula cresce acima de um certo limiar. A Tabela 2.1 mostra a evolução temporal dos estados pela via biológica, passando por todas as fases seqüenciais do ciclo celular, desde o estado $G_{1}$ excitado, a fase $S$, a fase $G_{2}$, a fase $M$, até o estado estacionário $G_{1}$ onde permanece. 


\section{Capítulo 3}

\section{Modelagem do Ciclo Celular}

\subsection{Modelo PGN do Ciclo Celular da Levedura}

Para estudar o efeito do ruído e do aumento do número de níveis de sinal, traduzimos o modelo de Li et al. do ciclo celular da levedura [3] em um modelo PGN de três níveis.

\subsubsection{Caso Determinístico de Três Níveis}

Um passo intermédio antes de construir o modelo PGN de três níveis foi mapear o modelo binário determinístico de Li et al. em um modelo determinístico de três níveis onde as variáveis de estado assumem valores em $R=\{0,1,2\}$. Sendo que a matriz de transição $\pi_{Y \mid \mathbf{X}}$ de uma PGN é quase determinística, este é simplesmente um caso limite da PGN que ocorre quando a probabilidade das transições mais prováveis $p_{y \mid \mathbf{x}} \rightarrow 1$, e representa um sistema com total ausência de ruído.

O mapeamento realizado se ilustra na Tabela 3.1. A tabela da esquerda representa a função de transição do modelo do ciclo celular da levedura binário determinístico definida na Seção 2.3.1, 


\begin{tabular}{|c|c|c|}
\multicolumn{3}{|c}{ Binário } \\
\hline \multirow{2}{*}{$d_{i}(t)$} & \multicolumn{2}{|c|}{$x_{i}(t)$} \\
\cline { 2 - 3 } & $x_{i}(t-1)=0$ & $x_{i}(t-1)=1$ \\
\hline$\vdots$ & $\vdots$ & $\vdots$ \\
3 & 1 & 1 \\
2 & 1 & 1 \\
$\mathbf{1}$ & $\mathbf{1}$ & $\mathbf{1}$ \\
$\mathbf{0}$ & $\mathbf{0}$ & $\mathbf{1}$ \\
$\mathbf{- 1}$ & $\mathbf{0}$ & $\mathbf{0}$ \\
-2 & 0 & 0 \\
-3 & 0 & 0 \\
$\vdots$ & $\vdots$ & $\vdots$ \\
\hline
\end{tabular}

\begin{tabular}{|c|c|c|c|}
\hline \multirow{3}{*}{$d_{i}(t)$} & \multicolumn{3}{|c|}{$x_{i}(t)$} \\
\cline { 2 - 4 } & $x_{i}(t-1)=0$ & $x_{i}(t-1)=1$ & $x_{i}(t-1)=2$ \\
\hline$\vdots$ & $\vdots$ & $\vdots$ & $\vdots$ \\
3 & 2 & 2 & 2 \\
$\mathbf{2}$ & $\mathbf{2}$ & $\mathbf{2}$ & $\mathbf{2}$ \\
$\mathbf{1}$ & $\mathbf{1}$ & $\mathbf{2}$ & $\mathbf{2}$ \\
$\mathbf{0}$ & $\mathbf{0}$ & $\mathbf{1}$ & $\mathbf{2}$ \\
$\mathbf{- 1}$ & $\mathbf{0}$ & $\mathbf{0}$ & $\mathbf{1}$ \\
$\mathbf{- 2}$ & $\mathbf{0}$ & $\mathbf{0}$ & $\mathbf{0}$ \\
-3 & 0 & 0 & 0 \\
$\vdots$ & $\vdots$ & $\vdots$ & $\vdots$ \\
\hline
\end{tabular}

Tabela 3.1: Mapeamento do modelo binário determinístico no modelo de três níveis determinístico do ciclo celular da levedura. Para as variáveis com a propriedade de auto degradação, o valor de $x_{i}(t)$ é aquele da coluna de $x_{i}(t-1)=0$, independentemente do valor $x_{i}(t-1)$.

e a tabela da direita representa seu mapeamento para a função de transição de três níveis determinística. O valor binário 1 foi mapeado para 2 no modelo de três níveis, e o valor binário 0 foi mapeado para 0. Valores intermédios (das funções de excitação - entrada - e de saída da função de transição) foram mapeados de forma conveniente, ou seja, de forma que fiquem entre os que possuem uma correspondência exata. Quando uma variável $x_{i}$ tem a propriedade de auto degradação (laços de linha de pontos na Figura 2.5), o valor de $x_{i}(t)$ é aquele da coluna de $x_{i}(t-1)=0$, independentemente do valor real de $x_{i}(t-1)$.

A Figura 3.1 mostra uma simulação ${ }^{1}$ deste modelo quando seu estado estacionário $G_{1}$ é ativado por um único pulso de $C S=2 \mathrm{em} t=-1$. O sistema percorre seqüencialmente todas as fases da via biológica do ciclo celular, desde o estado $G_{1}$ excitado, as fases $S, G_{2}, M$, até o estado estacionário $G_{1}$, onde permanece na ausência de sinal de ativação $C S$. A seqüência do ciclo celular, tem um comprimento total de 13 passos de tempo discreto (período do ciclo). Como era de esperar, este modelo de três níveis determinístico tem exatamente o mesmo comportamento

\footnotetext{
${ }^{1}$ Todas as simulações foram realizadas com SGEN (Simulator for Gene Expression Networks) [20].
} 


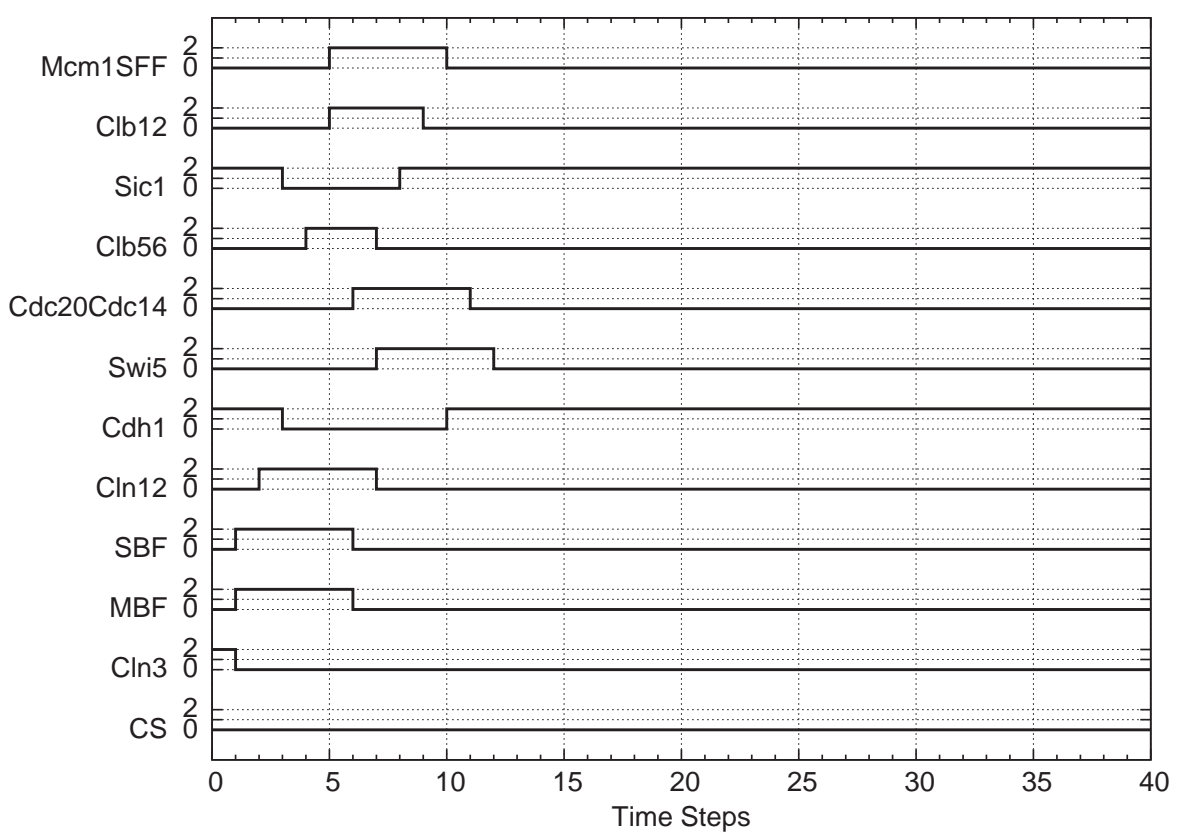

Figura 3.1: Simulação do modelo do ciclo celular da levedura de três níveis determinístico, ativado por um único pulso de $C S=2 \mathrm{em} t=-1$. Depois do estado "START" em $t=0$, o sistema percorre a via biológica, passando por todas as fases seqüencias do ciclo celular: $G_{1}$ em $t=1,2,3 ; S$ em $t=4 ; G_{2}$ em $t=5 ; M$ em $t=6, \ldots, 10 ; G_{1}$ em $t=11$; e a partir de $t=12$ o sistema permanece no estado estacionário $G_{1}$ - toda as variáveis em nível zero exceto Sic $1=C d h 1=2$.

dinâmico do modelo binário de [3], a partir do qual foi derivado.

\subsubsection{Especificação da PGN}

A entrada total que atua sobre uma variável de estado genérica $x_{i}(t) \in\{0,1,2\}(1 \leq i \leq N)$ é representada por sua função excitadora associada:

$$
d_{i}(t-1)=\sum_{j=1}^{N} a_{j i} x_{j}(t-1) .
$$

Como este é um sistema com memória $m=1, a_{j i}=a_{j i}^{1}=$ é o peso da variável $x_{j}$ no tempo $t-1$ na função excitadora da variável $x_{i}$. Se a variável $x_{j}$ ativa a variável $x_{i}$ (seta de linha cheia 
na Figura 2.5), então $a_{j i}=1$; se a variável $x_{j}$ inibe a variável $x_{j}$ (seta de linha de traços na Figura 2.5), então $a_{j i}=-1$; de outra forma, $a_{j i}=0$. Seja

$$
f_{i}(t)=\left\{\begin{array}{lll}
2 & \text { se } & d_{i}(t-1) \geq t h 2_{x_{i}} \\
1 & \text { se } & t h 1_{x_{i}} \leq d_{i}(t-1)<t h 2_{x_{i}} \\
0 & \text { se } & d_{i}(t-1)<t h 1_{x_{i}}
\end{array}\right.
$$

a função de transição estocástica

escolhe como próximo valor de cada variável

$$
x_{i}(t)=\left\{\begin{array}{ccl}
f_{i}(t) & \text { com probabilidade } & P \approx 1, \\
a & \text { com probabilidade } & (1-P) / 2, \text { ou } \\
b & \text { com probabilidade } & (1-P) / 2,
\end{array}\right.
$$

onde $a, b \in\{0,1,2\}-\left\{y_{i}\right\}$, e $t h 1_{x_{i}}, t h 2_{x_{i}}$ são os limiares para os valores de saída '1' e '2' na componente da função de transição associada à variável $x_{i}$. Esta componente é uma instanciação da composição da função estocástica $g_{i}$ com as combinações lineares $\alpha$ e $\beta$, indicada na Subseção 2.1.4 como conseqüência dos axiomas da PGN. Para que este modelo convirja para o determinístico da seção anterior (Tabela 3.1) quando $P \rightarrow 1$, os limiares devem ter os seguintes valores. Se a variável $x_{i}$ tem a propriedade de auto-degradação (laços de linha de pontos na Figura 2.5), $t h 1_{x_{i}}=1$ e $t h 2_{x_{i}}=2$. Se não há auto-degradação no nó $i$, estes limiares dependem do valor prévio de $x_{i}$ da seguinte forma: 


\begin{tabular}{rccc}
\hline & $x_{i}(t-1)=0$ & $x_{i}(t-1)=1$ & $x_{i}(t-1)=2$ \\
\hline \hline$t h 1_{x_{i}}$ & 1 & 0 & -1 \\
$t h 2_{x_{i}}$ & 2 & 1 & 0 \\
\hline
\end{tabular}

\subsubsection{Simulações do Modelo PGN de Três Níveis do Ciclo Celular da Leve- dura na Presença de 1\% de Ruído}

Simulamos o modelo PGN de três níveis do ciclo celular da levedura com probabilidade $P=$ 0.99, para representar a presença de $1 \%$ de ruído no sistema (um resumo mais completo destas simulações na Subseção A.1.1 do Apêndice A).

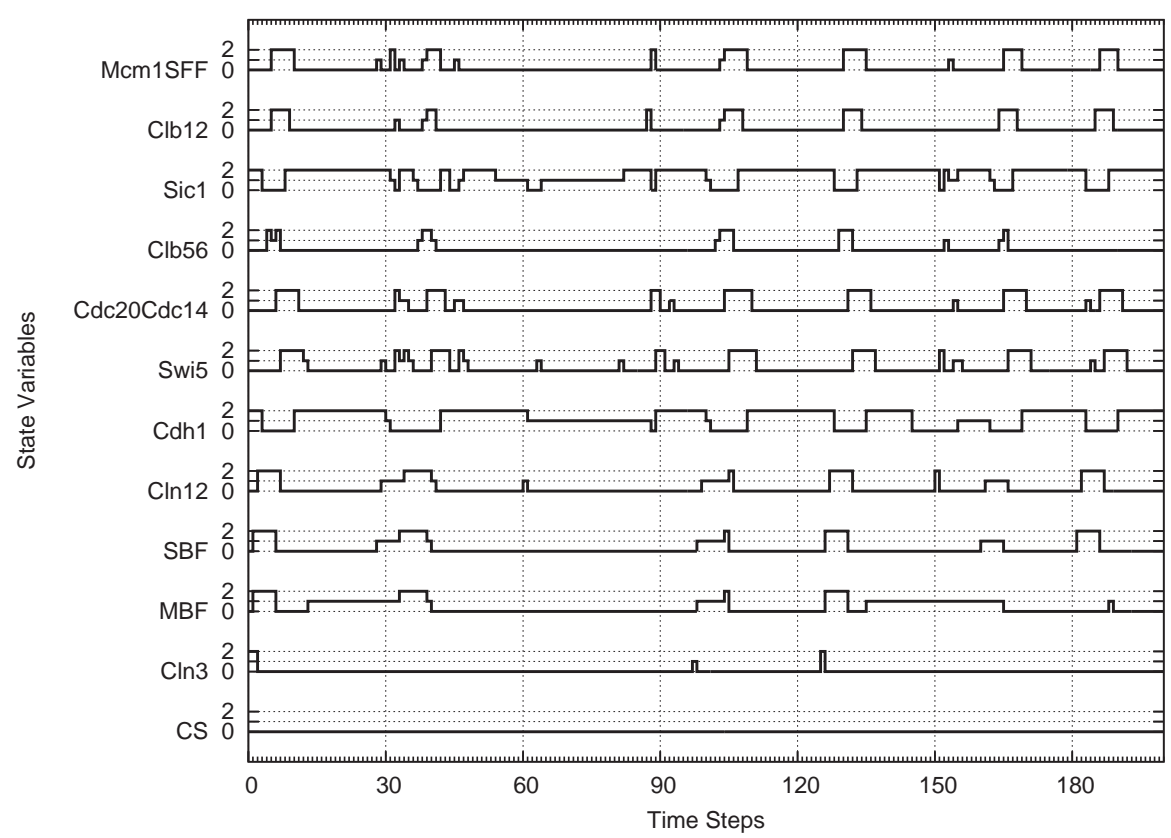

Figura 3.2: Simulação do modelo PGN de três níveis do ciclo celular da levedura com $1 \%$ de ruído (PGN com $P=0.99$ ) ativado por um único pulsos de $C S=2 \mathrm{em} t=-1$. Depois do tempo $t=12$ o sistema deveria permanecer no estado estacionário $G_{1}$ — todas as variáveis em nível zero, exceto Sic1 $=C d h 1=2-($ comparar com a Figura 3.1$)$, mas esta pequena quantidade de ruído (1\%) é suficiente para tirar o sistema completamente fora do seu comportamento normal.

A Figura 3.2 mostra uma simulação de 200 passos do sistema quando o estado estacionário 
$G_{1}$ é ativado por um único pulso de $C S=2$ em $t=-1$. Comparando com a Figura 3.1, observamos que esta pequena quantidade de ruído é suficiente para degradar completamente o comportamento do sistema. Em particular, é observado que quando o sistema deveria permanecer no estado estacionário $G_{1}$ depois do tempo do período do ciclo -13 passos- e sem nenhum sinal ativador $C S$, o ruído não é resistido pelo sistema e abundantes formas de onda espúrias são geradas.

Seguidamente, simulamos o sistema aumentando a freqüência dos pulsos ativadores $C S$. Na Figura 3.3(a) (CS = oscilador de período 20) a distância entre os pulsos ativadores $C S$ é maior que o período do ciclo, e portanto, quando um novo pulso ativador chega, o ciclo prévio já foi completado. Na Figura 3.3(b) (CS= oscilador de período 6) o tempo entre pulsos ativadores consecutivos é menor que o período do ciclo e, portanto, alguns pulsos ativadores atuam quando ainda o ciclo anterior não foi finalizado. Nestas figuras, como na Figura 3.2 e nas simulações da Subseção A.1.1, o ruído perturba seriamente a progressão da onda de sinal do ciclo celular, como também tira ao sistema fora do estado estacionário $G_{1}$ quando deveria permanecer nele. Verificamos que sem ruído o sistema se comporta normalmente: todos os ciclos iniciados percorrem a via biológica e concluem, e um novo ciclo não é iniciado por um sinal ativador $C S$ quando o ciclo anterior ainda não finalizou. Concluímos que este sistema não é robusto na presença de ruído estocástico com probabilidade de acontecer de apenas $1 \%$. 


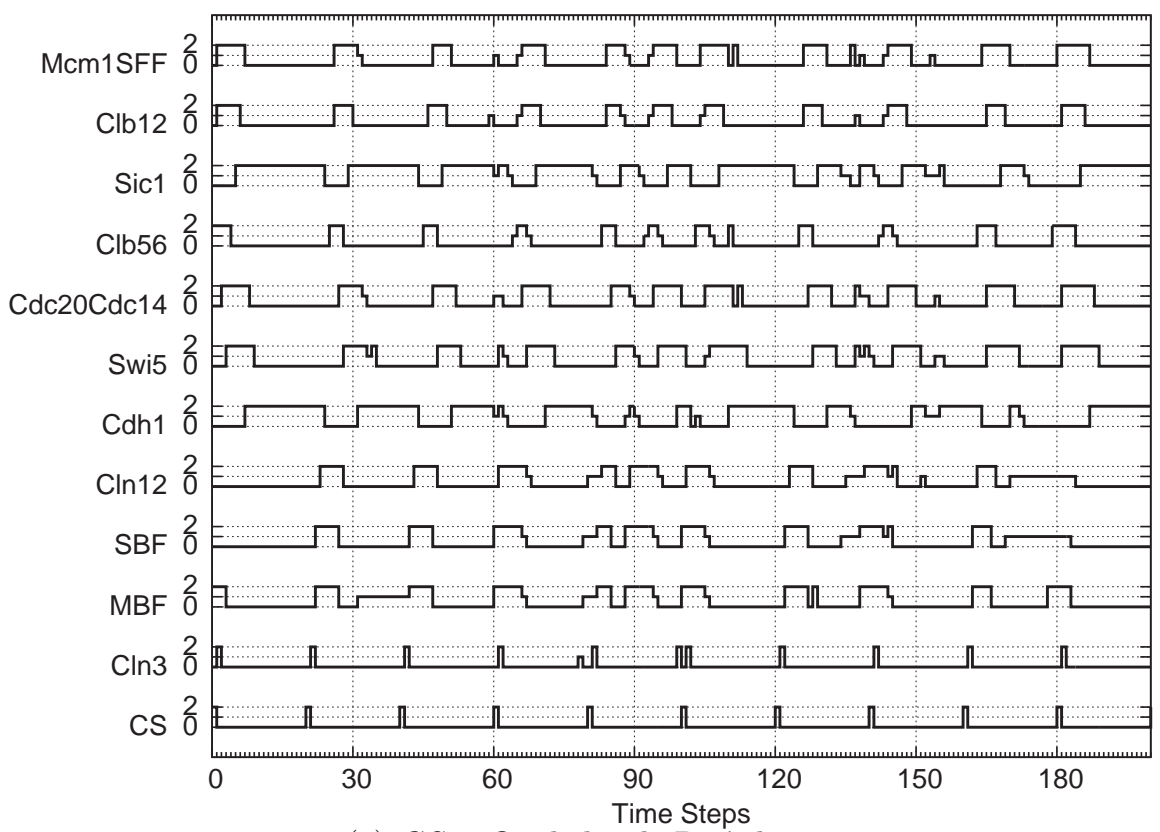

(a) $C S=$ Oscilador de Período 20 .

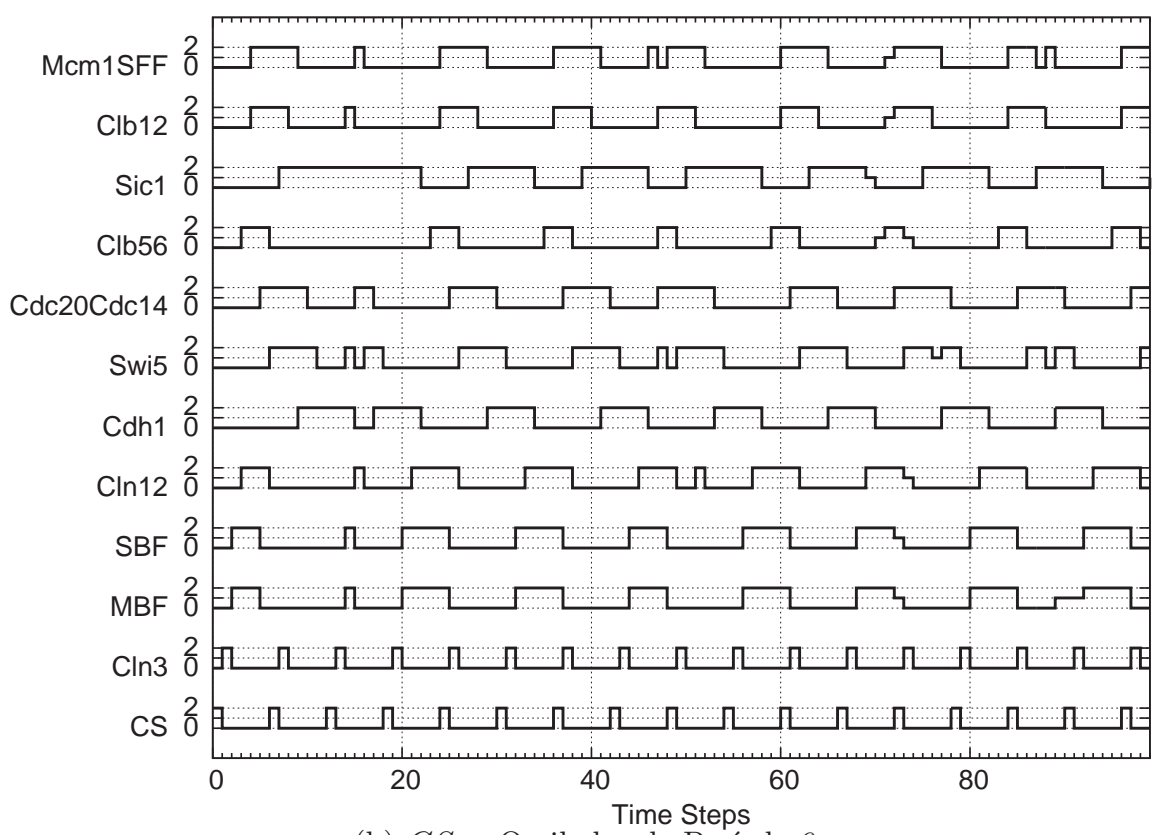

(b) $C S=$ Oscilador de Período 6 .

Figura 3.3: Simulação do modelo PGN de três níveis do ciclo celular da levedura com $1 \%$ de ruído (PGN com $P=0.99$ ) ativado por pulsos de $C S$ de freqüência crescente. A pequena quantidade de ruído presente no sistema é suficiente para destruir a onda de sinal da via biológica do ciclo celular. 


\subsection{Nosso Modelo de Controle da Progressão Ciclo Celular}

Usamos a PGN para construir um modelo hipotético baseado em componentes e características estruturais encontradas em sistemas biológicos (integradores, redundância, sinais ativadores e inibidores, realimentação negativa e positiva, etc.), que apresenta um comportamento dinâmico similar aos observados em sistemas reais de controle do ciclo celular: propagação de ondas de sinais de controle, ativação seqüencial e ordenada de processos com a correta temporização, estabilidade ante mudanças nos sinais de entrada, robustez frente a certos tipos de ruído, etc.

Durante a progressão do ciclo celular biológico, determinadas famílias de genes são expressas — transitória ou sustentadamente - em momentos específicos: determinadas fases ou transições entre fases do ciclo celular. Em células de mamíferos, a transição $G_{0} / G_{1}$ do ciclo celular requer da expressão sequencial de genes que codificam familias de fatores de transcrição. Por exemplo, os genes fos, c-fos e fos B são essencialmente regulados no nível de transcrição e expressos por um breve período de tempo $(0,5$ a $1 \mathrm{~h})$, exibindo mRNAs e proteínas de vida média muito curta. Por outra parte, a progressão pela fase $G_{1}$ e a transição $G_{1} / S$ são controladas pela máquina reguladora do ciclo celular formada por proteínas de expressão prolongada (CDKs — "Cyclin-Dependent Kinases" - e a proteína Rb) ou transitória (ciclinas D e E). Os genes que codificam as ciclinas D e E são transcritos na metade e no final da fase $G_{1}$, respectivamente. Em realidade, existem varias CDKs que regulam a progressão ao longo das fases e transições do ciclo celular, cujas atividades dependen de ciclinas que são expressas transitóriamente seguindo uma ordem seqüencial rigorosa. Este tipo de regulação da progressão do ciclo celular resulta altamente conservada nos eucariotos, desde a levedura até os mamíferos, e para representar esta característica central do ciclo celular biológico, organizamos nosso modelo em camadas sucessivas de genes expressos seqüencialmente no tempo. A onda de expressão gênica regula o 


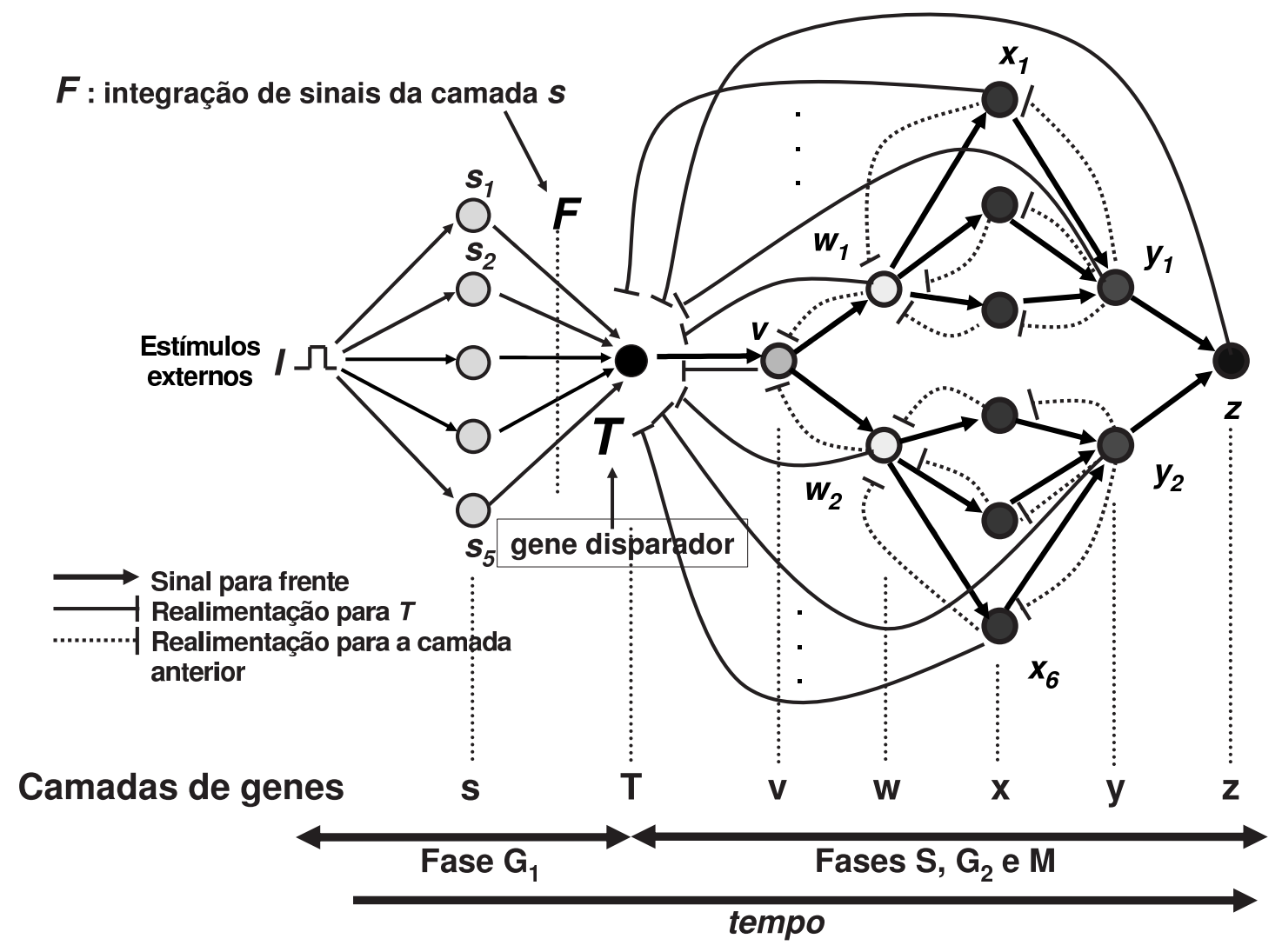

Figura 3.4: Arquitetura do nosso modelo estrutural do controle da progressão do ciclo celular.

momento específico em que as diversas funções são executadas, sua duração, e o avanço ordenado na progressão do ciclo celular.

A Figura 3.4 ilustra a arquitetura de nosso modelo de controle da progressão do ciclo celular $[13,14]$. Diversos sinais regulatórios (ativadores — para frente, no sentido da onda de sinale de realimentação — negativa - entre as camadas de genes $\mathbf{s}, \mathbf{T}, \mathbf{v}, \mathbf{w}, \mathbf{x}, \mathbf{y}$ e $\mathbf{z}$ ) determinam o comportamento dinâmico do sistema. As camadas de genes representam etapas consecutivas durante fases clássicas do ciclo celular $G_{1}, S, G_{2}$ e $M$. Estão constituídas por genes — variáveis de estado - expressos durante a execução de cada etapa e agrupadas em dois partes principais: i) fase $G_{1}$ — camada $\mathbf{s}$ - que representa o crescimento da célula imediatamente antes do início 
da replicação do DNA (i.e. fase $S$ ), durante a qual a célula responde a estímulos regulatórios externos (sinal $I$ na figura 3.4) e ii) fases $S, G_{2}$ e $M$ - camadas $\mathbf{T}, \mathbf{v}, \mathbf{w}, \mathbf{x}, \mathbf{y}$ e $\mathbf{z}-$ desde a replicação do DNA até a mitose. O gene $T$ disparador da fase $S$ representa um importante "checkpoint" (ponto de controle) do ciclo celular, atuando como interface entre os sinais reguladores da fase $G_{1}$ e a iniciação da replicação do DNA. O sinal F, indicado na Figura 3.4, representa a integração no gene $T$ dos sinais ativadores provenientes da camada $\mathbf{s}$. Partimos da suposição básica de que o sistema de controle do ciclo celular está formado por módulos de ondas seqüências paralelas de expressão gênica (camadas $\mathbf{s}$ a $\mathbf{z}$ ) organizadas ao redor de um "checkpoint" (gene disparador T) que integra sinais ativadoras e de realimentação negativa. Por exemplo, o gene disparador $T$ integra os sinais ativadores provenientes da camada $\mathbf{s}$, e de realimentação negativa provenientes das camadas seguintes, evitando a iniciação de uma nova onda de expressão gênica — novo ciclo — enquanto a onda anterior ainda não acabou de realizar seu ciclo. Uma serie de módulos de "checkpoint" ao longo do ciclo regulam o crescimento celular e a replicação do genoma durante as fases seqüencias $G_{1}, S$ e $G_{2}$ e a duplicação celular pela mitose.

A figura 3.5 mostra um exemplo típico dos sinais regulatórios que atuam sobre um destes módulos. No caso, o gene $w_{1}$ é eventualmente excitado pelos sinais ativadores e inibidores indicados na parte a) da figura. A componente da função de transição associada a $w_{1}$ recebe como entradas estes sinais e com eles determina o próximo valor de expressão do gene. Quando expresso, $w_{1}$ envia os tipos de sinal indicados em b) para as demais variáveis do sistema. Desta forma, em nosso modelo, a expressão de um dos genes nas camadas $\mathbf{v}$ até $\mathbf{z}$ (depois do gene disparador $T$ na Figura 3.4), tipicamente gera três tipos de sinais:

- Um sinal ativador para os genes da próxima camada de controle, tendente a fazer progredir a seqüência do ciclo celular. 


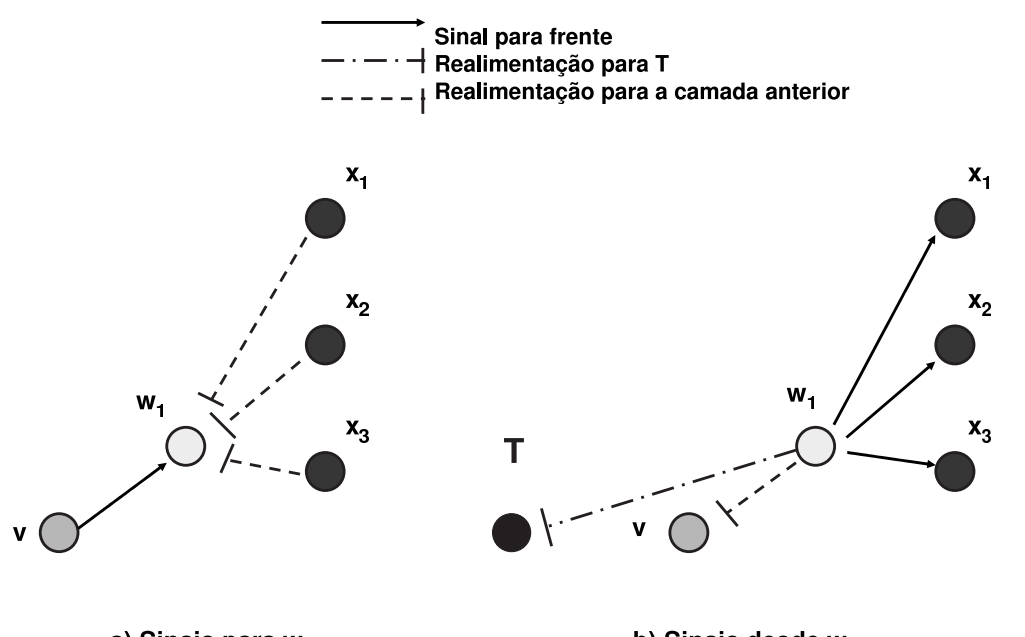

a) Sinais para $w_{1}$

b) Sinais desde $w_{1}$

Figura 3.5: Exemplo de sinais regulatórios típicos em nosso modelo. Os sinais em a) determinam o nível de expressão futuro do gene $w_{1}$, o qual — quando expresso- emite os sinais indicados em b).

- Um sinal de realimentação inibidor para os genes da camada anterior tendente a deter o avanço de uma nova onda de sinal — no sentido do ciclo celular - durante algum tempo.

- Um sinal de realimentação inibidor para o gene disparador $T$ que tende a evitar o início de uma nova onda de expressão gênica enquanto o ciclo atual está ainda em andamento.

Os sinais de realimentação negativa desempenham uma importante função reguladora - e temporizadora - tendente a assegurar que uma nova onda de sinal não seja disparada nem propagada a traves do sistema enquanto a anterior ainda não acabou sua progressão pela seqüência do ciclo celular. Isto impõe no modelo algumas características essenciais de robustez do ciclo celular biológico, tais como o disparo em forma única e irreversível dos eventos, e que o presente ciclo deve ser completado antes de iniciar de um novo ciclo de divisão celular. A realimentação negativa é o principal mecanismo de controle que permite uma resposta robusta a pertubações nos 
sistemas biológicos [27]. Por outra parte, as vias de sinalização paralela atuam como mecanismos de reserva fornecendo outro tipo de robustez ao aumentar a tolerância a falhas do sistema.

\subsubsection{Especificação Completa da PGN}

A entrada total que atua sobre uma variável genérica $x_{i}(t) \in\{0,1,2\}(1 \leq i \leq N)$ é representada por sua função excitadora associada:

$$
d_{i}(t-1)=\sum_{j=1}^{N} \sum_{k=1}^{m} a_{j i}^{k} x_{j}(t-k)
$$

onde $m$ é a memória do sistema, e $a_{j i}^{k}$ é o peso da variável $x_{j}$ no tempo $t-k$ na função excitadora da variável $x_{i}$. Seja

$$
y_{i}(t)=\left\{\begin{array}{lll}
2 & \text { se } & d_{i}(t-1) \geq t h 2_{x_{i}} \\
1 & \text { se } & t h 1_{x_{i}} \leq d_{i}(t-1)<t h 2_{x_{i}} \\
0 & \text { se } & d_{i}(t-1)<t h 1_{x_{i}}
\end{array}\right.
$$

a função de transição estocástica escolhe como próximo valor de cada variável

$$
x_{i}(t)=\left\{\begin{array}{ccl}
y_{i}(t) & \text { com probabilidade } & P \approx 1, \\
a & \text { com probabilidade } & (1-P) / 2, \text { ou } \\
b & \text { com probabilidade } & (1-P) / 2,
\end{array}\right.
$$

onde $a, b \in\{0,1,2\}-\left\{y_{i}\right\}$ e $t h 1_{x_{i}}$, th $2_{x_{i}}$, são os limiares para os valores de saída '1' e '2' na função de transição do gene $x_{i}$.

A Tabela 3.2.1 mostra os valores dos pesos da PGN e os limiares da função de transição usados. Nela, $a_{j i}^{k}$ é o peso para os valores de expressão dos genes na camada $j$ no tempo $t-k$ 


\begin{tabular}{cc}
\hline Pesos & Limiares \\
\hline \hline$a_{F P}^{k}=6, k=5,6, \ldots, 9$ & $t h_{P}^{(1)}=9, t h_{P}^{(2)}=12$ \\
$a_{j P}^{1}=-2, j=v, w, x, y, z$ & \\
\hline$a_{P v}^{k}=4, k=5,6, \ldots, 9$ & $t h_{v}^{(1)}=11, t h_{v}^{(2)}=22$ \\
$a_{w v}^{k}=-2, k=1,2$ & \\
\hline$a_{v w}^{k}=6, k=5,6, \ldots, 9$ & $t h_{w}^{(1)}=20, t h_{w}^{(2)}=35$ \\
$a_{x w}^{k}=-1, k=1,2$ & \\
\hline$a_{w x}^{k}=5, k=5,6, \ldots, 9$ & $t h_{x}^{(1)}=20, t h_{x}^{(2)}=28$ \\
$a_{y x}^{k}=-1, k=1,2$ & \\
\hline$a_{x y}^{5}=2$ & $t h_{y}^{(1)}=6, t h_{y}^{(2)}=12$ \\
\hline$a_{y z}^{5}=2$ & $t h_{z}^{(1)}=4, t h_{z}^{(2)}=8$ \\
\hline
\end{tabular}

Tabela 3.2: Valores dos pesos da PGN e limiares da função de transição.

na função excitadora no tempo $t$ dos genes da camada $i$. Os valores não mostrados na tabela são zero e os limiares são os mesmos para todos os genes de uma mesma camada.

\subsubsection{Resultados Experimentais}

Simulamos nosso modelo hipotético do sistema de controle da progressão do ciclo celular, como uma PGN com $P=0.99$ (1\% de ruído no sistema) excitada por diferentes sinais de ativação $F$, os quais representam a integração de sinais provenientes da camada $\mathbf{s}$ no gene disparador $T$ (um resumo mais completo destas simulações na Subseção A.2.1 do Apêndice A). Começamos com um único pulso de ativação $(F=2)$, e continuamos com pulsos de $F$ de freqüência crescente — período decrescente - ou seja, pulsos de ativação cada vez mais freqüentes — em cada simulação - até chegar a um sinal de ativação constante $F=2$. 


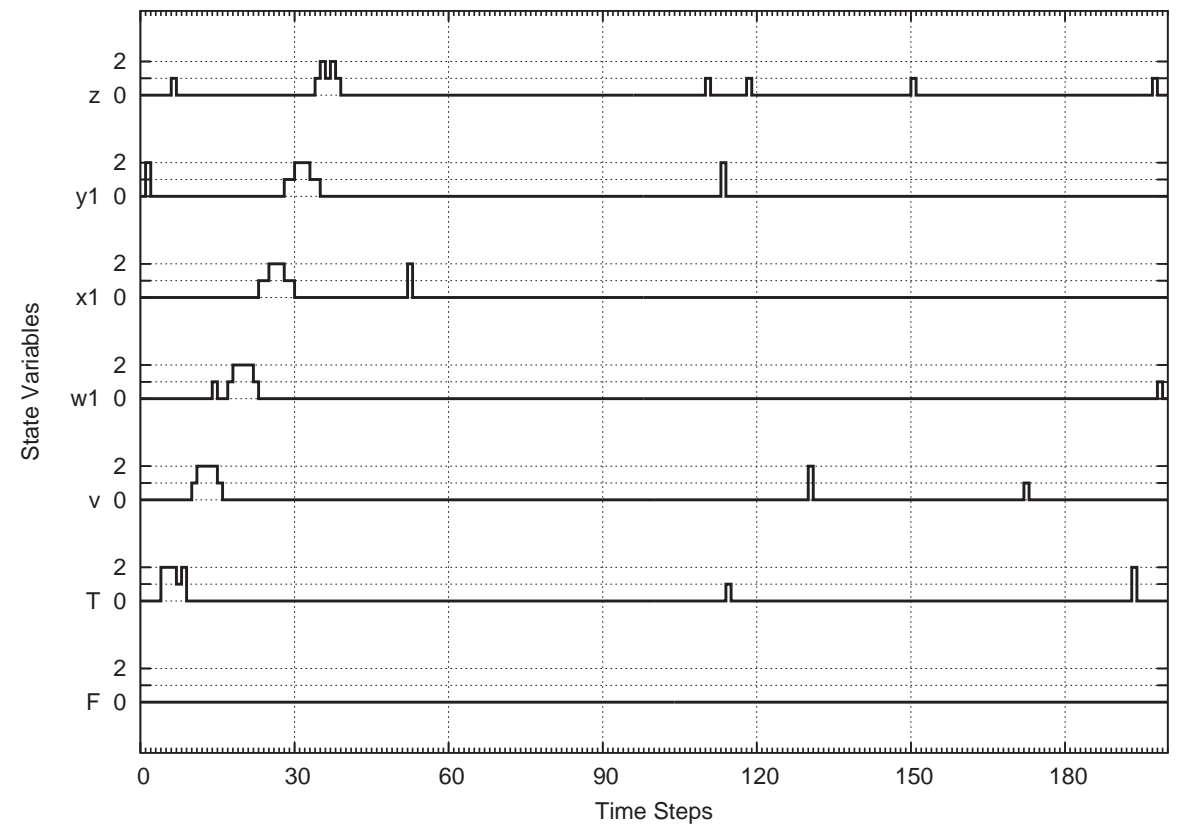

(a) Um único pulso de início $F=2$ em $t=-1$.

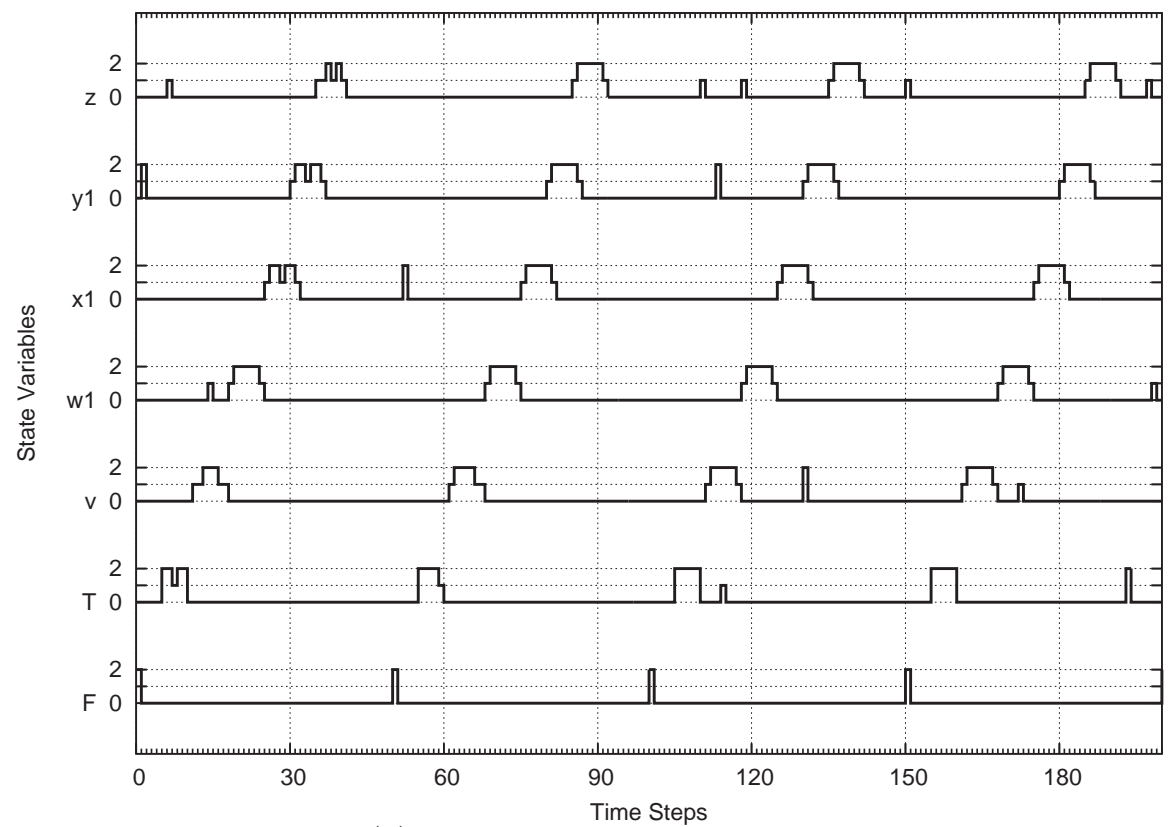

(b) $F=$ Oscilador de Período 50.

Figura 3.6: Simulação de nosso modelo PGN de três níveis do sistema de controle da progressão do ciclo celular, com $1 \%$ de ruído (PGN com $P=0.99$ ) e novos pulsos de ativação de $F$ ocorrendo depois de que o ciclo anterior finalizou. 
A condição inicial adotada em todas as simulações de nosso modelo foi que todas as variáveis correspondentes às camadas $\mathbf{T}$ até $\mathbf{z}$ tem valor zero nos $m$-memória do sistema - instantes de tempo prévios, o que representa, no modelo, o estado estacionário $G_{1}$, no qual o sistema permanece depois de acabado o ciclo de divisão e em ausência de uma ativação $F$ suficiente para iniciar um novo ciclo (em esta fase a célula cresce ao mesmo tempo que monitora estímulos externos para decidir quando inicia uma nova divisão). Por simplicidade, nas figuras, para ilustrar a propagação da onda de sinal mostramos apenas um gene representativo de cada camada.

Um único pulso de $F$ (Figura 3.6(a)) faz o sistema passar por todas as etapas do ciclo celular e depois permanecer novamente no estado estacionário $G_{1}$ — todos os sinais em nível zero- com uma quantidade muito pequena de ruído. Comparando esta simulação com a da Figura 3.2, observamos que o comportamento deste sistema quase não é afetado por este nível de ruído durante o ciclo ou em estado estacionário. Esses pequenos pulsos adicionais que aparecem fora dos trens de sinal, são o único efeito observável da presença de $1 \%$ de ruído, pois eles não aparecem quando o sistema é simulado sem ruído (Figura A.27). A Figura 3.6(b) mostra que quando novos pulsos de ativação $F$ são aplicados depois que o ciclo anterior finalizou, os ciclos começam e são completados normalmente.

Quando os pulsos de ativação $F$ chegam mais freqüentemente, um novo ciclo é iniciado somente se o anterior já finalizou (Figura 3.7(a) —e também Figuras A.21, A.22 e A.23 do Apêndice A). Os pulsos de $F$ que ocorrem quando um ciclo está ainda em andamento, no conseguem disparar o gene $T$. Esta importante ação reguladora é devida ao efeito inibidor dos sinais de realimentação negativa provenientes das camadas posteriores $-\mathbf{v}$ a $\mathbf{z}-$, que trazem para o gene disparador $T$ a informação de que um ciclo anterior está sendo executado e se opõem ao disparo de uma nova onda de sinal (i.e., início de um novo ciclo de divisão celular). Vemos, 


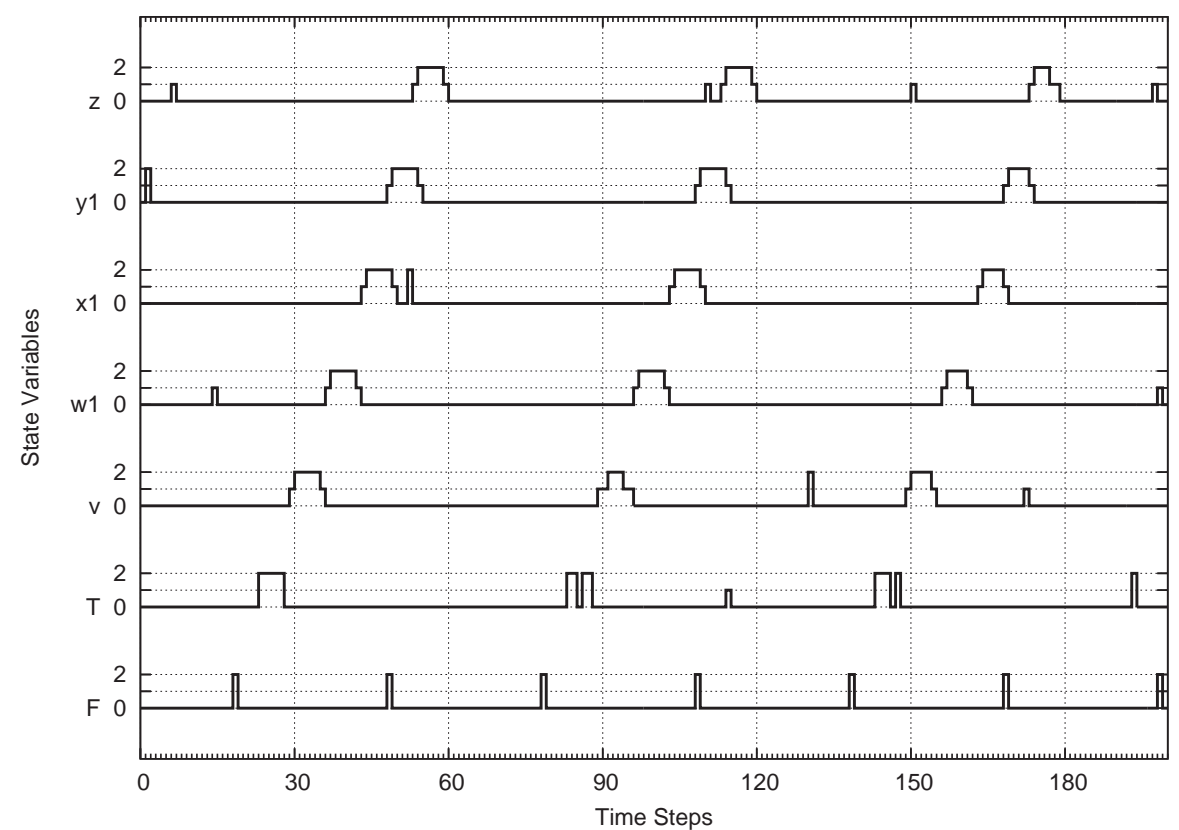

(a) $F=$ Oscilador de Período 30 .

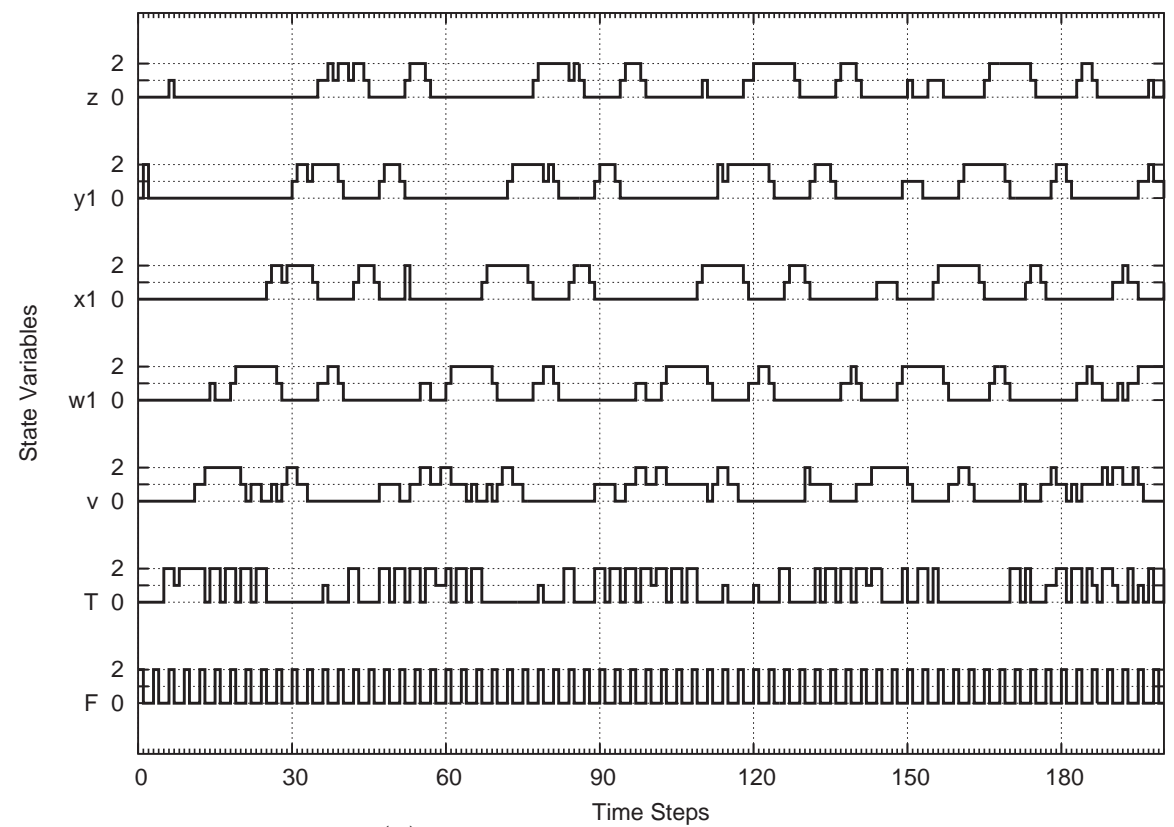

(b) $F=$ Oscilador de Período 3.

Figura 3.7: Simulação de nosso modelo PGN de três níveis do sistema de controle da progressão do ciclo celular, com $1 \%$ de ruído (PGN com $P=0.99$ ) e pulsos ativadores de $F$ que arribam eventualmente antes do que o ciclo prévio termine. 
nestas simulações, que não aparecem trens de sinal espúrio geradas pelo ruído (os pulsos de ruído não conseguem se propagar, pois são detidos pelas realimentações negativas), e que o ruído não consegue deter a progressão normal da onda do ciclo celular (todos os ciclos normalmente iniciados executam sua seqüência normal e terminam). Ou seja, a robustez estrutural fornecida pelas realimentações negativas favorece a propagação da onda de sinal do ciclo celular e inibe a propagação de ondas de sinal espúrio. Se um trem de pulsos $F$ muito freqüente consegue disparar o gene $T$ antes do que ciclo em andamento termine, esse sinal não consegue se propagar a traves das camadas seguintes (Figuras 3.7(a), A.21, e A.22). O avanço desse sinal é inibido pelos sinais de realimentação negativa que as camadas por onde o ciclo anterior está passando enviam para a camada anterior. Estas realimentações negativas para a camada anterior fornecem também um efeito temporizador, dando a cada etapa — ou camada - uma determinada quantidade de tempo para os processos sendo controlados, detendo o avanço de uma nova onda de sinal proveniente das camadas anteriores por algum tempo. Por meio destes dois tipos de realimentação negativa - para a camada anterior e para o gene disparador $T$ - o sistema consegue resistir o excesso de ativação mantendo seu período natural, de forma análoga ao que acontece na natureza no ciclo celular biológico.

Finalmente, em concordância com o fato de que a robustez dos sistemas biológicos não é ilimitada, uma ativação muito freqüente (período 3, período 2 ou $F=2$ constante —Figuras 3.7(b), A.25 e A.26) consegue de fato vencer a resistência das realimentações negativas e tirar ao sistema fora do seu comportamento normal.

Para realizar a comparação do modelos de Li com o nosso, simulamos ambos com $1 \%$ de ruído. Em outras simulações, aumentamos gradualmente o ruído no nosso modelo para averiguar quanto ele pode resistir — Subseção A.2.2—, e diminuímos gradualmente o ruído no modelo 
de Li para determinar a menor quantidade que tem efeitos não desejados na sua dinâmica —Subseção A.1.2 - Em nosso modelo, observamos que é necessário um ruído acima de 3\% para que um pulso de ruído consiga se propagar como um trem de sinal espúrio (Figura A.30) e 5\% de ruído é necessário para deter uma onda de sinal normal, evitando que finalize o ciclo em andamento (Figura A.32). Nas simulações do modelo binário de Li, observamos que, com um ruído tão pequeno como 0.05\%, um pulso espúrio consegue se propagar até o final do ciclo (Figura A.16). 


\subsection{Modelo do Controle da Progressão do Ciclo Celular com Atrasos Aleatórios}

Ampliamos nosso modelo para que ele admita a possibilidade de atrasos aleatórios nos seus sinais regulatórios, mantendo seu comportamento, estabilidade e robustez anteriores. Tais atrasos introduzem uma nova forma de estocacidade — nos parâmetros do sistema - tentando modelar o tempo variável em que os sinais intra-celulares exercem seu efeito regulador, devido a diversos motivos, tais como localização espacial, degradação de componentes ativos, etc..

\subsubsection{Especificação da PGN}

Nesta versão do modelo, antes de calcular a função excitadora de cada variável, a componente da função de transição associada a ela escolhe um atraso aleatório $t_{d}$ para seus argumentos, com a distribuição de probabilidades dada na Tabela 3.3.

\begin{tabular}{cc}
\hline $\mathbf{t}_{\mathbf{d}}$ & $\mathbf{P}\left(\mathbf{t}_{\mathbf{d}}\right)$ \\
\hline \hline 0 & 0.2 \\
\hline 1 & $\mathbf{0 . 6}$ \\
\hline 2 & 0.2 \\
\hline
\end{tabular}

Tabela 3.3: Probabilidades dos atrasos $\mathbf{t}_{\mathbf{d}}$.

Uma vez sorteados estes atrasos, a função de transição estocástica definida na Subseção 3.2.1, usando os pesos e limiares indicados na Tabela 3.4, calcula a evolução temporal do sistema. Os parâmetros da função de transição, mais especificamente os pesos da PGN, dependem destes atrasos variáveis. Tal como é indicado na Tabela 3.4, os atrasos produzem deslocamento tempo- 
ral dos pesos, e assim, das entradas da função excitadora de cada variável. Este sistema já não é invariante por translação no tempo, mas adaptativo. A cada passo ele escolhe uma PGN de um conjunto de PGNs candidatas (cada uma determinada por uma das possíveis combinações de atrasos de suas variáveis de estado). O sistema de controle — atuando por médio das realimentações negativas - deve se adaptar às mudanças dos parâmetros e manter a funcionalidade do sistema, ou seja, deve ser robusto ante a perturbação de seus parâmetros internos.

\begin{tabular}{cc}
\hline \hline Pesos $\left(k=k^{\prime}+t_{d}\right)$ & Limiares \\
\hline \hline$a_{F T}^{k^{\prime}}=6, k^{\prime}=5, \ldots, 9$ & $t h_{T}^{(1)}=9$ \\
\hline$a_{j T}^{k^{\prime}}=-1.33 ; j=v, w, x, y, z ; k^{\prime}=1$ & $t h_{T}^{(2)}=12$ \\
\hline$a_{j T}^{k^{\prime}}=-0.67 ; j=v, w, x, y, z ; k^{\prime}=2$ & \\
\hline \hline$a_{T v}^{k^{\prime}}=5, k^{\prime}=5, \ldots, 9$ & $t h_{v}^{(1)}=11$ \\
\hline$a_{w v}^{k^{\prime}}=-0.77, k^{\prime}=1, \ldots, 9$ & $t h_{v}^{(2)}=22$ \\
\hline$a_{v w}^{k^{\prime}}=7, k^{\prime}=3, \ldots, 7$ & $t h_{w}^{(1)}=15$ \\
\hline$a_{x w}^{k^{\prime}}=-0.83, k^{\prime}=1, \ldots, 9$ & $t h_{w}^{(2)}=25$ \\
\hline$a_{w x}^{k^{\prime}}=6, k^{\prime}=4, \ldots, 8$ & $t h_{x}^{(1)}=20$ \\
\hline$a_{y x}^{k^{\prime}}=-1.77, \quad k^{\prime}=1, \ldots, 9$ & $t h_{x}^{(2)}=28$ \\
\hline \hline$a_{x y}^{k^{\prime}}=3, k^{\prime}=6$ & $t h_{y}^{(1)}=6$ \\
\hline \hline$a_{y z}^{k^{\prime}}=3, k^{\prime}=6$ & $t h_{y}^{(2)}=12$ \\
\hline \hline
\end{tabular}

Tabela 3.4: Valores dos pesos da PGN e limiares da função de transição no modelo com atrasos aleatórios nos sinais de regulação.

Na Tabela $3.4, a_{j i}^{k}$ indica o peso dos valores de expressão dos genes na camada $j$ no tempo 
$t-k$ (onde $k=k^{\prime}-t_{d}$ ) na função excitadora dos genes da camada $i$ no tempo $t$. Os valores não mostrados são zero. Os limiares são os mesmos para todos os genes de uma mesma camada, mas o atraso $t_{d}$ não é. Ele é escolhido individualmente para cada gene pela componente da função de transição associada a ele em cada instante de tempo discreto $t$.

\subsubsection{Resultados Experimentais}

Este novo modelo com atrasos aleatórios foi simulado nas mesmas condições que o modelo anterior atingindo um comportamento dinâmico similar (um resumo mais completo destas simulações na Subseção A.2.3 do Apêndice A). Os atrasos aleatórios com que os sinais são deslocados em cada passo da simulação, fazem que a largura das formas de onda e o período do ciclo resultem variáveis e mais compridos que no modelo prévio.

A Figura 3.8 mostra o comportamento do sistema quando ele é ativado por um único pulso de $F=2$ e por um trem de pulsos de período maior do que o período do ciclo. O sistema se comporta normalmente, com uma pequena quantidade de ruído, de intensidade muito menor que a dos sinais de regulação.

Quando os pulsos chegam mais freqüentemente e o período do sinal ativador é mais curto que o período do ciclo (Figura 3.9(a)), um novo ciclo não é iniciado se o ciclo anterior ainda não foi completado. Finalmente, quando a ativação $F$ se torna muito freqüente ou constante (Figura 3.9(b)), as realimentações negativas não conseguem mais exercer sua ação reguladora e o sistema sai do seu comportamento normal.

Estes resultados mostram a estabilidade e robustez do modelo proposto para o controle da progressão do ciclo celular na presença simultânea de ruído e atrasos aleatórios nos sinais de regulação, para uma ampla variedade de sinais ativadores [14]. Particularmente, mostram como 


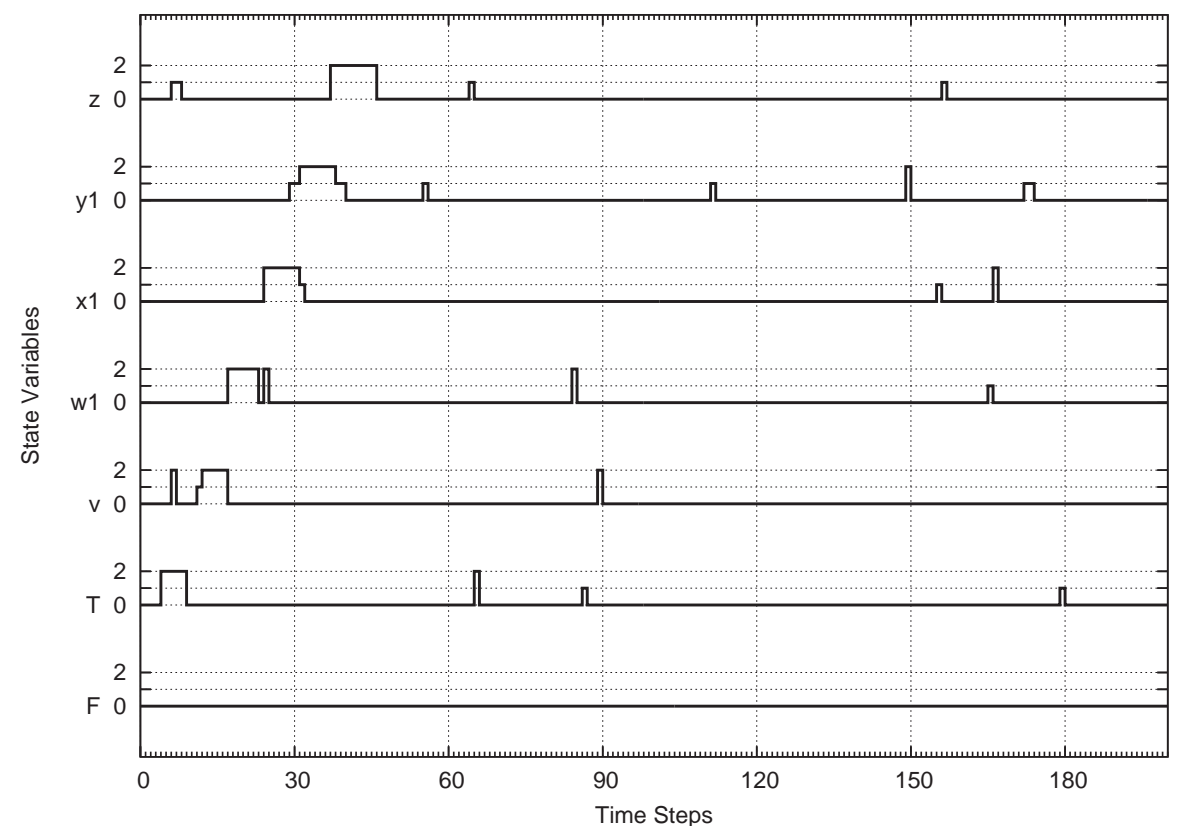

(a) Um único pulso de início de $F=2$ em $t=-1$.

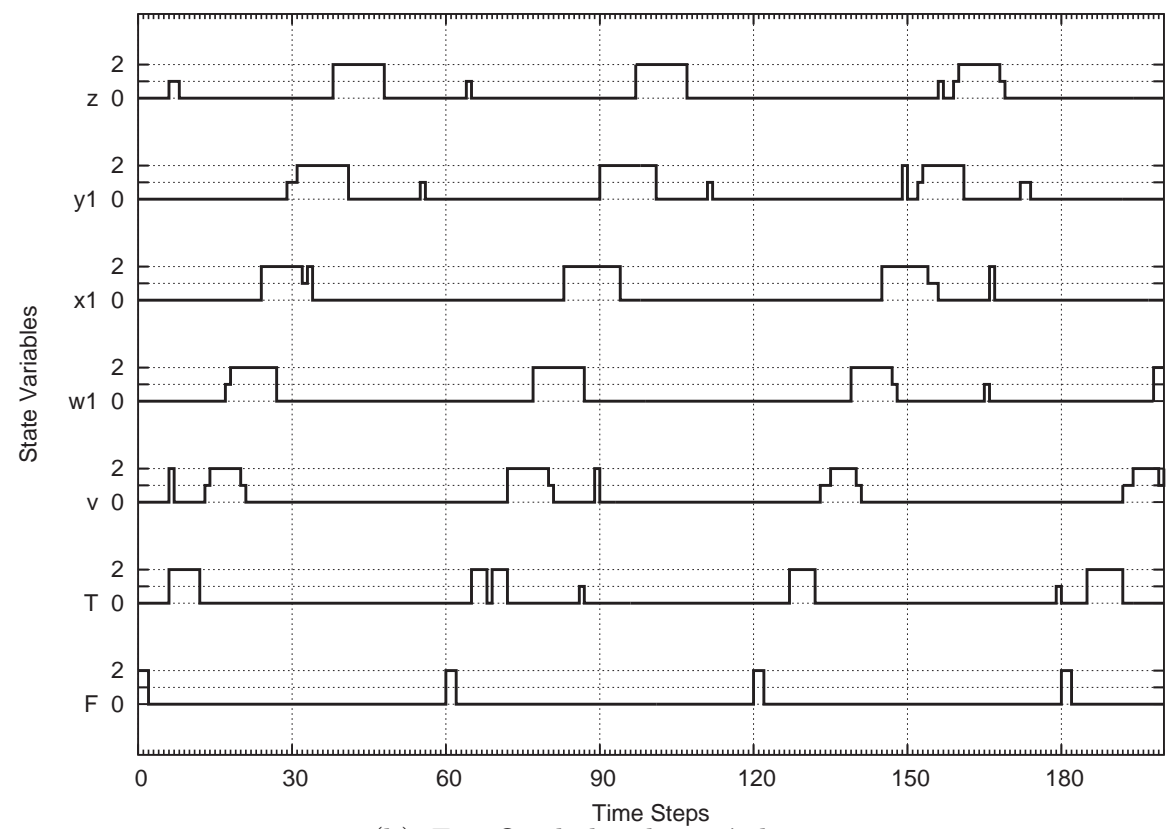

(b) $F=$ Oscilador de período 60 .

Figura 3.8: Simulação de nosso modelo PGN de três níveis do sistema de controle da progressão do ciclo celular com atrasos aleatórios e $1 \%$ de ruído (PGN com $P=0.99$ ), quando os pulsos ativadores de $F$ chegam depois de que o ciclo anterior finalizou. 


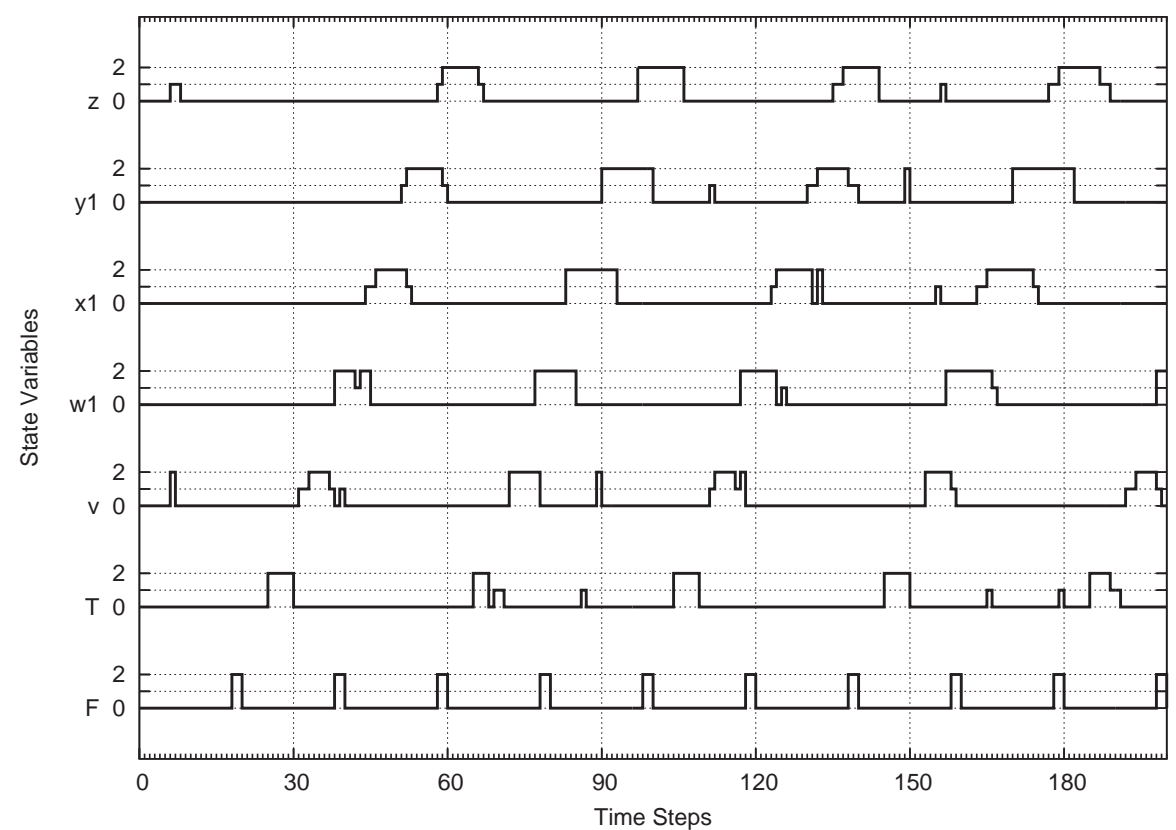

(a) $F=$ Oscilador de período 20 .

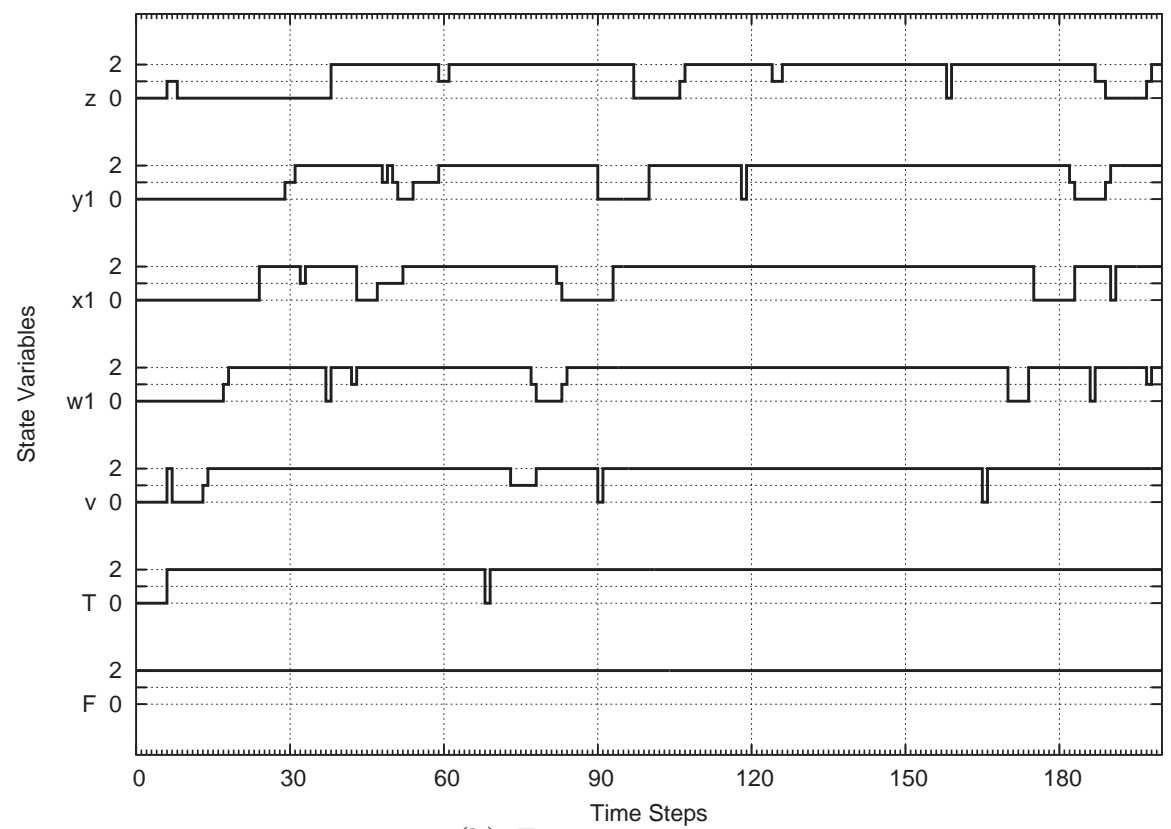

(b) $F=2$ constante.

Figura 3.9: Simulação de nosso modelo PGN de três níveis do sistema de controle da progressão do ciclo celular com atrasos aleatórios, $1 \%$ de ruído (PGN com $P=0.99$ ), quando os pulsos ativadores de $F$ chegam antes de que o ciclo anterior termine e com ativação constante $F=2$. 
este tipo de realimentações reguladoras é capaz de fornecer robustez ante a perturbação de parâmetros internos do sistema [27].

Testes exaustivos de estabilidade e robustez: Na Subseção A.2.4 do Apêndice A são apresentadas simulações — sua interpretação - referentes a testes realizados com o objetivo de entender melhor o funcionamento do modelo, seu comportamento, limites de estabilidade e robustez, e os efeitos produzidos pelos diferentes mecanismos de controle por realimentação negativa. Eles foram realizados nas seguintes condições: i) diminuindo gradualmente a força das realimentações, ii) eliminando algum tipo de realimentação, e iii) aumentando gradualmente o nível de ruído presente no sistema. 


\subsection{Modelo de Controle da Progressão do Ciclo Celular com Atrasos Aleatórios e Realimentação Positiva}

Mediante a inclusão de realimentação positiva, nosso modelo foi capaz de apresentar um comportamento autoexcitado, iniciando uma nova divisão celular depois da finalização da anterior, sem necessitar de estímulo externo. Esse comportamento oscilatório é observado na natureza na divisão das células embrionárias [10]. Em nosso modelo foi suficiente incluir um sinal de realimentação positiva do gene $z$ —última camada - para o gene disparador $T$ para obter tal característica dinâmica. A especificação da PGN é exatamente a mesma do modelo prévio com atrasos aleatórios, agregando mais um peso diferente de zero: $a_{z T}^{k}=7$ (onde $k=5+t_{d}$ ).

\subsubsection{Resultados Experimentais}

Na simulação da Figura 3.10 o sistema é ativado inicialmente por um único pulso de $F=$ 2 em $t=-1,-2$. De forma análoga ao ciclo celular embrionário, a realimentação positiva produz uma atividade auto-excitada, onde todos os ciclos são completados normalmente e com a temporização correta de todas as diferentes fases. Um novo ciclo começa logo após a de que o anterior foi completado, sem a necessidade de um novo sinal ativador F. A Figura 3.10(b) mostra que quando um sinal é enfraquecido pelo efeito combinado do ruído e os atrasos aleatórios, a realimentação positiva - em ausência da ativação $F$ - consegue colocar o sistema de volta na sua atividade cíclica de amplitude normal. Estas simulações mostram a flexibilidade deste modelo PGN para representar diferentes tipos de comportamento dinâmico, tal como o do ciclo celular embrionário, onde a realimentação positiva desempenha um papel central na manutenção de oscilações não atenuadas [14]. 


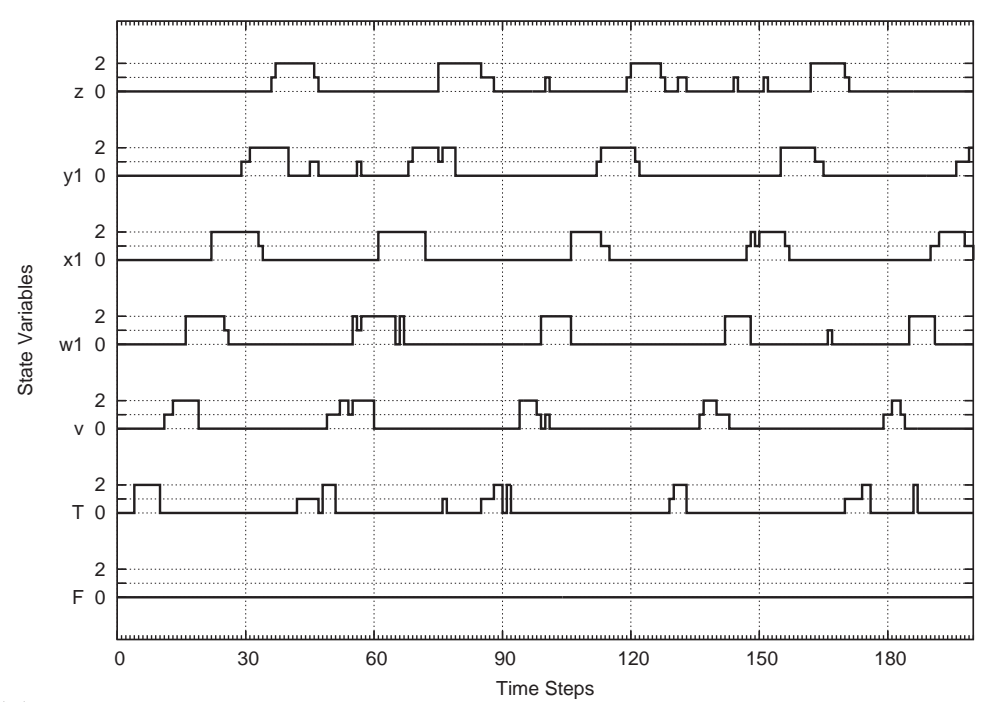

(a) Devido à realimentação positiva de $z$ para $T$, um novo ciclo é iniciado logo após a finalização do anterior, sem a necessidade de um novo sinal ativador $F$. Este comportamento é típico do ciclo celular embrionário, o qual depende de laços de realimentação positiva para manter oscilações não atenuadas com a temporização correta.

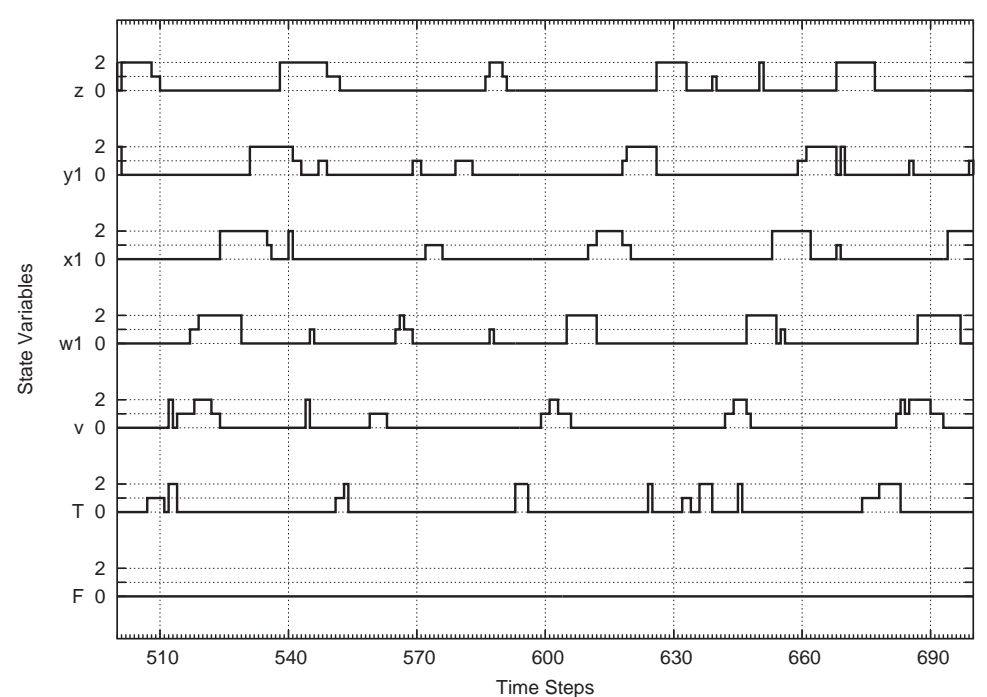

(b) O segundo ciclo em esta figura resulta algo enfraquecido (pelo efeito do ruído e os atrasos aleatórios), mas a realimentação positiva consegue reverter a situação (sem necessidade da ativação de $F$ ) e o sistema retoma sua atividade cíclica com amplitude normal.

Figura 3.10: Modelo de controle da progressão do ciclo celular com atrasos aleatórios e realimentação positiva do gene $z$ para o gene disparador $T\left(a_{z T}^{k}=7, k=5+t_{d}\right), 1 \%$ de ruído e um único pulso ativador inicial $F=2$ em $t=-1,-2$. 


\section{Capítulo 4}

\section{Conclusão}

Elaboramos um modelo PGN hipotético do controle da progressão do ciclo celular inspirado na descrição qualitativa de fenômenos biológicos bem conhecidos: o ciclo celular é uma seqüência de eventos disparados por um sinal de controle que se propaga como uma onda; nele existem subsistemas integradores de sinal; laços de realimentação negativa e positiva; estruturas replicadas trabalhando em paralelo fazem o sistema tolerante a falhas. Nosso modelo reflete o fato conhecido de que sistemas de controle no mundo real habitualmente são estáveis, robustos, tolerantes a falhas e sujeitos a pequenas variações probabilísticas de seus parâmetros.

Os parâmetros do modelo foram ajustados com base no comportamento esperado do sistema através da análise de simulações exaustivas. Este esforço de modelagem não tinha a intenção de representar detalhes dos mecanismos moleculares tais como a cinética e termodinâmica das interações entre proteínas, funcionamento da maquinaria de transcrição, microRNA e regulação dos fatores de transcrição, mas seus efeitos conjuntos no controle da expressão gênica e no comportamento global da rede [2]. Trata-se de um modelo discreto simplificado capaz de reproduzir 
o comportamento genético qualitativo com a finalidade de lograr um melhor entendimento do funcionamento dos mecanismos de regulação do ciclo celular, estabelecendo hipóteses úteis para ser investigadas no sistema real $[5,32]$. O modelo é descrito de uma forma homogênea, simples de implementar, e completamente caracterizado por umas poucas equações e uma tabela de parâmetros, o que torna as simulações facilmente reprodutíveis.

Nosso modelo para o controle da progressão do ciclo celular foi capaz de representar algumas propriedades do comportamento do sistema biológico real, tais como: i) propagação seqüencial de ondas de expressão gênica; ii) estabilidade na presença de excitação variável; iii) robustez no presença de ruido nos parâmetros do sistema: iii-i) predição por uma regra estocástica quase determinística; iii-ii) escolha estocástica de uma regra de predição estocástica quase determinística (atrasos aleatórios); e iv) auto estimulação por realimentação positiva.

Ao contrário de outros modelos encontrados na literatura, nosso modelo PGN, além de representar de forma muito focalizada a regulação do ciclo celular em termos de expressão gênica, opera como processos genéticos quase determinísticos influenciados estocásticamente. Esta dinâmica do nosso modelo, no limite do determinístico e estocástico, reflete fatos longamente observados na biologia. Apesar de que mecanismos que controlam processos tais como a divisão ou diferenciação celular poderiam ser interpretados globalmente como inerentemente determinísticos, quando olhamos um pouco mais em detalhe, o "ruido" é um fator presente no contexto celular, que deve ser considerado numa modelagem realista dos fenômenos. Os sistemas biológicos tiveram que evoluir para desempenhar suas funções básicas "convivendo" com o nível de estocacidade existente, portanto ela é um dos fatores determinantes do funcionamento dos mecanismos de regulação celular. Como tal nível de estocacidade é moderado — seguramente como conseqüência da viabilidade dos sistemas -, nosso modelo opera de forma 
quase-determinística, mas sem desconsiderar a estocacidade.

A presença de numerosos laços de realimentação negativa no modelo assegura estabilidade e robustez. Eles implicam que, frente a diferentes perturbações do ruido, o sistema é capaz de corrigir automaticamente estímulos externos que poderiam destruir a célula. Este tipo de mecanismos tem sido reportados como sendo muito comuns na natureza [27]. A realimentação negativa constitui o principal mecanismo de controle que permite uma resposta (ou adaptação) robusta a perturbações, e pode também levar a robustez a perturbações de parâmetros internos, como no caso dos atrasos aleatórios que deslocam temporalmente o valor dos pesos da PGN.

Em particular, pensamos que a falta de robustez do modelo de Li et al. do ciclo celular da levedura pode ser devida à ausência de algumas destas realimentações negativas, as quais podem existir no sistema de controle biológico. Com a inclusão de realimentação positiva, nosso modelo pode apresentar uma atividade oscilatória similar à observada nas células embrionárias. A estrutura paralela da arquitetura do modelo representa redundância biológica, a qual aumenta a tolerância a falhas do sistema.

Este modelo foi capaz de reproduzir qualitativamente o comportamento do modelo de Li et al., e o comportamento observado do modelo de Pomerening et al.. Ainda, ao contrário desses modelos, ele apresenta uma forte robustez à variação aleatória dos parâmetros do sistema.

Nosso modelo reproduz o comportamento qualitativo observado, e nossa implementação sugere uma possível forma para a realização desses mecanismos nos sistemas biológicos. Esta informação em conjunto com dados de sinais de controle reais, pode ser muito útil no entendimenento desses fenômenos observados nas células. O próximo passo natural desta pesquisa é estimar o modelo PGN da rede regulatória do ciclo celular a partir de dados dinâmicos analogamente ao realizado com o sistema regulatório do parasita da malária [11, 12]. A análise destes dados 
dinâmicos pode permitir a investigação de algumas conjeturas sobre os mecanismos de controle do ciclo celular induzidas por nosso modelo, tal como a existência de laços de realimentação negativa desconhecidos, responsáveis pela estabilidade e robustez do sistema biológico. Esta pesquisa encontra-se em andamento e estão sendo usados dados de expressão gênica do ciclo celular da levedura, obtidos por medições seqüenciais de microarray [15, 16]. 
Apêndices 
. 
Apêndice A

Simulações do Sistema de Controle

do Ciclo Celular 
. 


\section{A.1 Simulações do Modelo de Li et al. do Ciclo Celular da}

\section{Levedura}

A.1.1 Modelo PGN de Três Níveis do Ciclo Celular da Levedura com 1\% de ruido (PGN with $P=0.99$ )

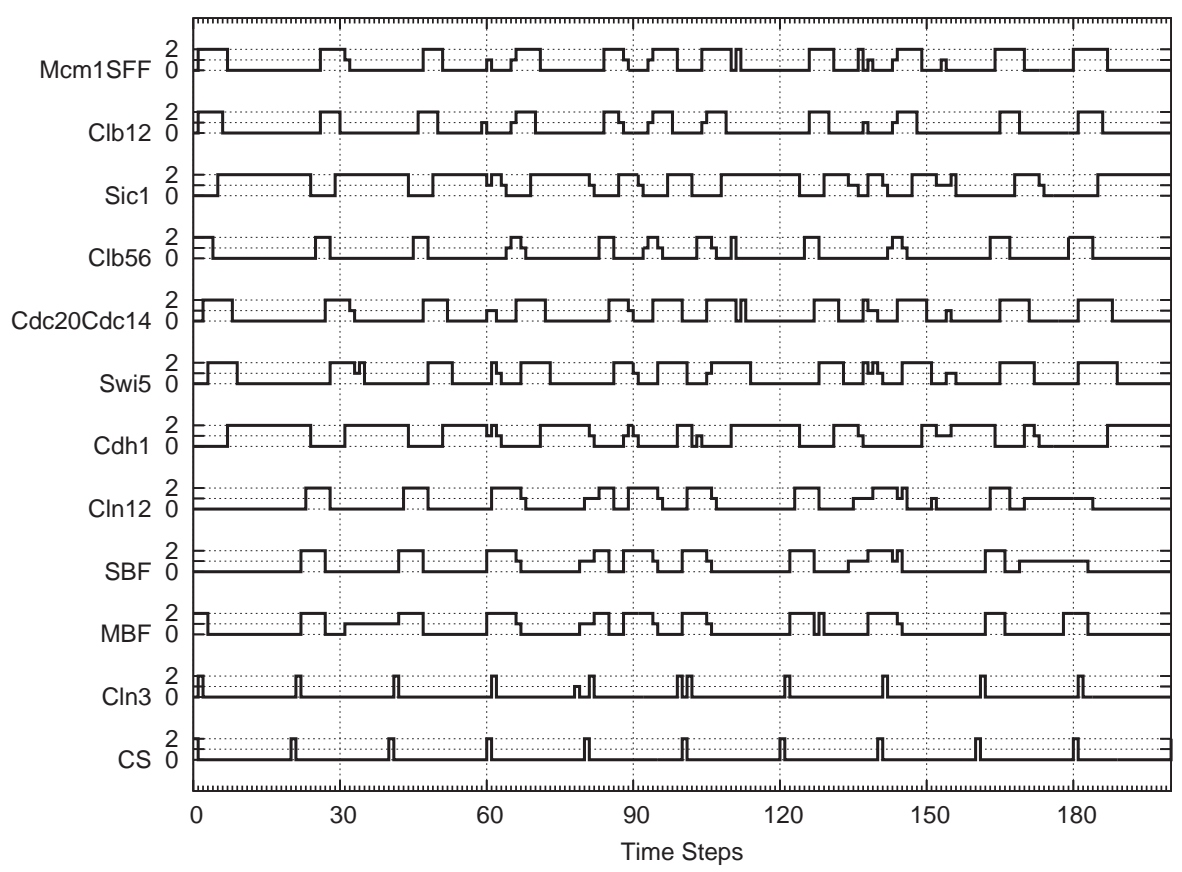

Figura A.1: Modelo PGN de três níveis do ciclo celular da levedura com 1\% de ruido (PGN com $P=0.99)$ ativado por $\mathbf{C S}=$ oscilador de período 20. 


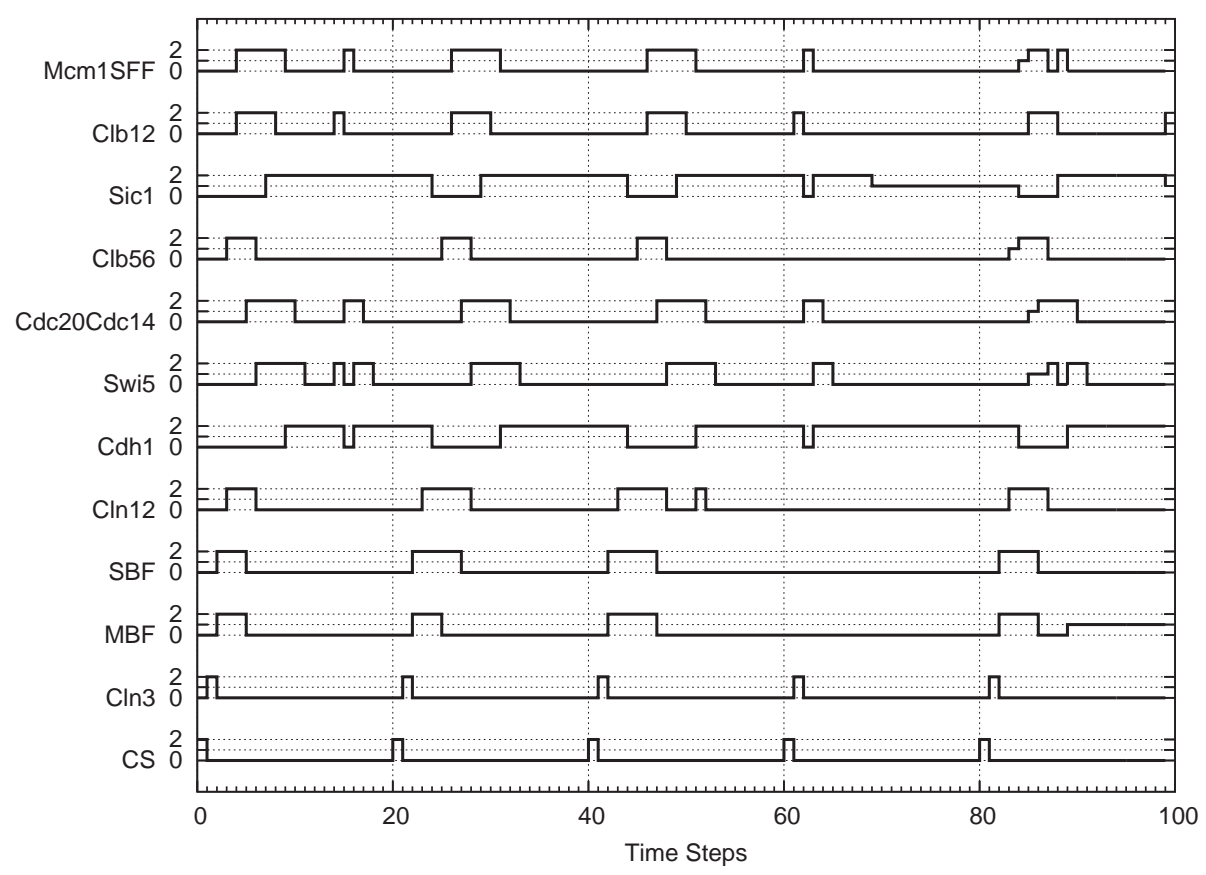

Figura A.2: Modelo PGN de três níveis do ciclo celular da levedura com $1 \%$ de ruido (PGN com $P=0.99)$ ativado por $\mathbf{C S}=$ oscilador de período 20 (100 primeiros passos $)$.

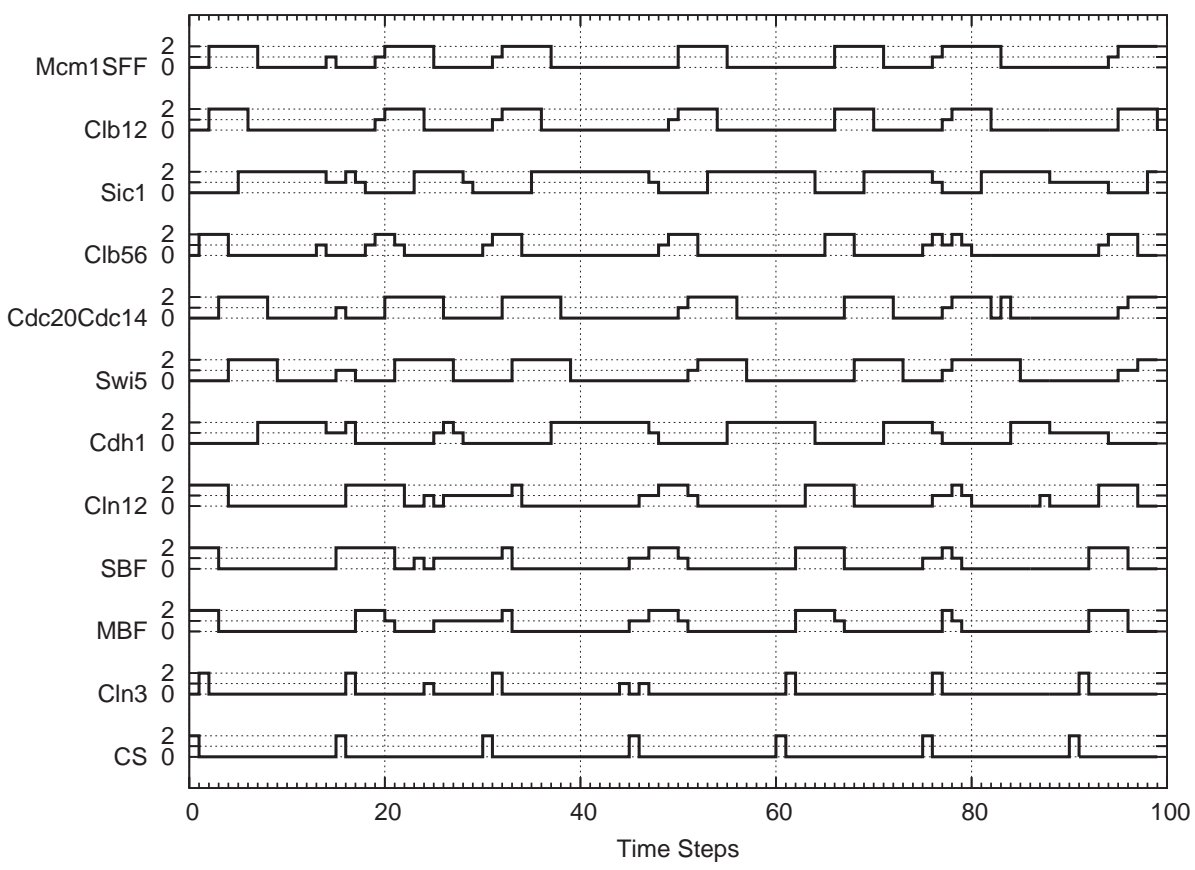

Figura A.3: Modelo PGN de três níveis do ciclo celular da levedura com 1\% de ruido (PGN com $P=0.99$ ) ativado por $\mathbf{C S}=$ oscilador de período 15 . 


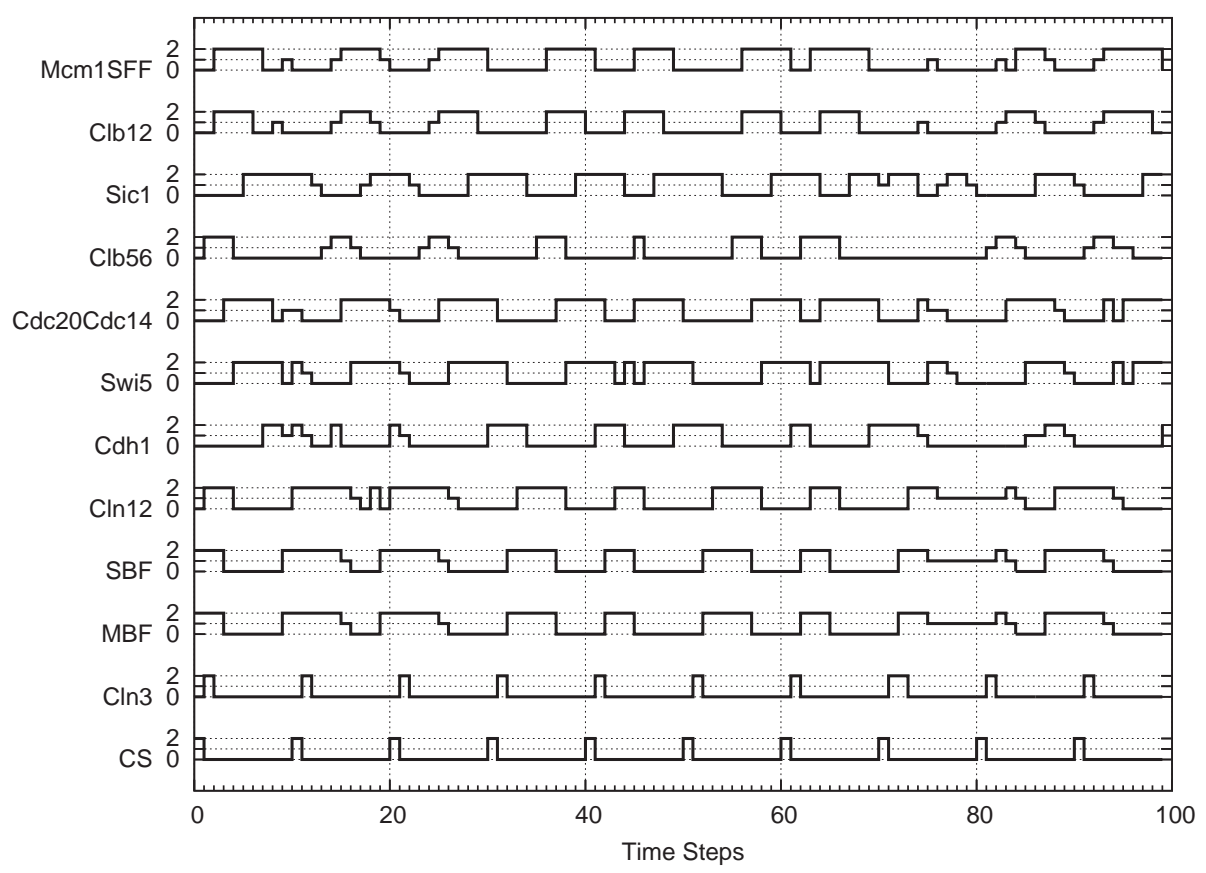

Figura A.4: Modelo PGN de três níveis do ciclo celular da levedura com $1 \%$ de ruido (PGN com $P=0.99)$ ativado por $\mathbf{C S}=$ oscilador de período 10.

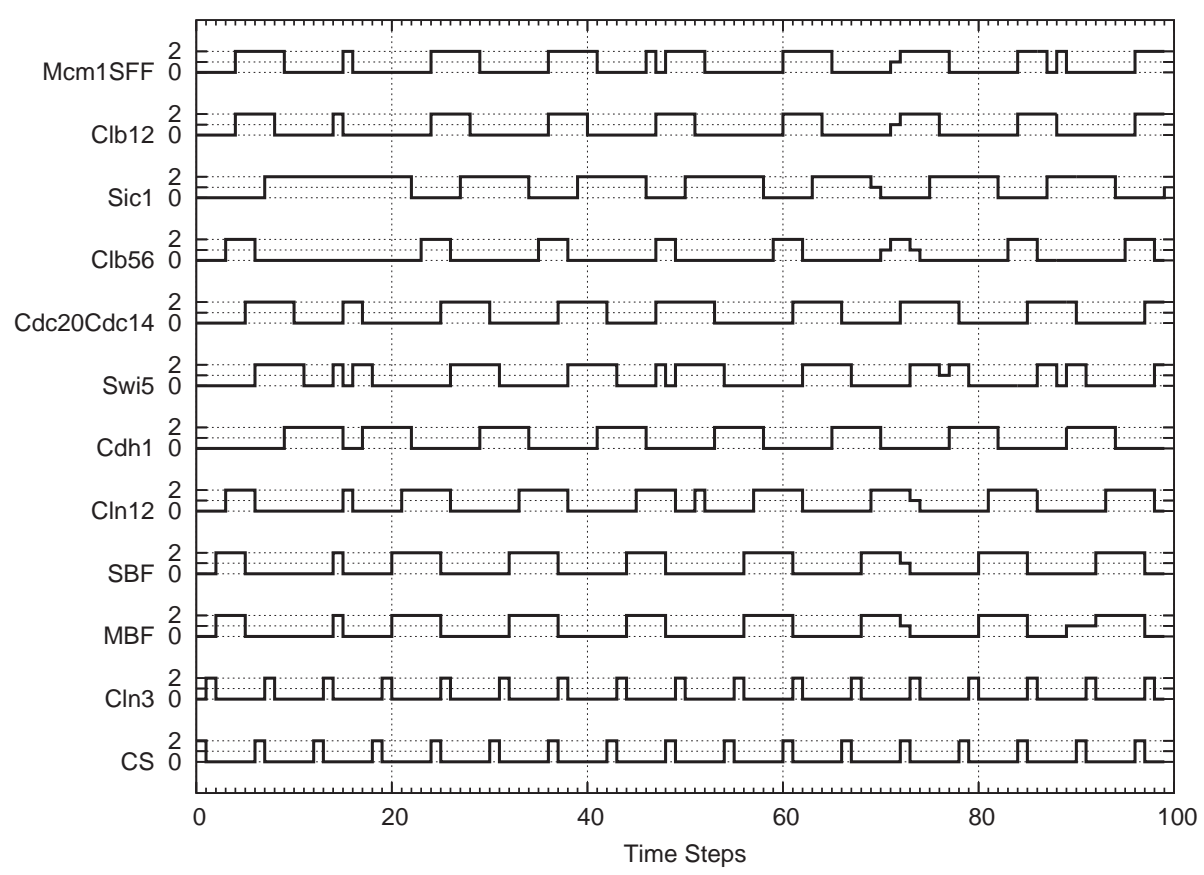

Figura A.5: Modelo PGN de três níveis do ciclo celular da levedura com 1\% de ruido (PGN com $P=0.99$ ) ativado por $\mathbf{C S}=$ oscilador de período 6 . 


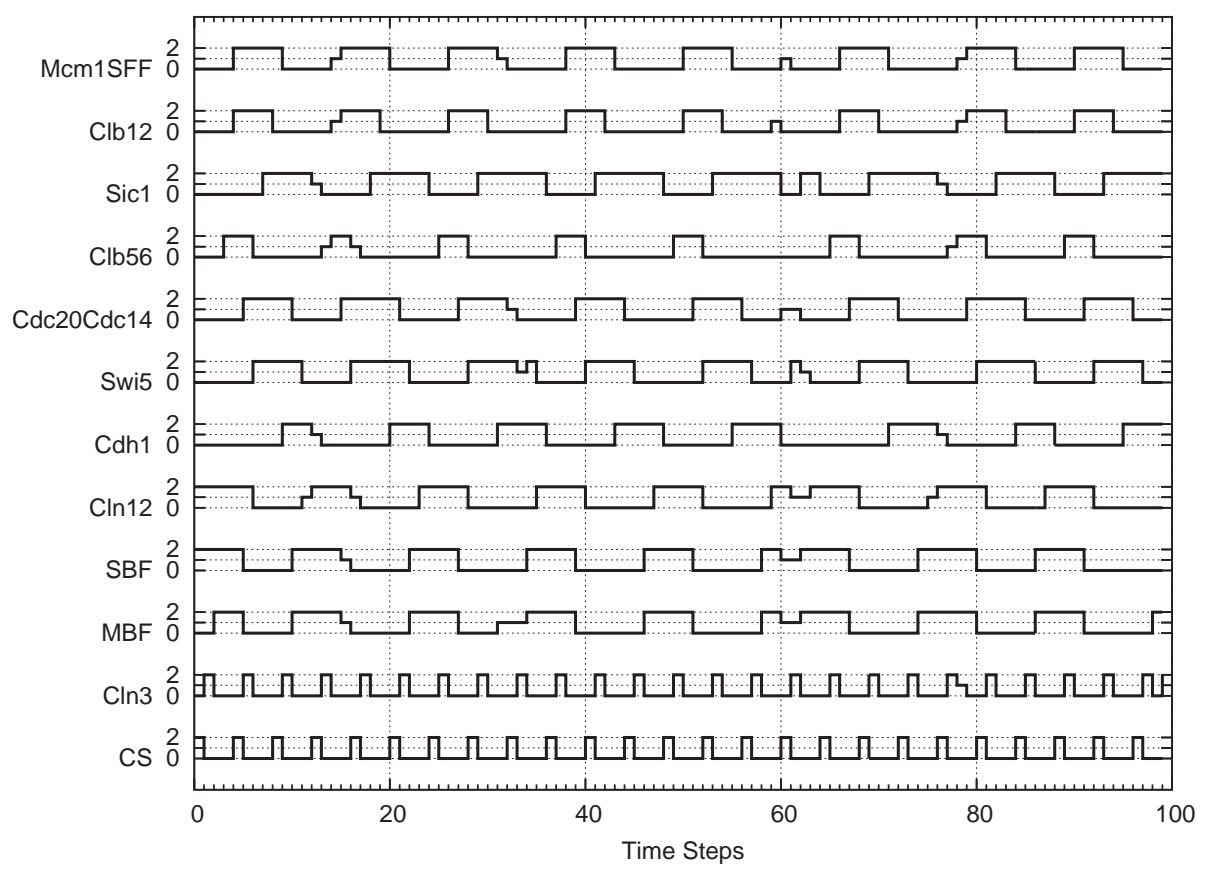

Figura A.6: Modelo PGN de três níveis do ciclo celular da levedura com 1\% de ruido (PGN com $P=0.99)$ ativado por $\mathbf{C S}=$ oscilador de período 4 .

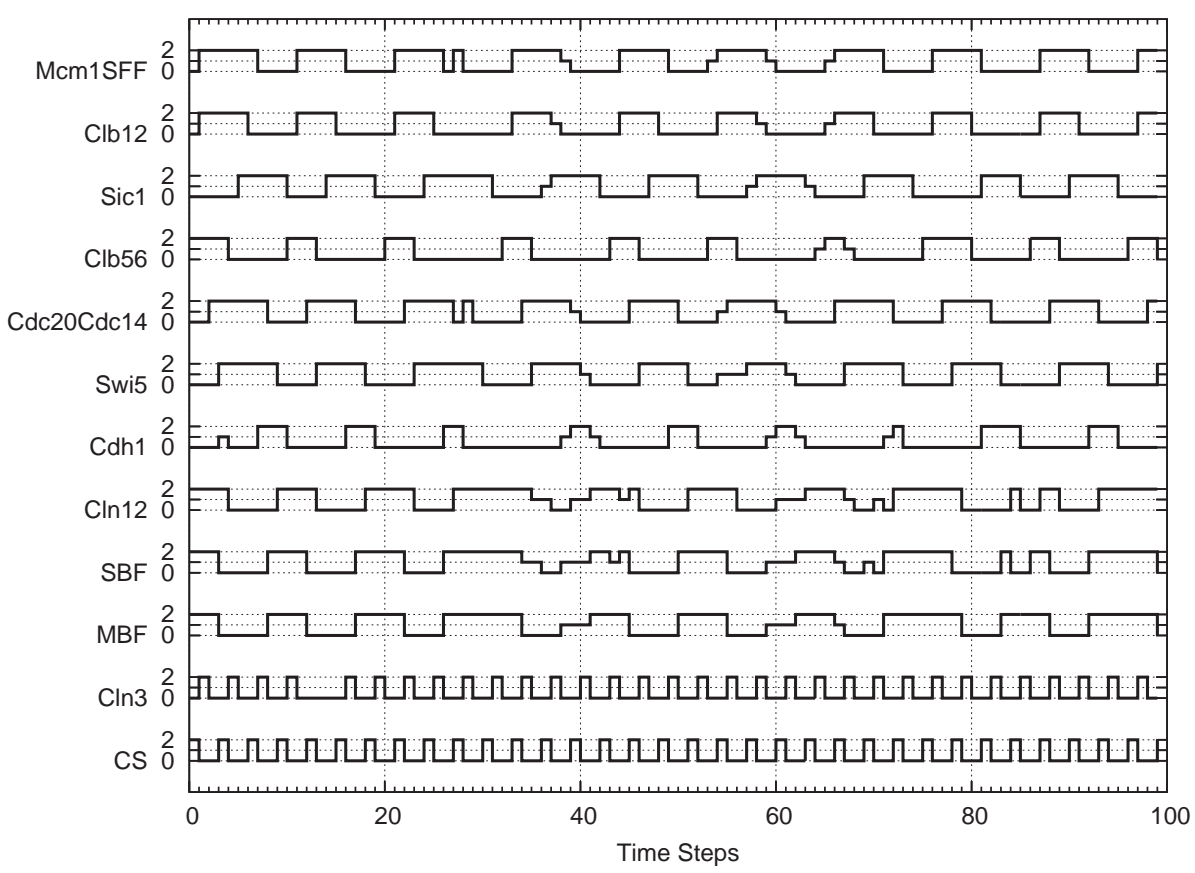

Figura A.7: Modelo PGN de três níveis do ciclo celular da levedura com 1\% de ruido (PGN com $P=0.99$ ) ativado por $\mathbf{C S}=$ oscilador de período 3 . 


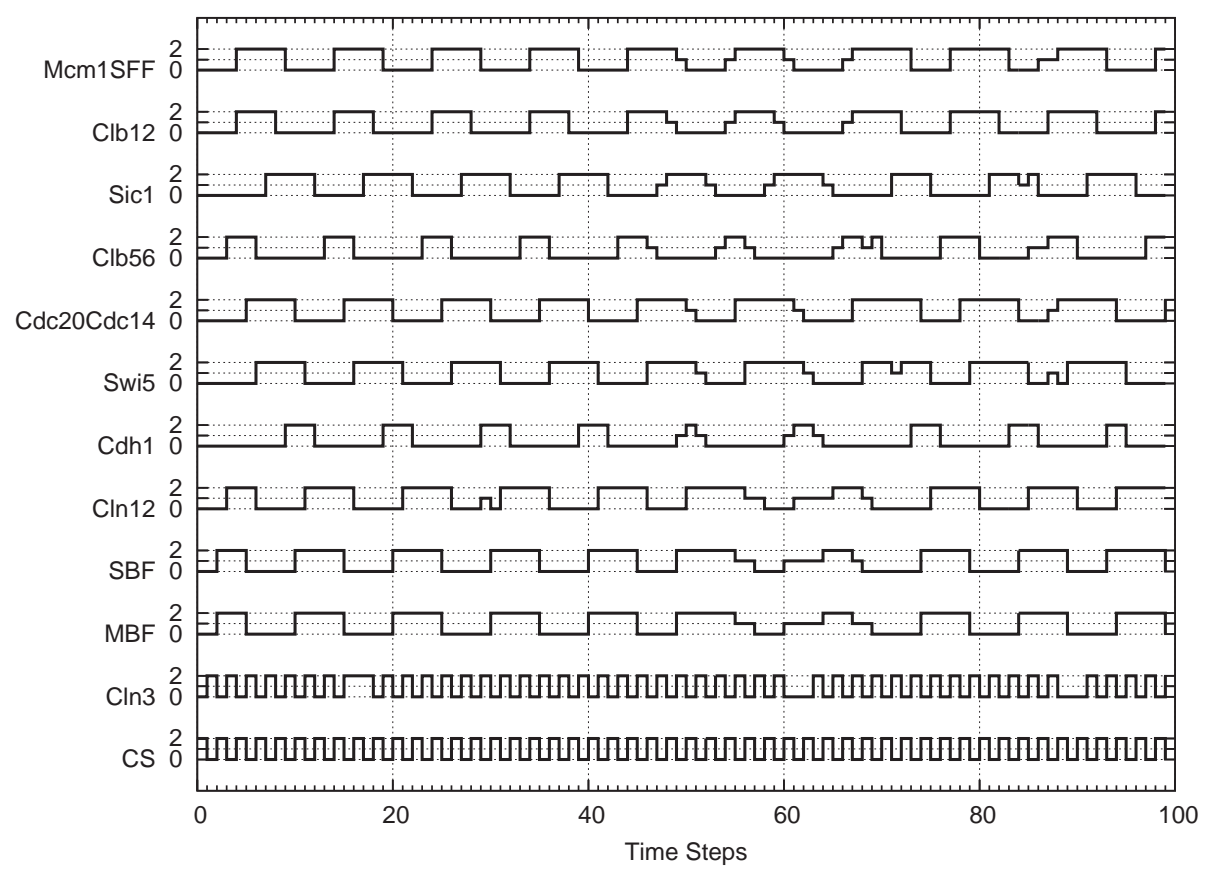

Figura A.8: Modelo PGN de três níveis do ciclo celular da levedura com 1\% de ruido (PGN com $P=0.99)$ ativado por $\mathbf{C S}=$ oscilador de período 2 .

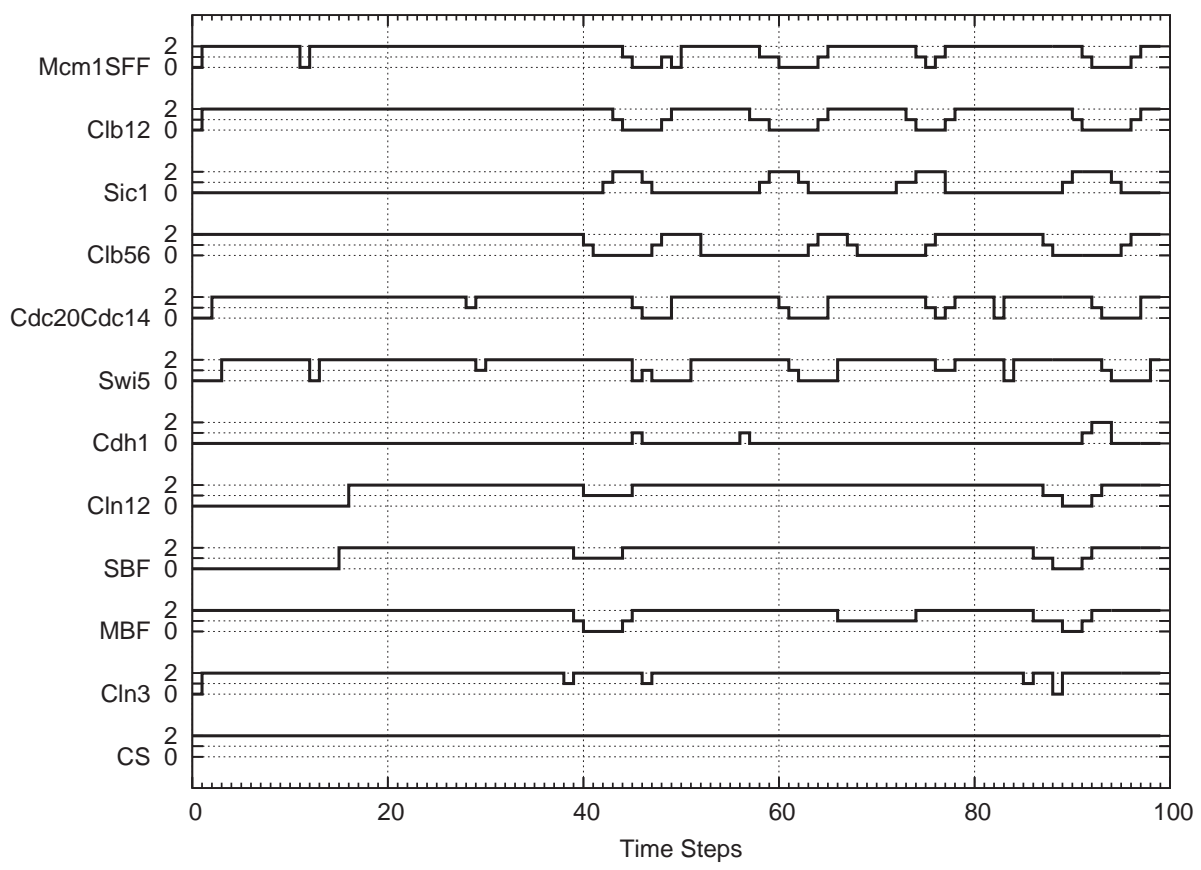

Figura A.9: Modelo PGN de três níveis do ciclo celular da levedura com 1\% de ruido (PGN com $P=0.99)$ ativado por um sinal constante $\mathbf{C S}=\mathbf{2}$. 


\section{A.1.2 Modelo Binário do Ciclo Celular da Levedura com Ruido Decrescente}

(a partir de 1\%)

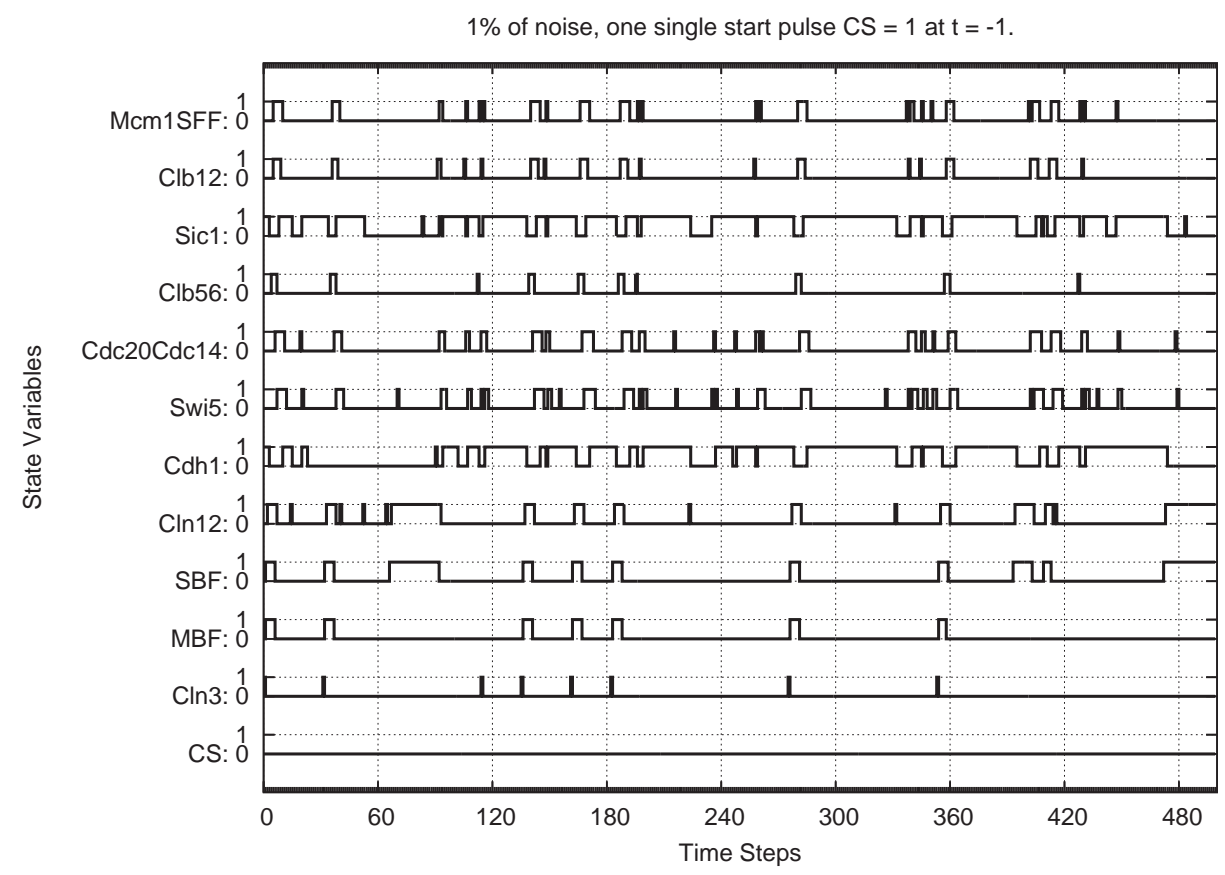

Figura A.10: Modelo PGN de três níveis do ciclo celular da levedura com 1\% de ruido (PGN com $P=0.99$ ) ativado por um único pulso de $C S=2$ em $t=-1$. 


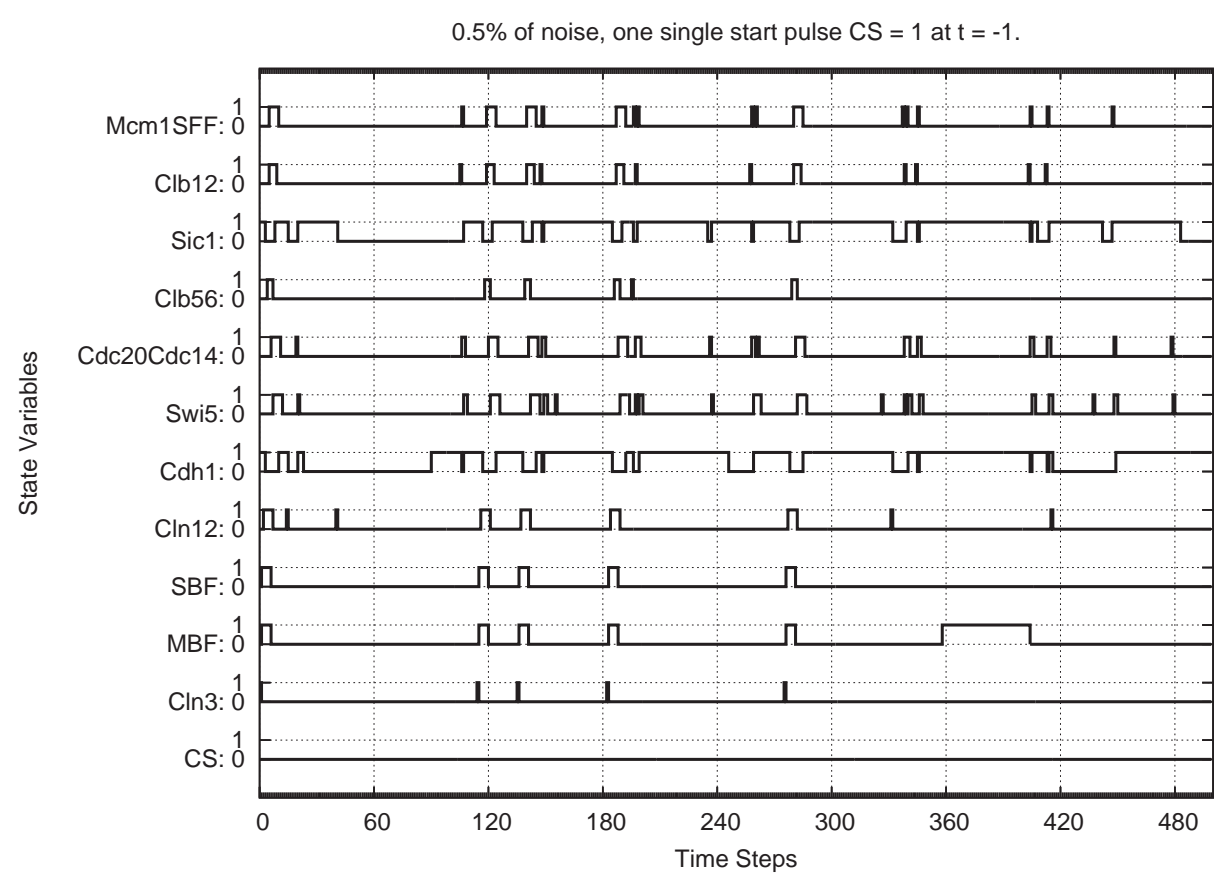

Figura A.11: Modelo PGN de três níveis do ciclo celular da levedura com $\mathbf{0 , 5 \%}$ de ruido (PGN com $P=0.995)$ ativado por um único pulso de $C S=2$ em $t=-1$.

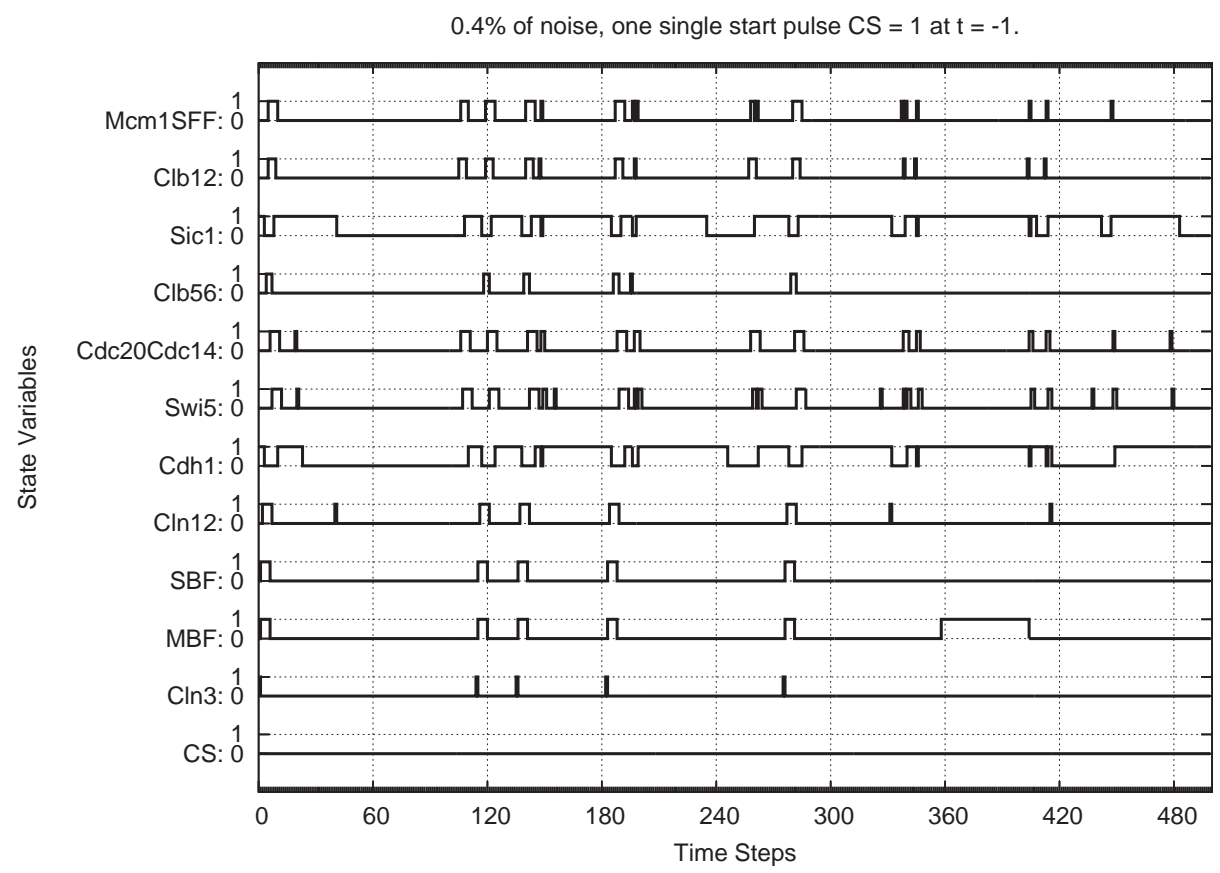

Figura A.12: Modelo PGN de três níveis do ciclo celular da levedura com $\mathbf{0}, \mathbf{4 \%}$ de ruido (PGN com $P=0.996$ ) ativado por um único pulso de $C S=2$ em $t=-1$. 


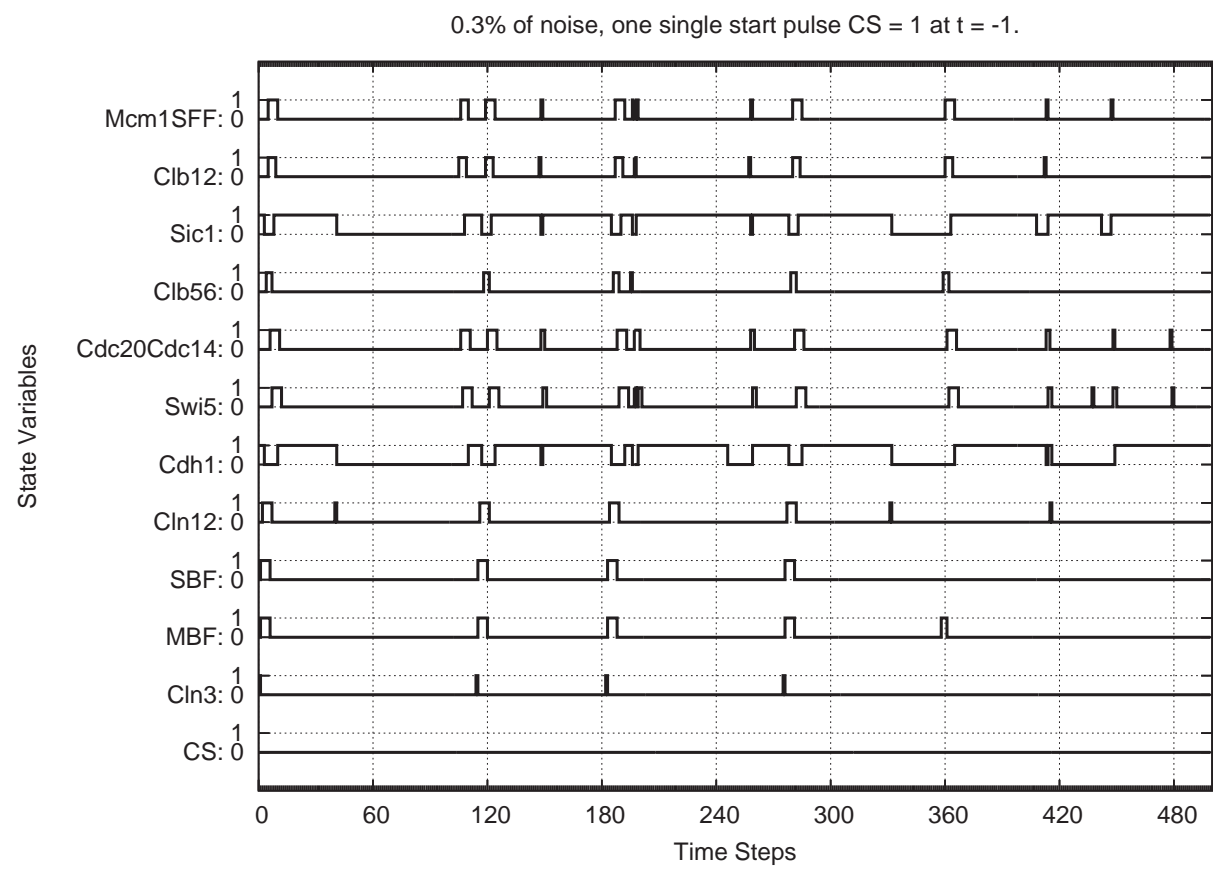

Figura A.13: Modelo PGN de três níveis do ciclo celular da levedura com $\mathbf{0}, \mathbf{3 \%}$ de ruido (PGN com $P=0.997$ ) ativado por um único pulso de $C S=2$ em $t=-1$.

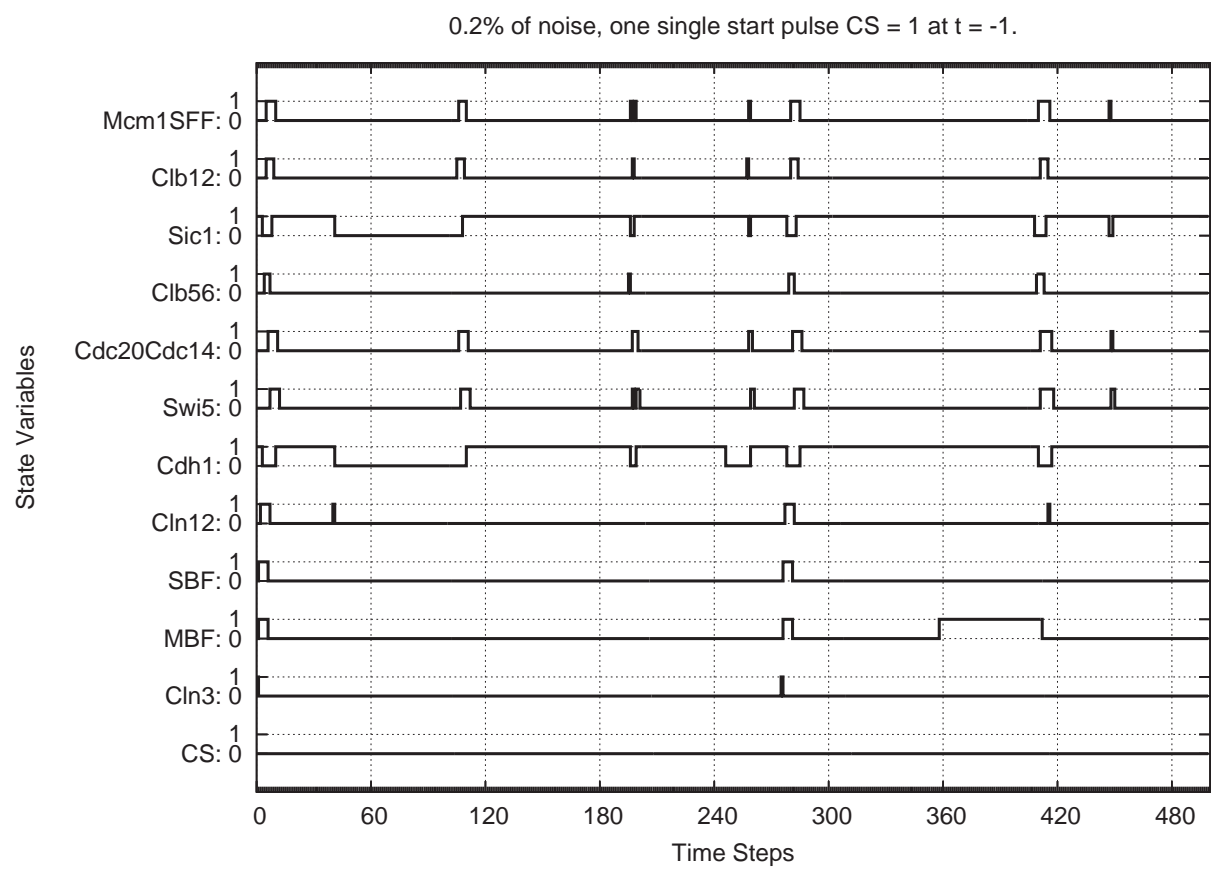

Figura A.14: Modelo PGN de três níveis do ciclo celular da levedura com $\mathbf{0}, \mathbf{2} \%$ de ruido (PGN com $P=0.998$ ) ativado por um único pulso de $C S=2$ em $t=-1$. 


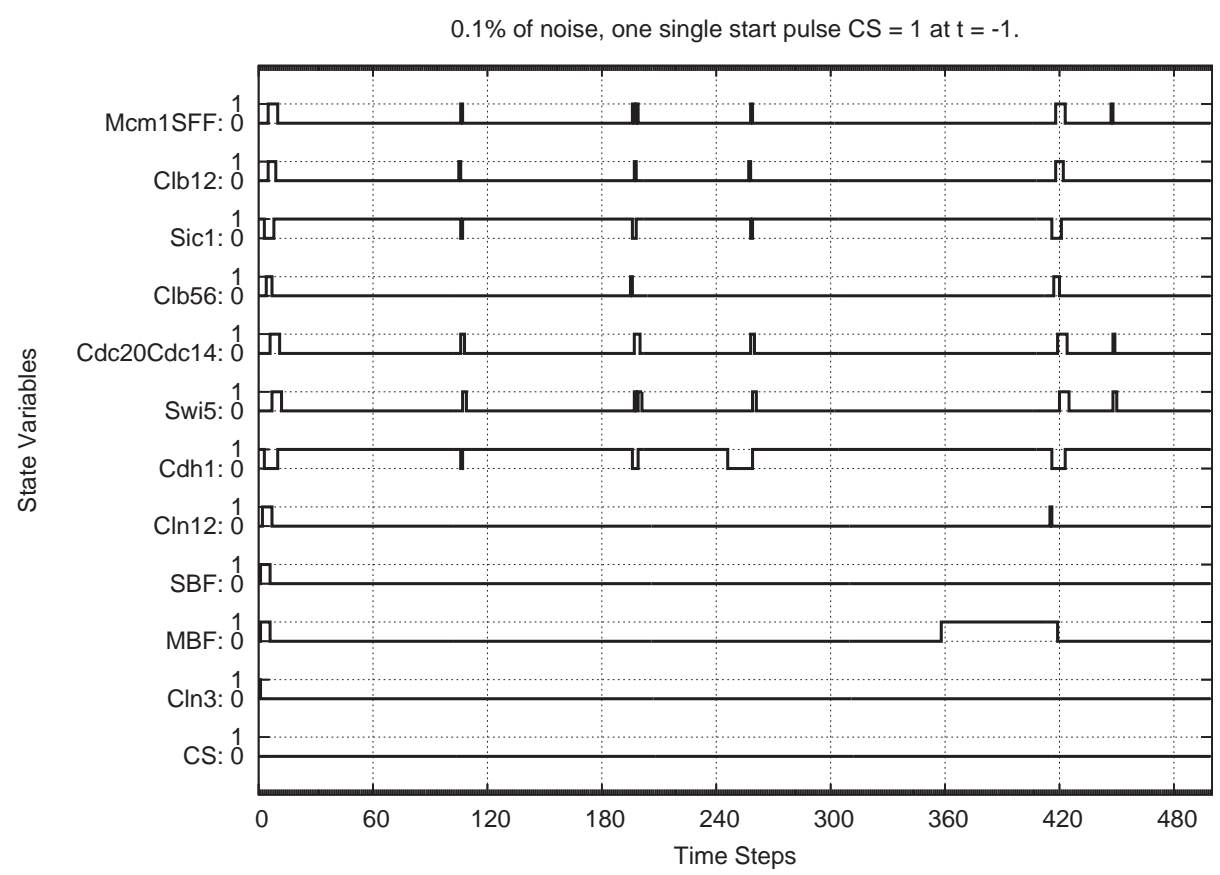

Figura A.15: Modelo PGN de três níveis do ciclo celular da levedura com $\mathbf{0 , 1 \%}$ de ruido (PGN com $P=0.999)$ ativado por um único pulso de $C S=2$ em $t=-1$.

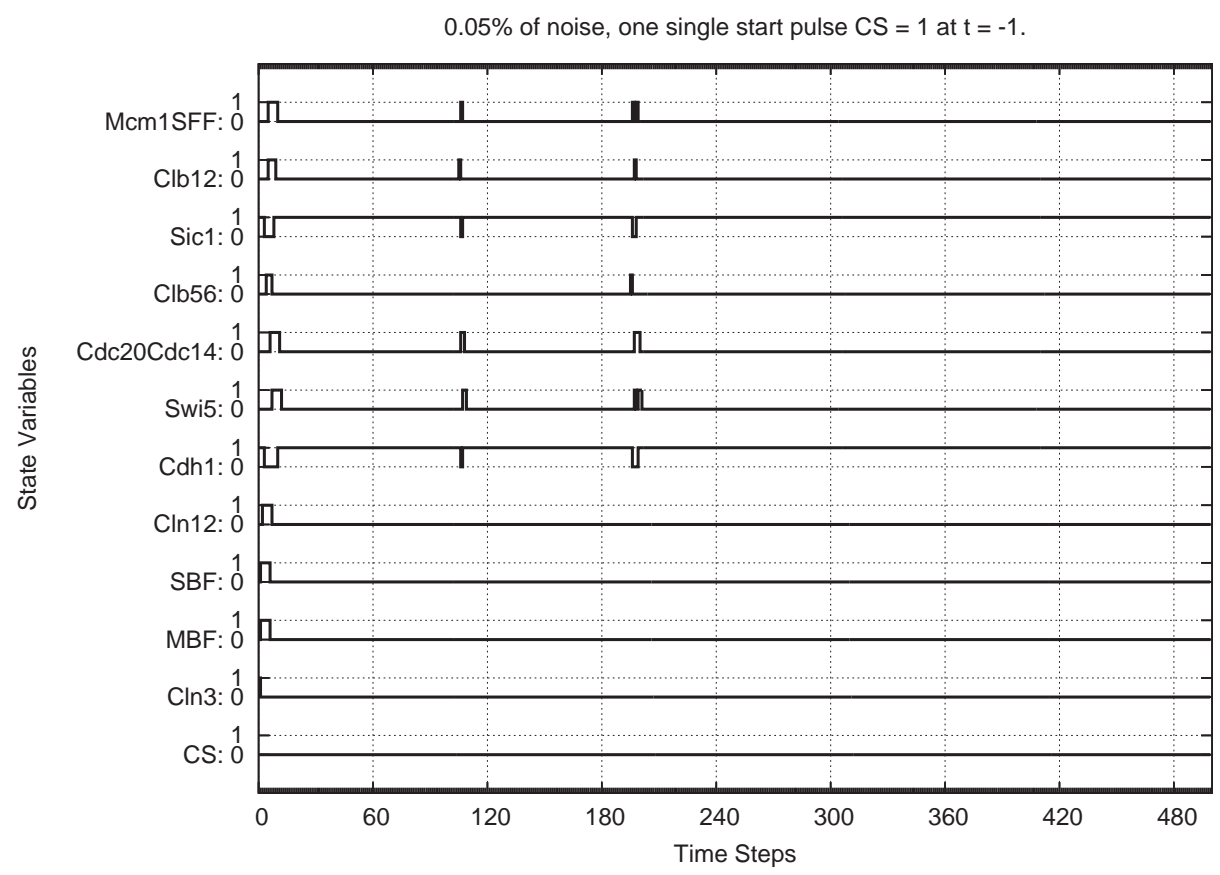

Figura A.16: Modelo PGN de três níveis do ciclo celular da levedura com $\mathbf{0 , 0 5 \%}$ de ruido (PGN com $P=0.9995$ ) ativado por um único pulso de $C S=2$ em $t=-1$. 


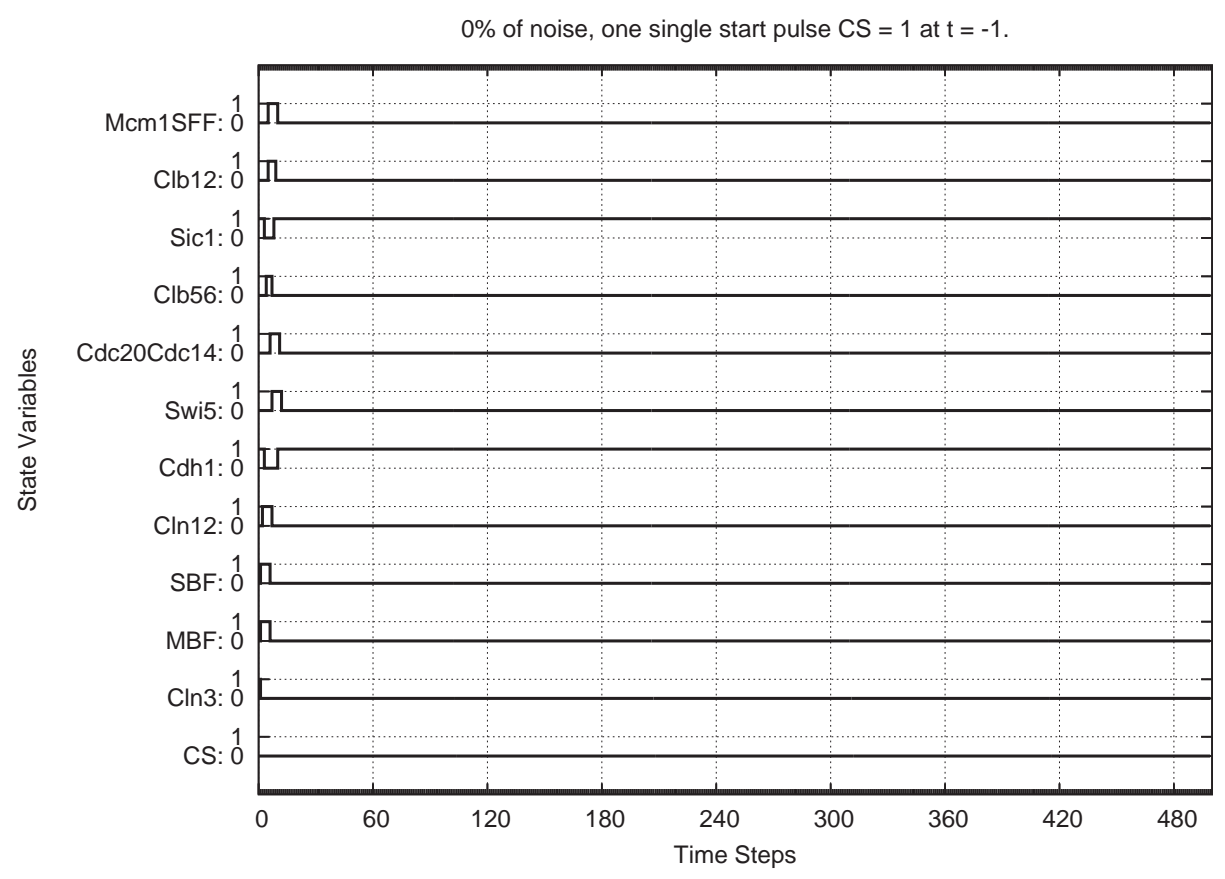

Figura A.17: Modelo PGN de três níveis do ciclo celular da levedura com $\mathbf{0 \%}$ de ruido (PGN com $P \rightarrow 1$, sistema determinístico) ativado por um único pulso de $C S=2 \mathrm{em} t=-1$. 


\section{A.2 Simulações de Nosso Modelo PGN do Controle da Progressão do Ciclo Celular}

A.2.1 Modelo PGN de Três Níveis com 1\% de Ruido (PGN com $P=0.99$ )

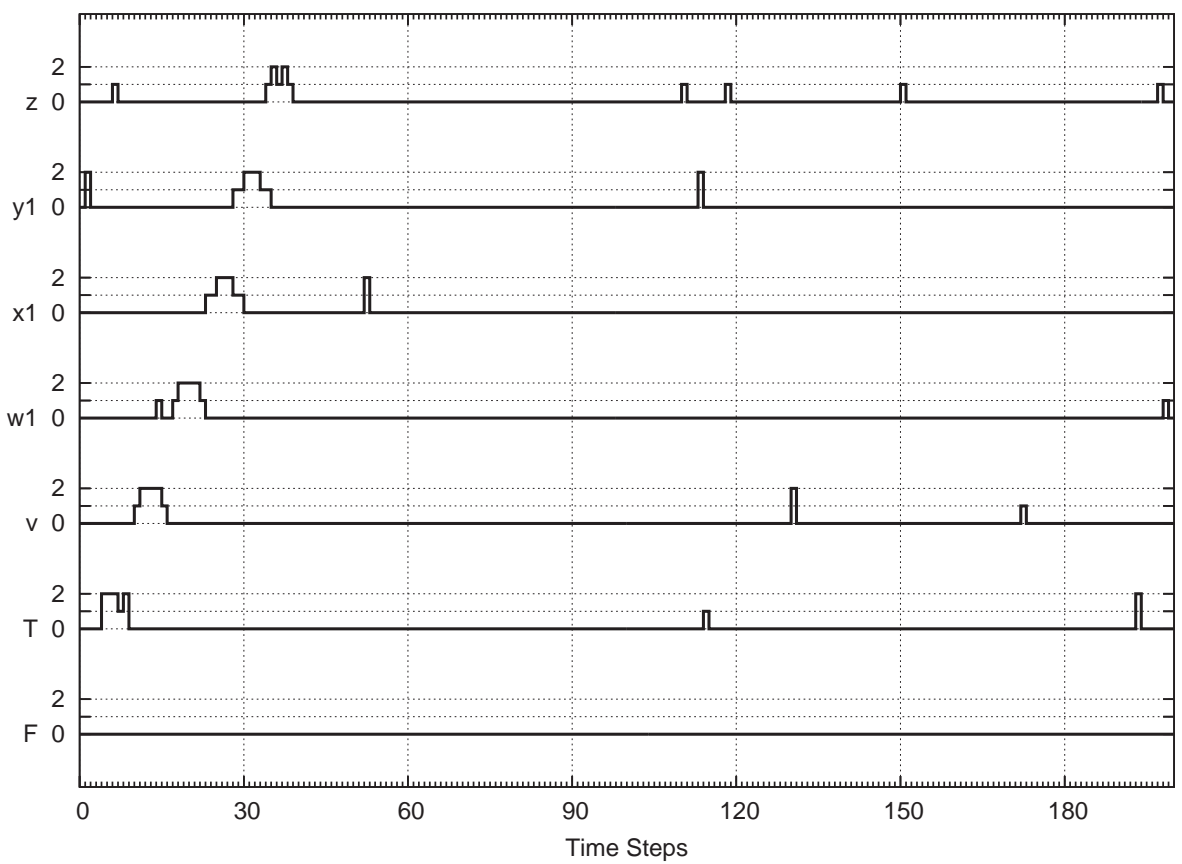

Figura A.18: Modelo PGN de três níveis do sistema de controle da progressão do ciclo celular, com $1 \%$ de ruído (PGN com $P=0.99$ ) ativado por um único pulso de $\mathbf{F}=\mathbf{2}$ em $\mathbf{t}=-\mathbf{1}$. 


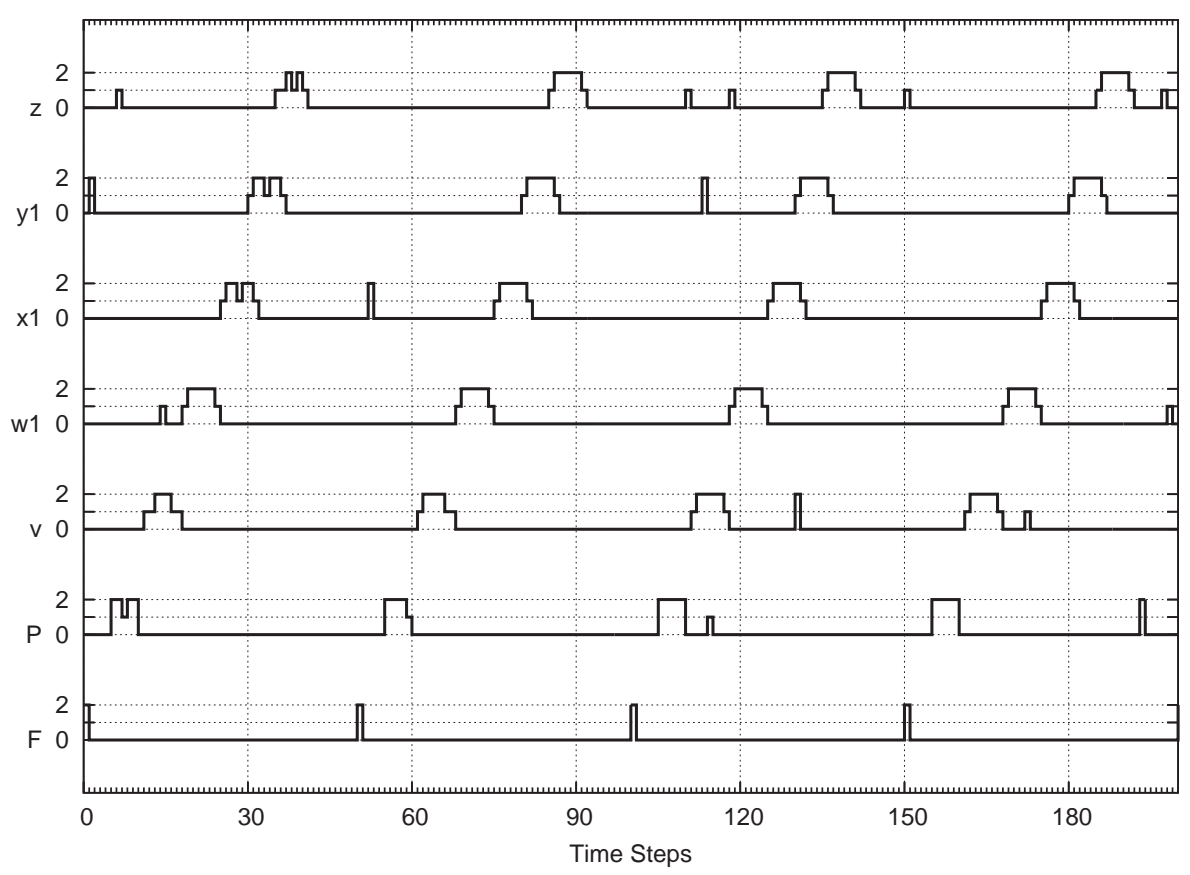

Figura A.19: Modelo PGN de três níveis do sistema de controle da progressão do ciclo celular, com $1 \%$ de ruído (PGN com $P=0.99$ ) ativado por $\mathbf{F}=$ oscilador de período 50 .

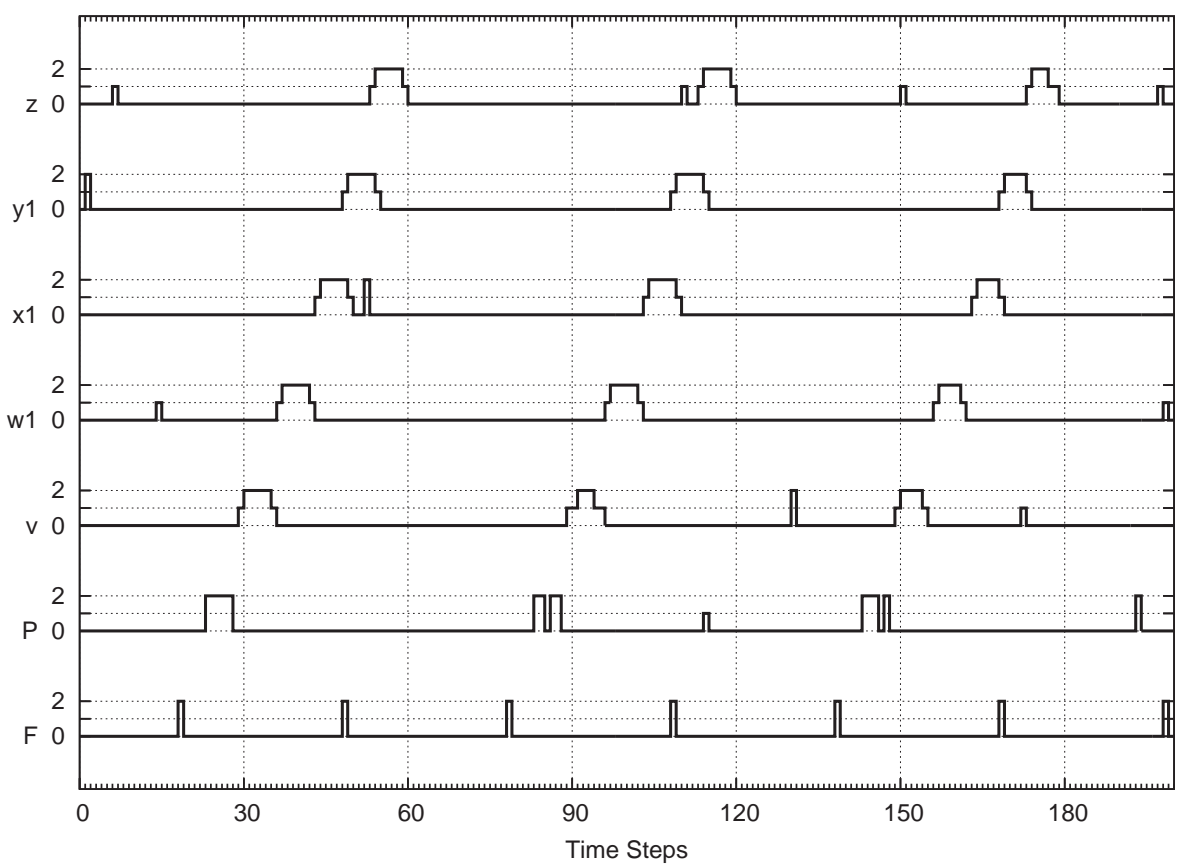

Figura A.20: Modelo PGN de três níveis do sistema de controle da progressão do ciclo celular, com $1 \%$ de ruído (PGN com $P=0.99$ ) ativado por $\mathbf{F}=$ oscilador de período 30 . 


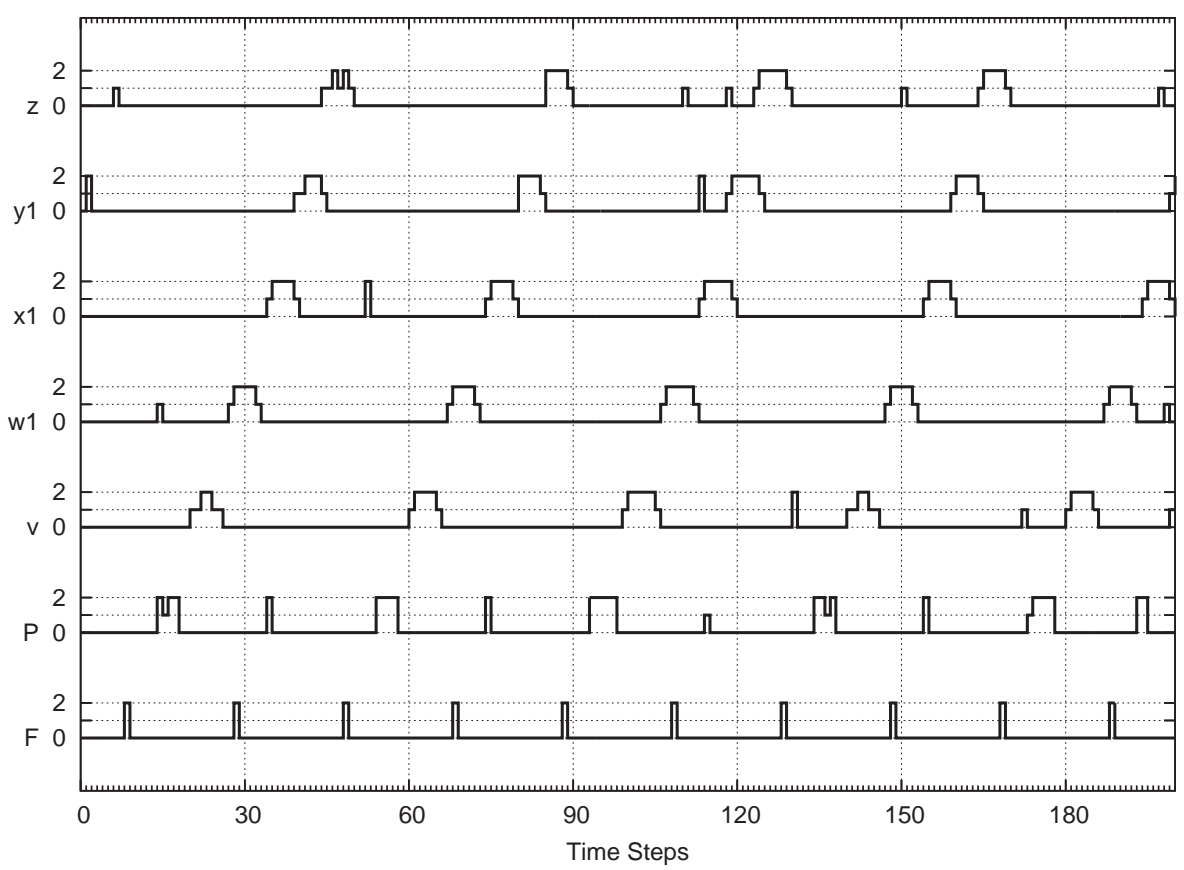

Figura A.21: Modelo PGN de três níveis do sistema de controle da progressão do ciclo celular, com $1 \%$ de ruído (PGN com $P=0.99$ ) ativado por $\mathbf{F}=$ oscilador de período 20 .

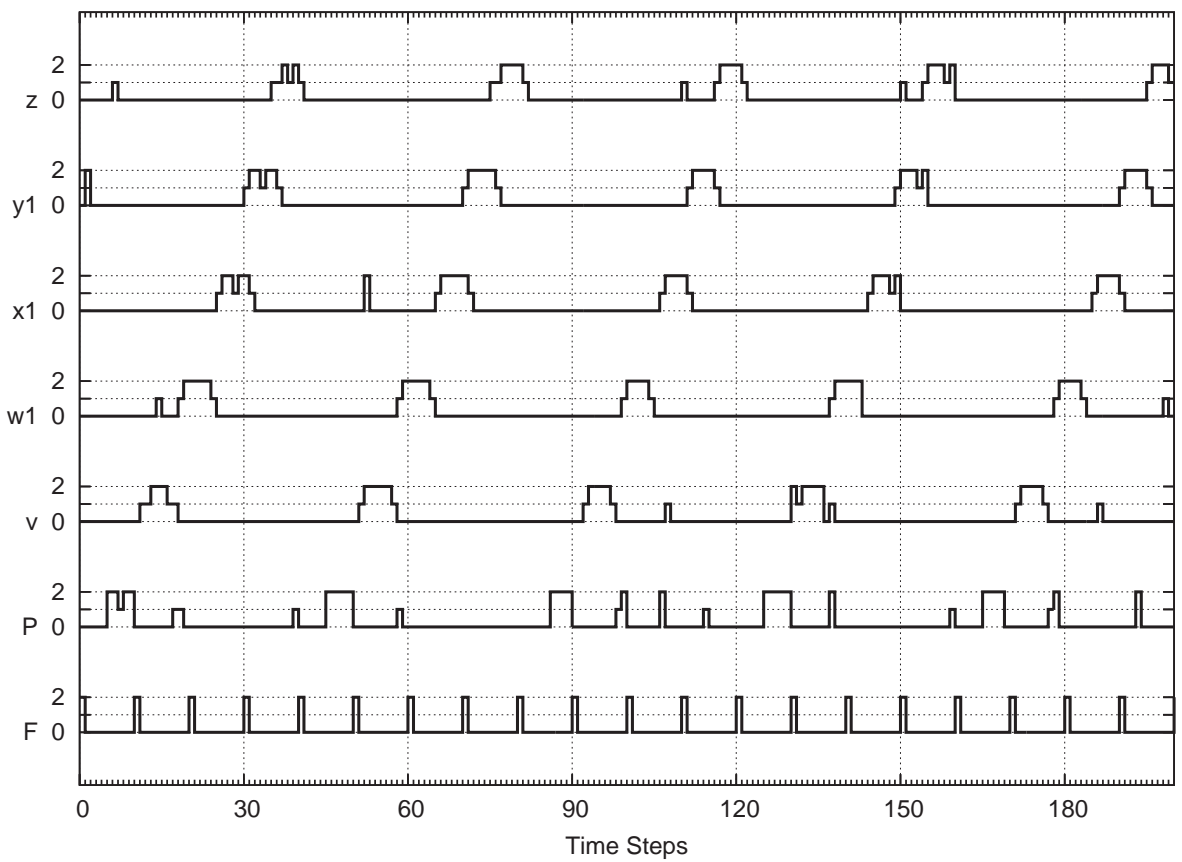

Figura A.22: Modelo PGN de três níveis do sistema de controle da progressão do ciclo celular, com $1 \%$ de ruído (PGN com $P=0.99$ ) ativado por $\mathbf{F}=$ oscilador de período 10 . 


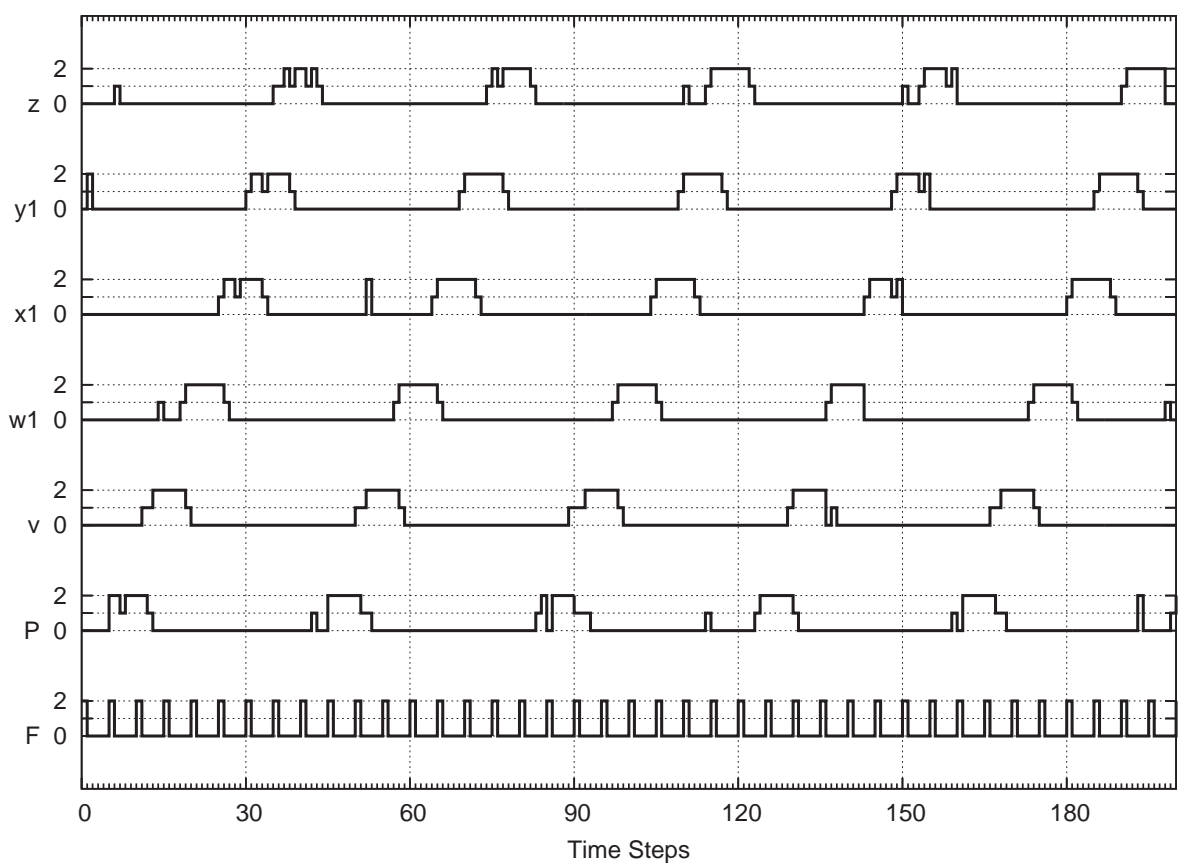

Figura A.23: Modelo PGN de três níveis do sistema de controle da progressão do ciclo celular, com $1 \%$ de ruído (PGN com $P=0.99$ ) ativado por $\mathbf{F}=$ oscilador de período 5 .

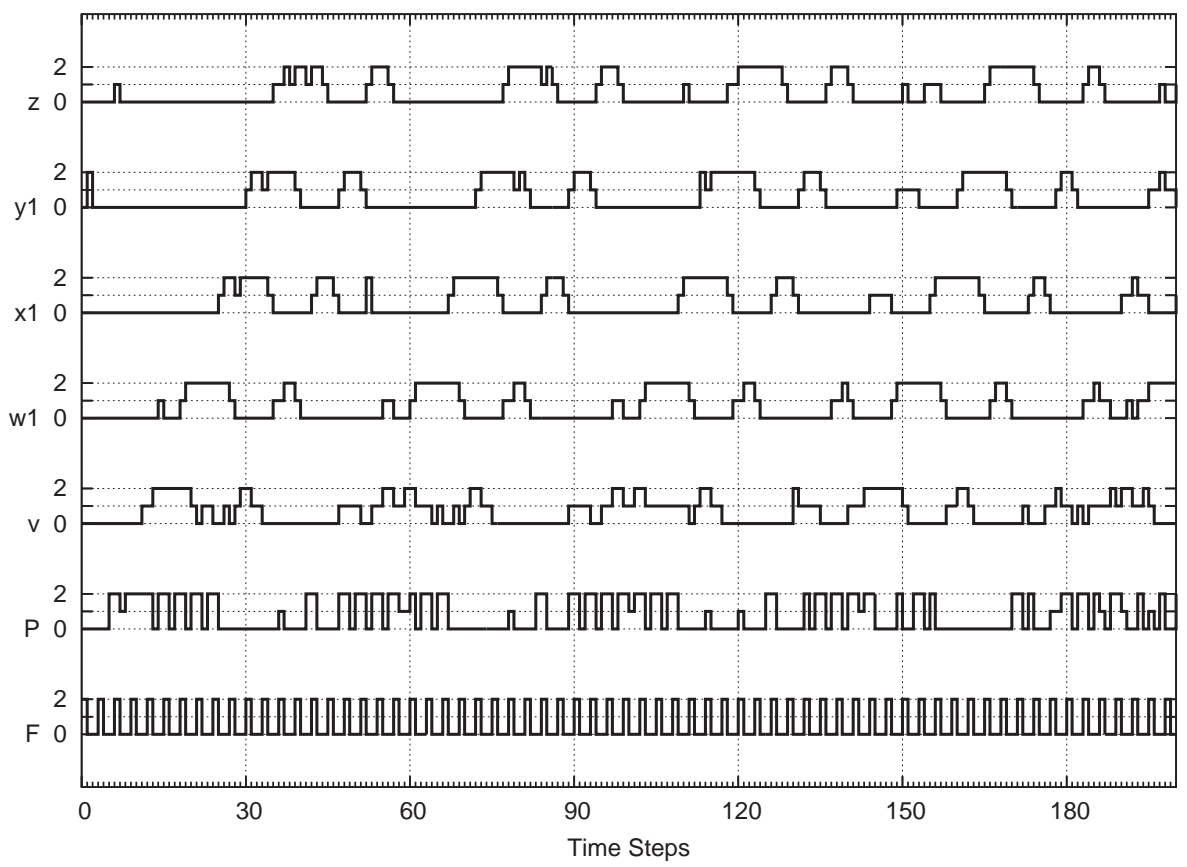

Figura A.24: Modelo PGN de três níveis do sistema de controle da progressão do ciclo celular, com $1 \%$ de ruído (PGN com $P=0.99$ ) ativado por $\mathbf{F}=$ oscilador de período 3 . 


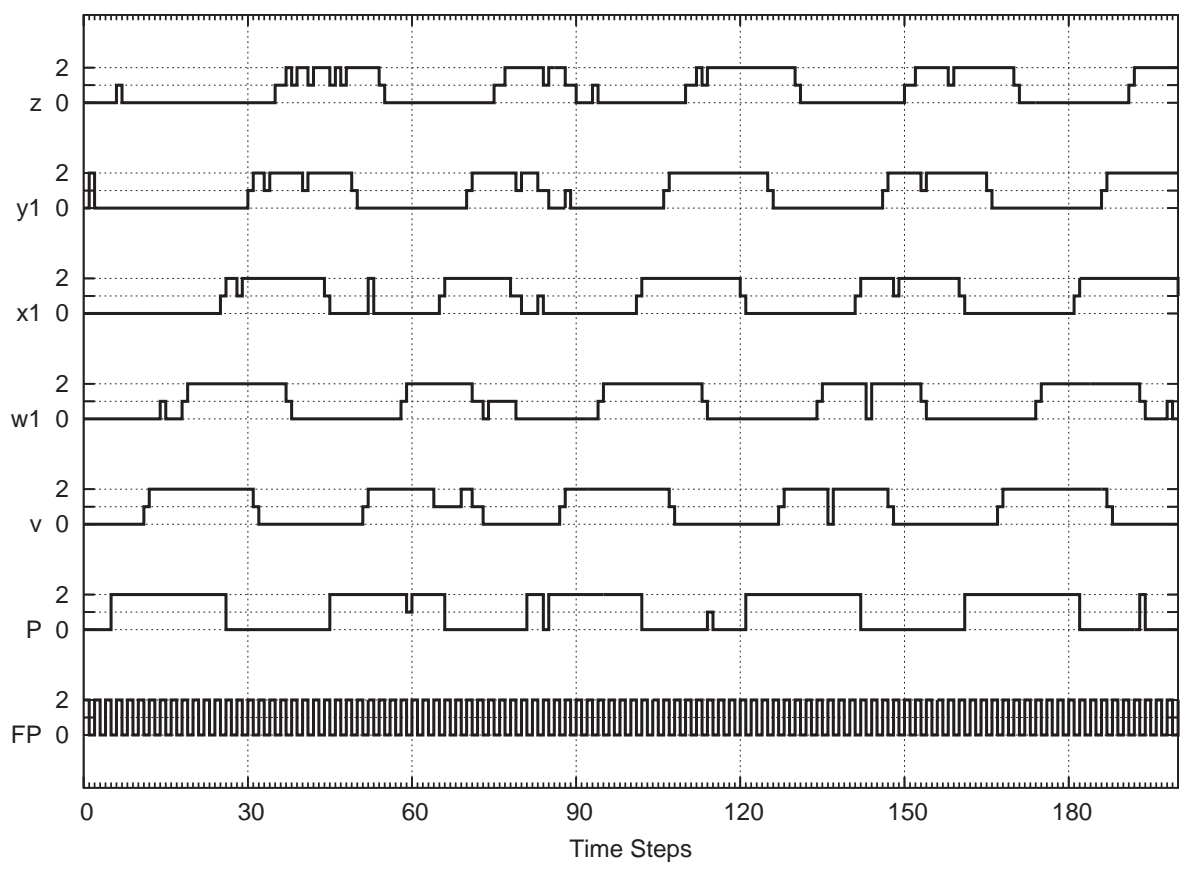

Figura A.25: Modelo PGN de três níveis do sistema de controle da progressão do ciclo celular, com $1 \%$ de ruído (PGN com $P=0.99$ ) ativado por $\mathbf{F}=$ oscilador de período 2 .

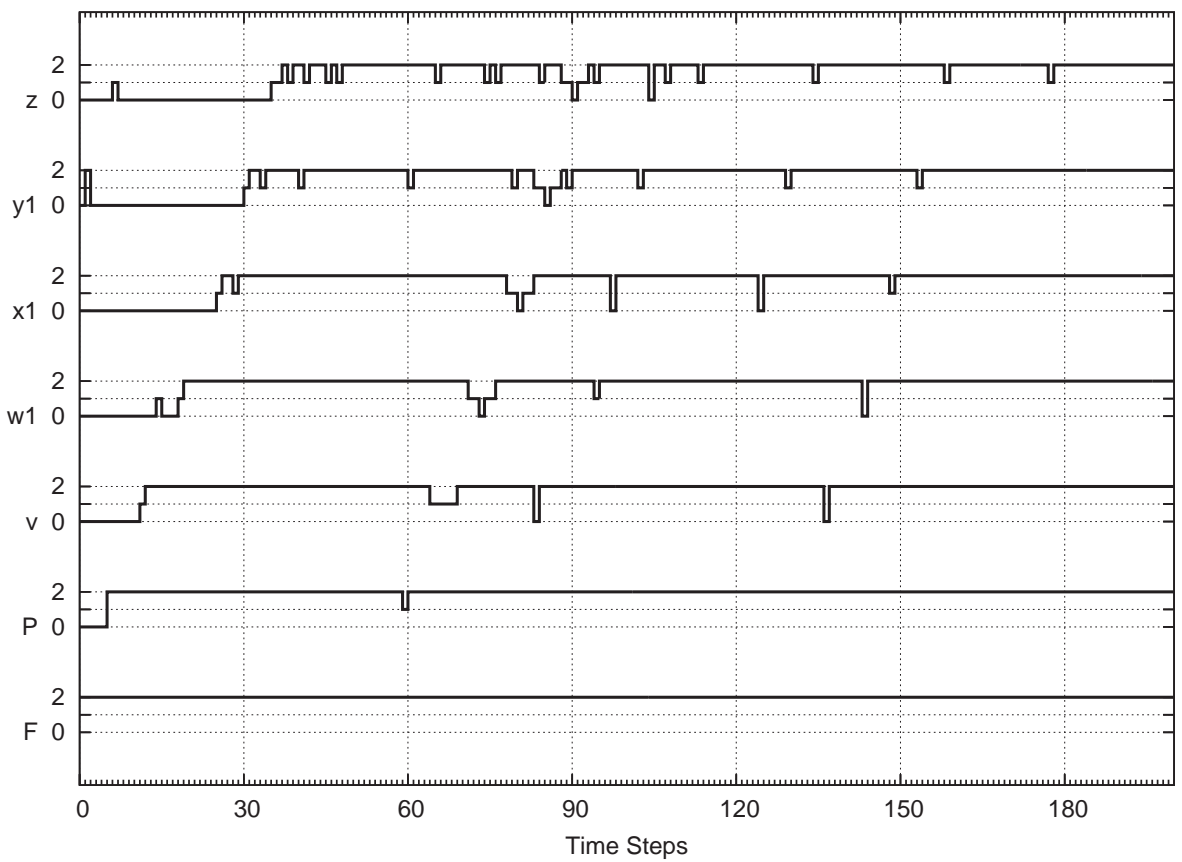

Figura A.26: Modelo PGN de três níveis do sistema de controle da progressão do ciclo celular, com $1 \%$ de ruído (PGN com $P=0.99$ ) ativado por um sinal constante $\mathbf{F}=\mathbf{2}$. 


\section{A.2.2 Modelo PGN de Três Níveis com Ruido Crescente}

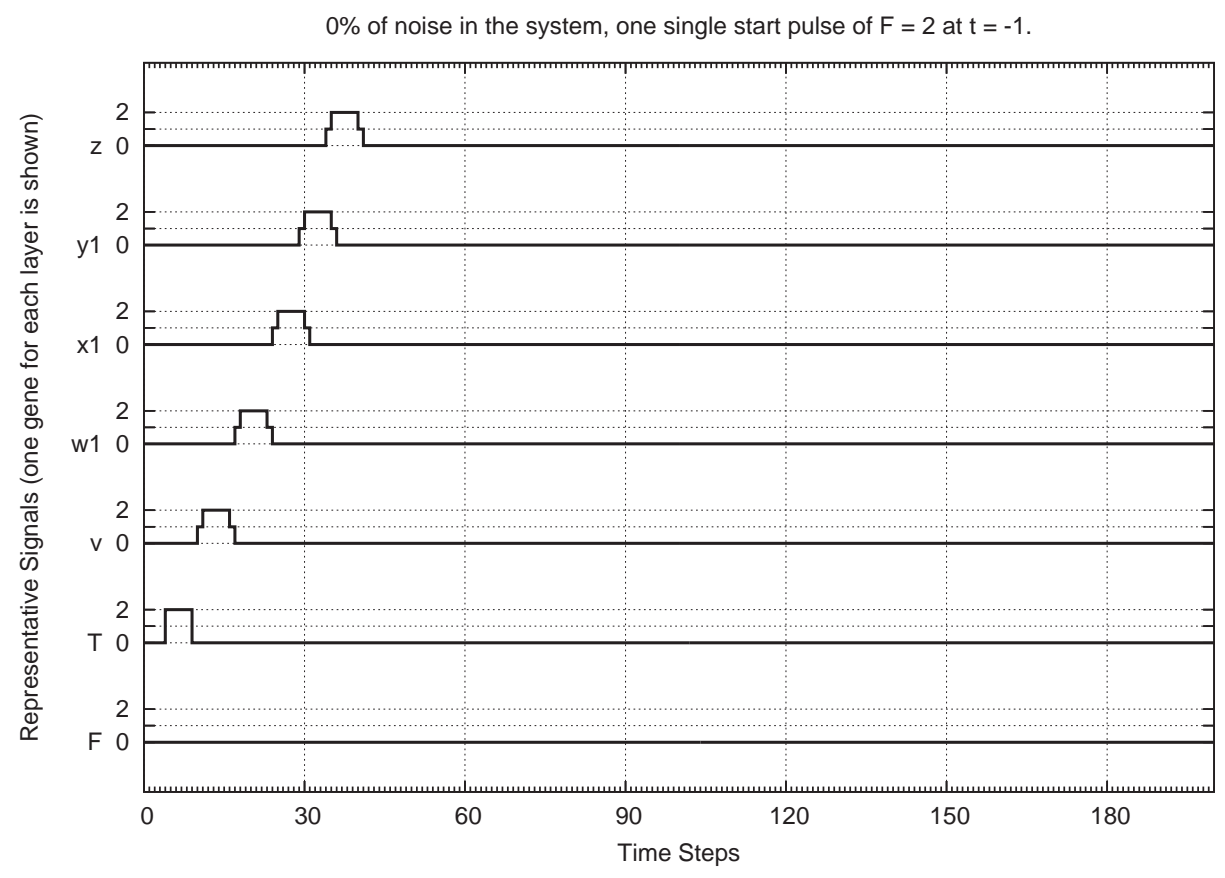

Figura A.27: Modelo PGN de três níveis do sistema de controle da progressão do ciclo celular com $\mathbf{0 \%}$ de ruido (PGN com $P \rightarrow 1$, sistema determinístico) ativado por um único pulso de $F=2$ em $t=-1$. 


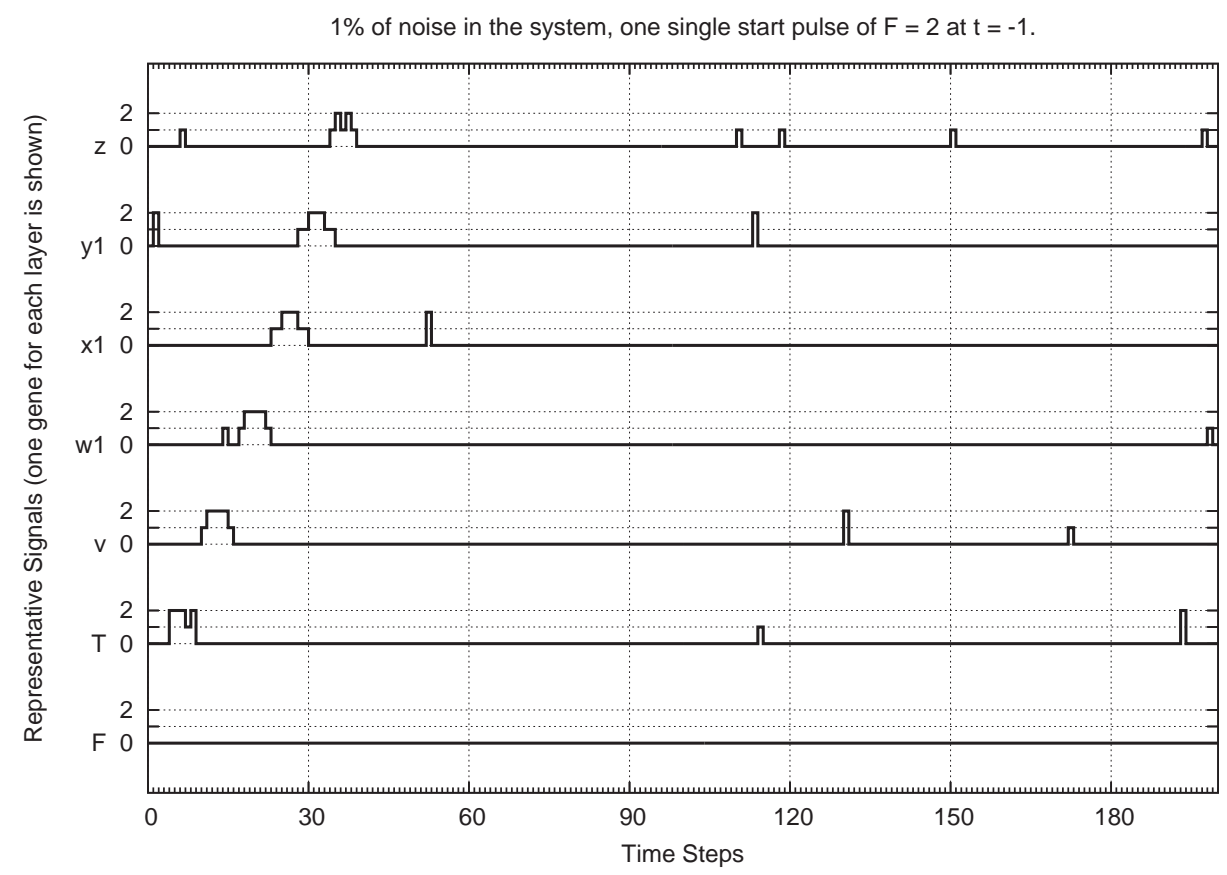

Figura A.28: Modelo PGN de três níveis do sistema de controle da progressão do ciclo celular com $\mathbf{1 \%}$ de ruido (PGN com $P=0.99$ ) ativado por um único pulso de $F=2$ em $t=-1$.

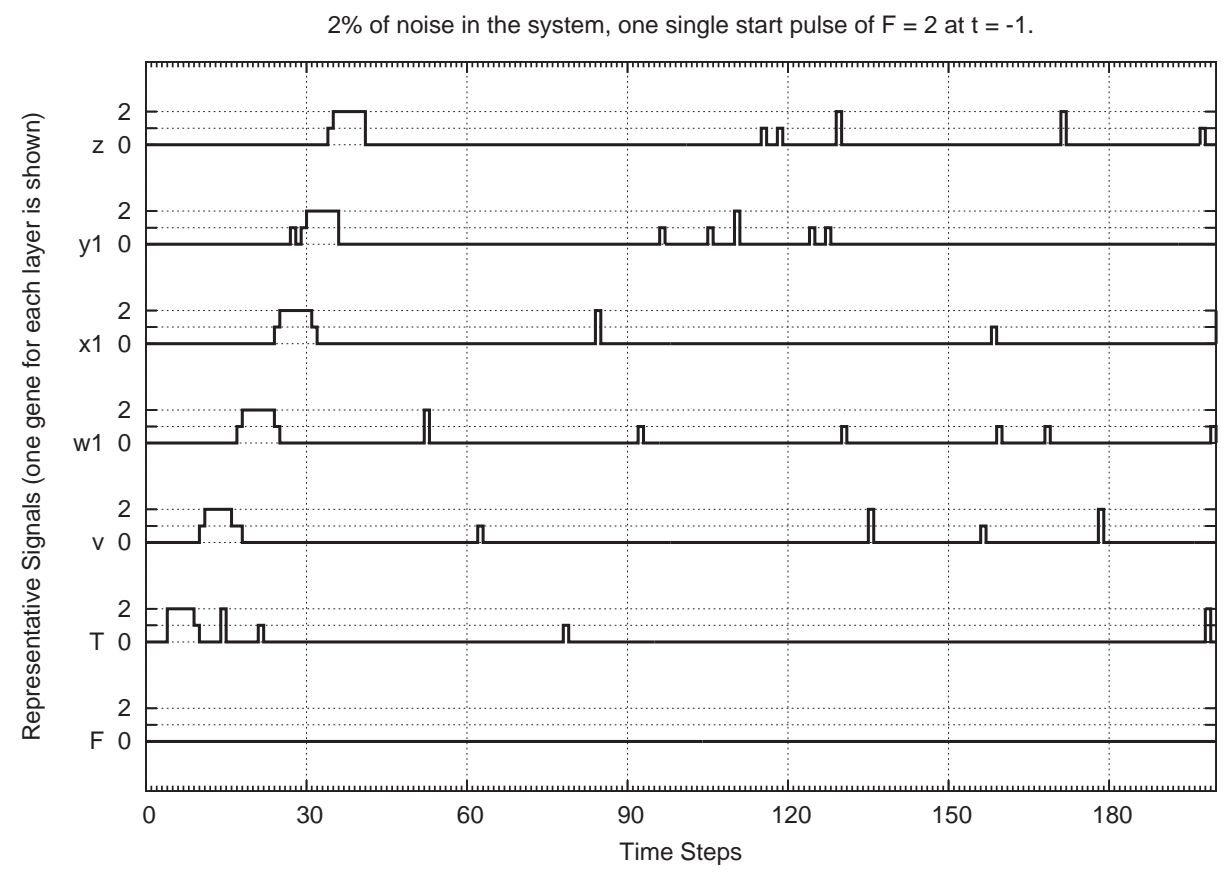

Figura A.29: Modelo PGN de três níveis do sistema de controle da progressão do ciclo celular com $\mathbf{2 \%}$ de ruido (PGN com $P=0.98$ ) ativado por um único pulso de $F=2$ em $t=-1$. 


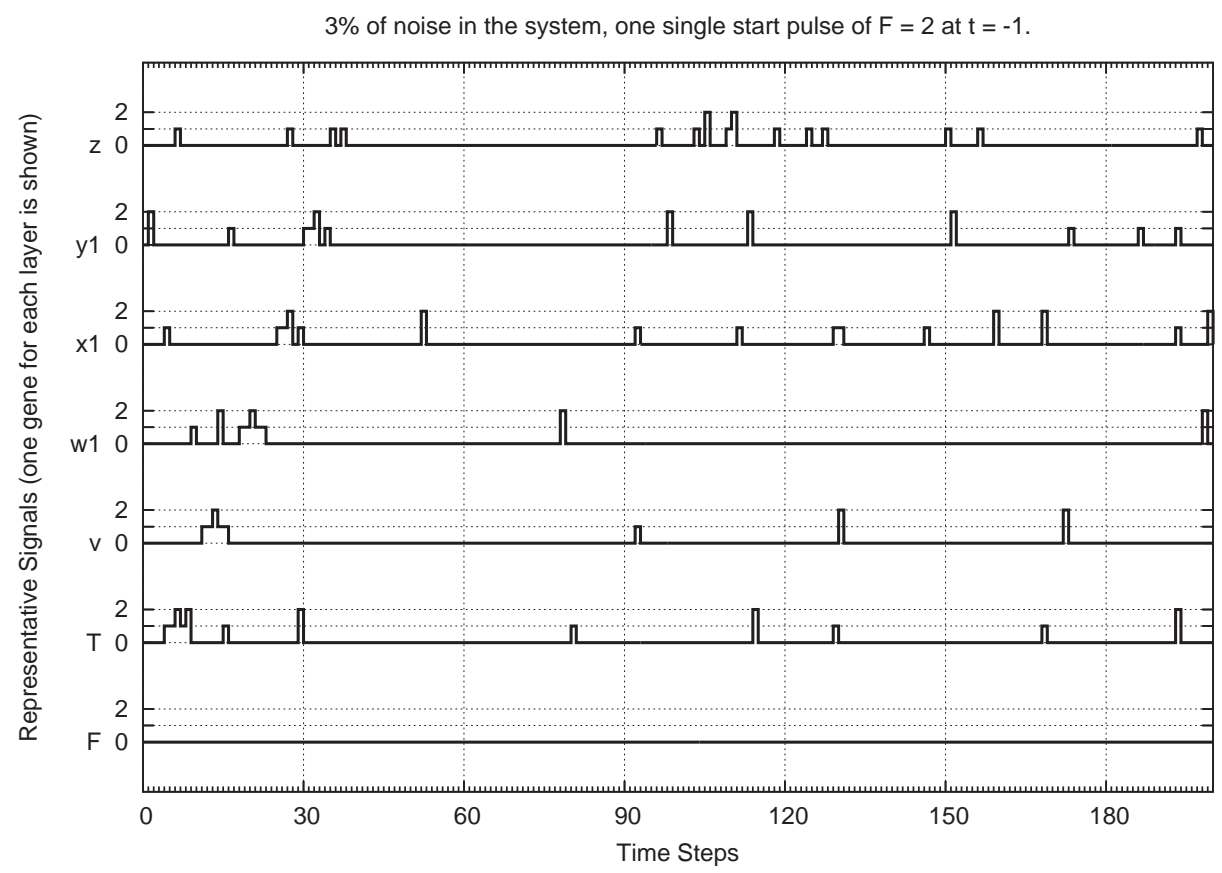

Figura A.30: Modelo PGN de três níveis do sistema de controle da progressão do ciclo celular com $\mathbf{3 \%}$ de ruido (PGN com $P=0.97$ ) ativado por um único pulso de $F=2$ em $t=-1$.

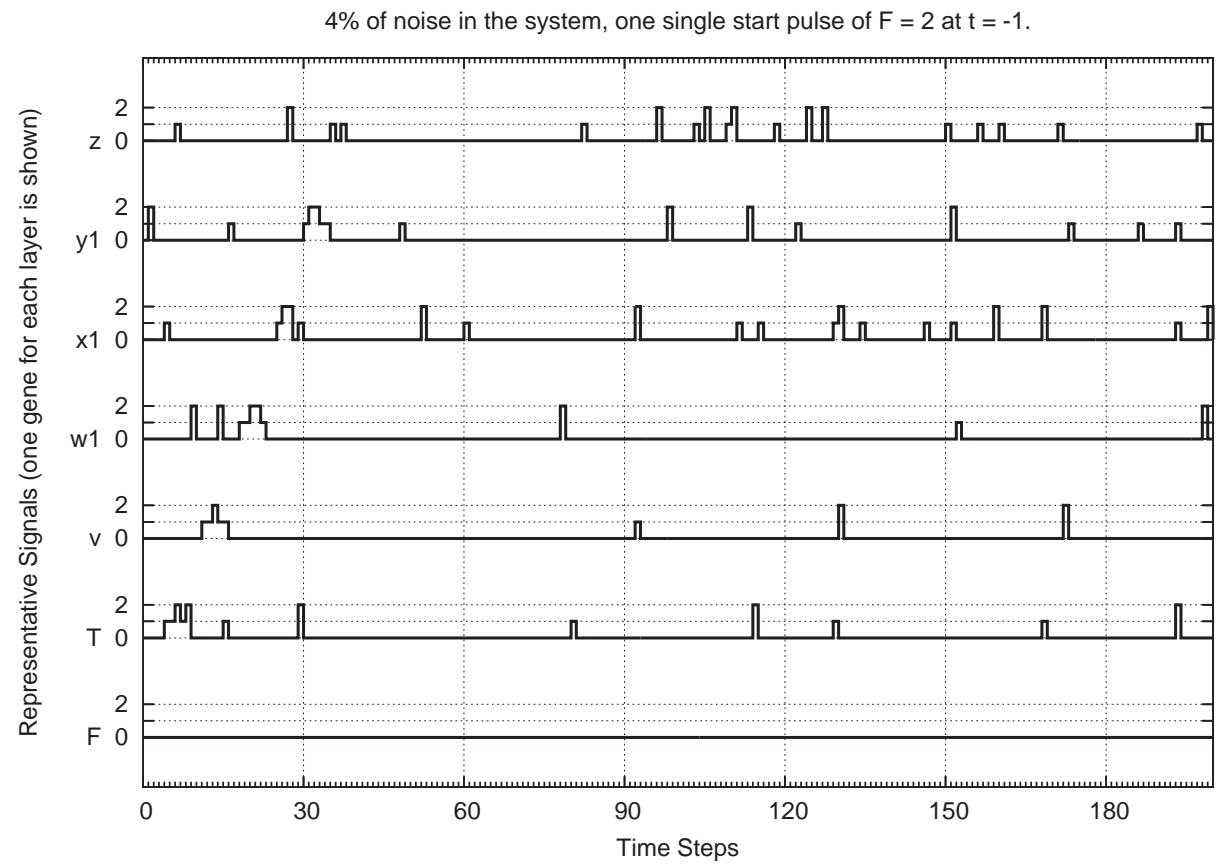

Figura A.31: Modelo PGN de três níveis do sistema de controle da progressão do ciclo celular com $4 \%$ de ruido (PGN com $P=0.96$ ) ativado por um único pulso de $F=2$ em $t=-1$. 


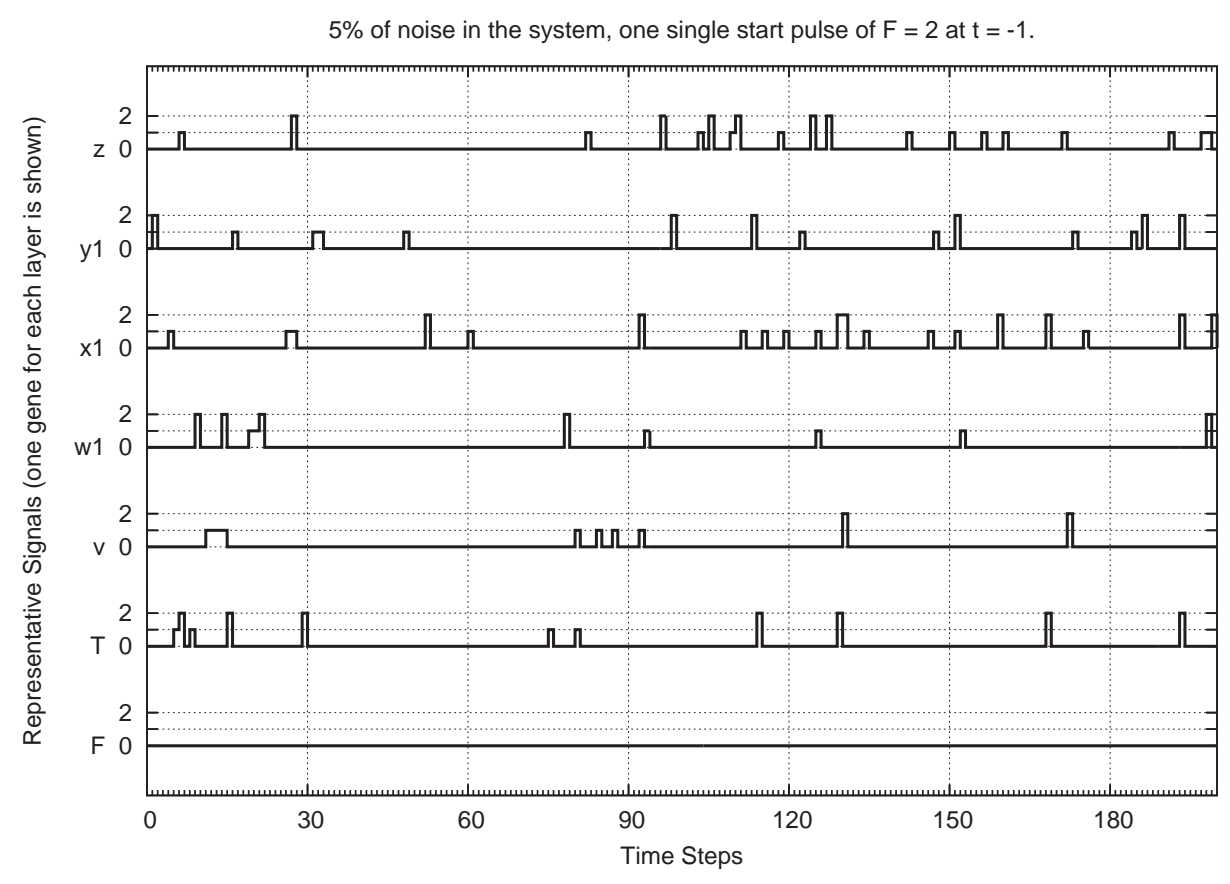

Figura A.32: Modelo PGN de três níveis do sistema de controle da progressão do ciclo celular com $\mathbf{5 \%}$ de ruido (PGN com $P=0.95$ ) ativado por um único pulso de $F=2$ em $t=-1$. 


\section{A.2.3 Modelo PGN de Três Níveis com Atrasos Aleatórios}

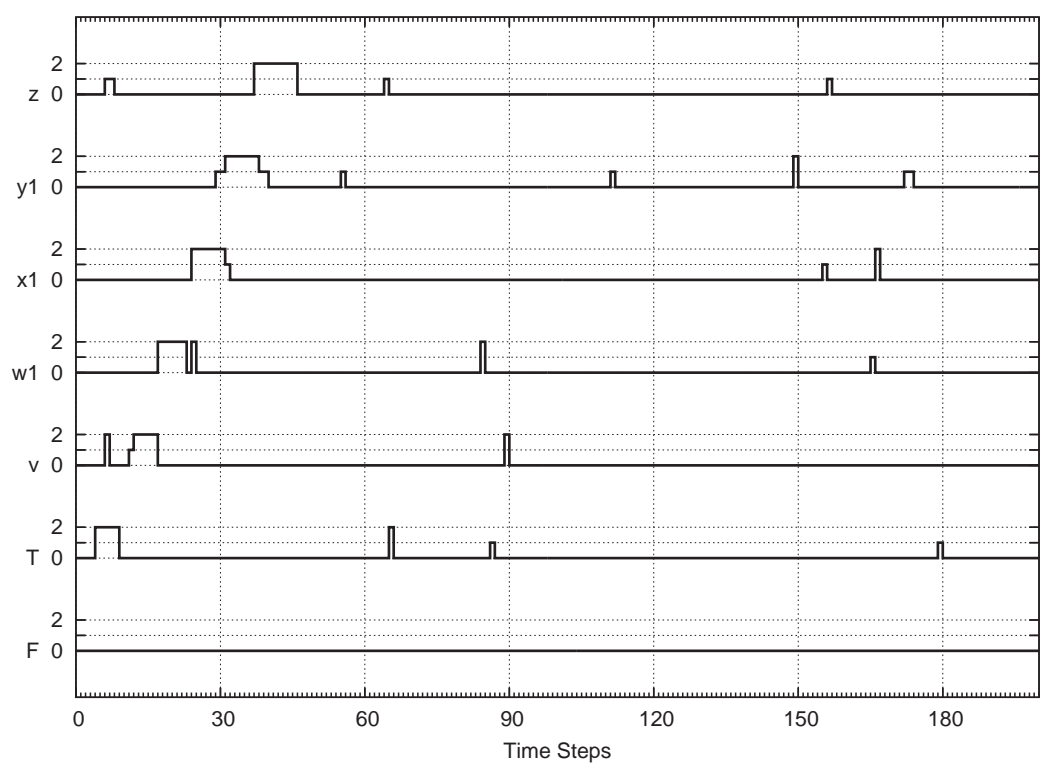

Figura A.33: Modelo PGN de três níveis do sistema de controle da progressão do ciclo celular com atrasos aleatórios, $1 \%$ de ruído (PGN com $P=0.99$ ) e ativado por um único pulso de $\mathbf{F}=\mathbf{2}$ em $\mathrm{t}=-\mathbf{1},-\mathbf{2}$.

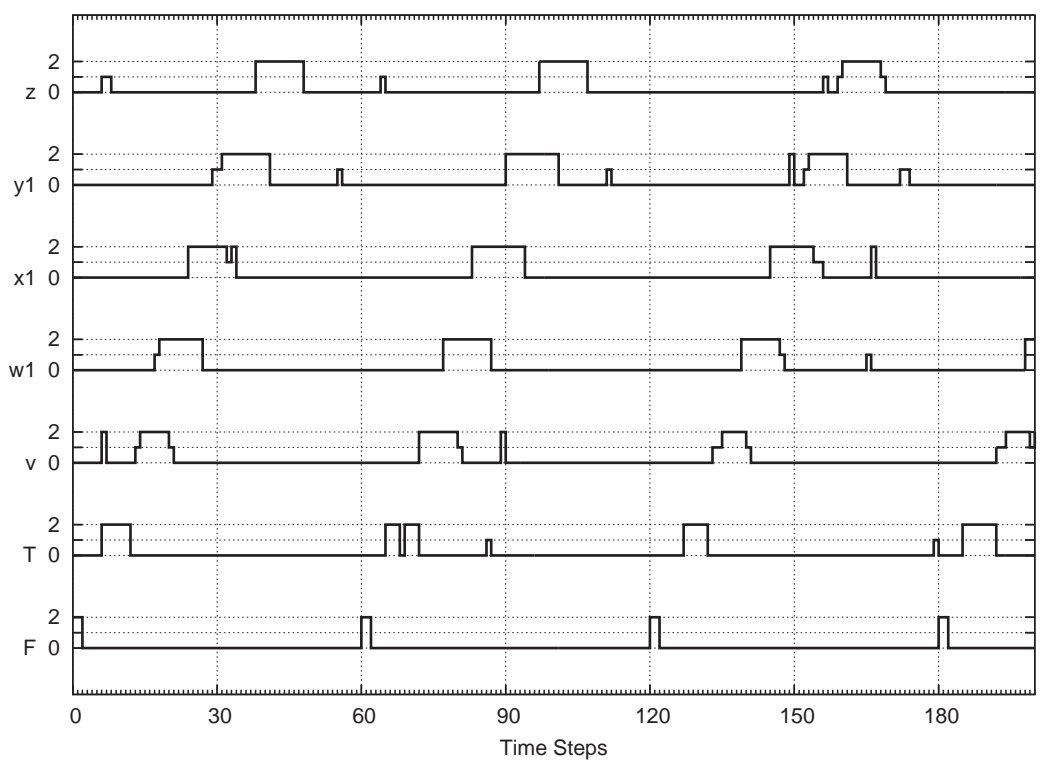

Figura A.34: Modelo PGN de três níveis do sistema de controle da progressão do ciclo celular com atrasos aleatórios, $1 \%$ de ruído (PGN com $P=0.99$ ) e ativado por $\mathbf{F}=$ oscilador de período 60 . 


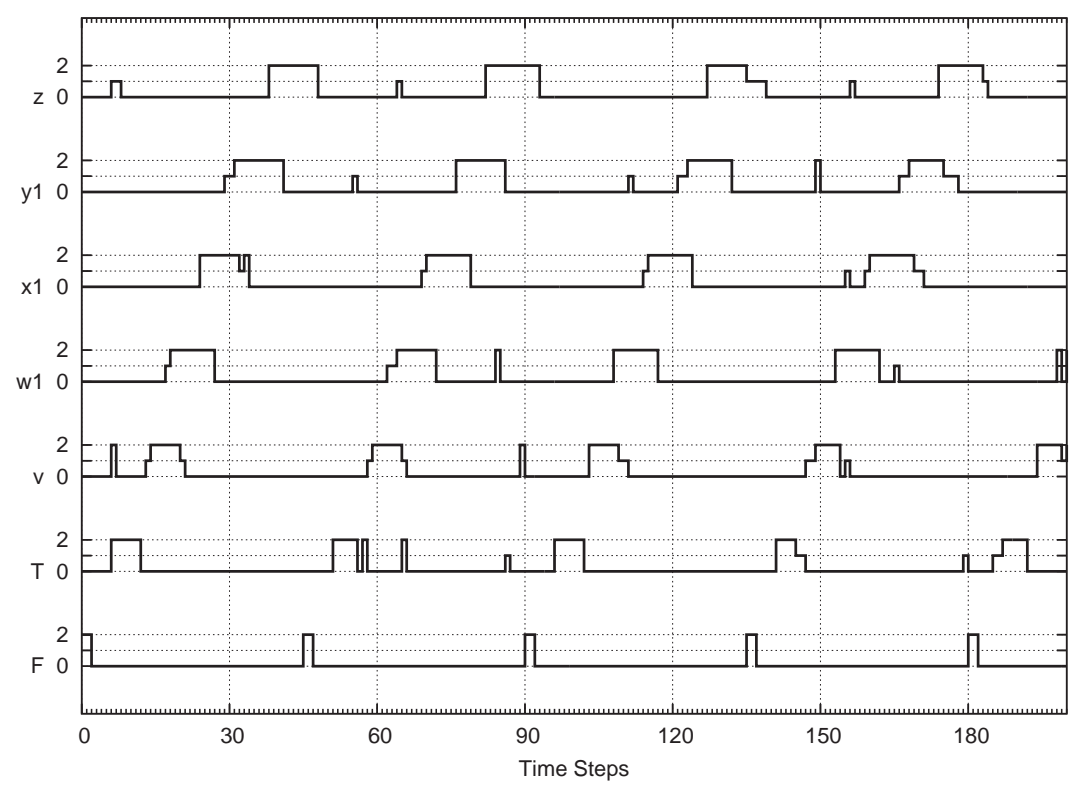

Figura A.35: Modelo PGN de três níveis do sistema de controle da progressão do ciclo celular com atrasos aleatórios, $1 \%$ de ruído (PGN com $P=0.99$ ) e ativado por $\mathbf{F}=$ oscilador de período 45 .

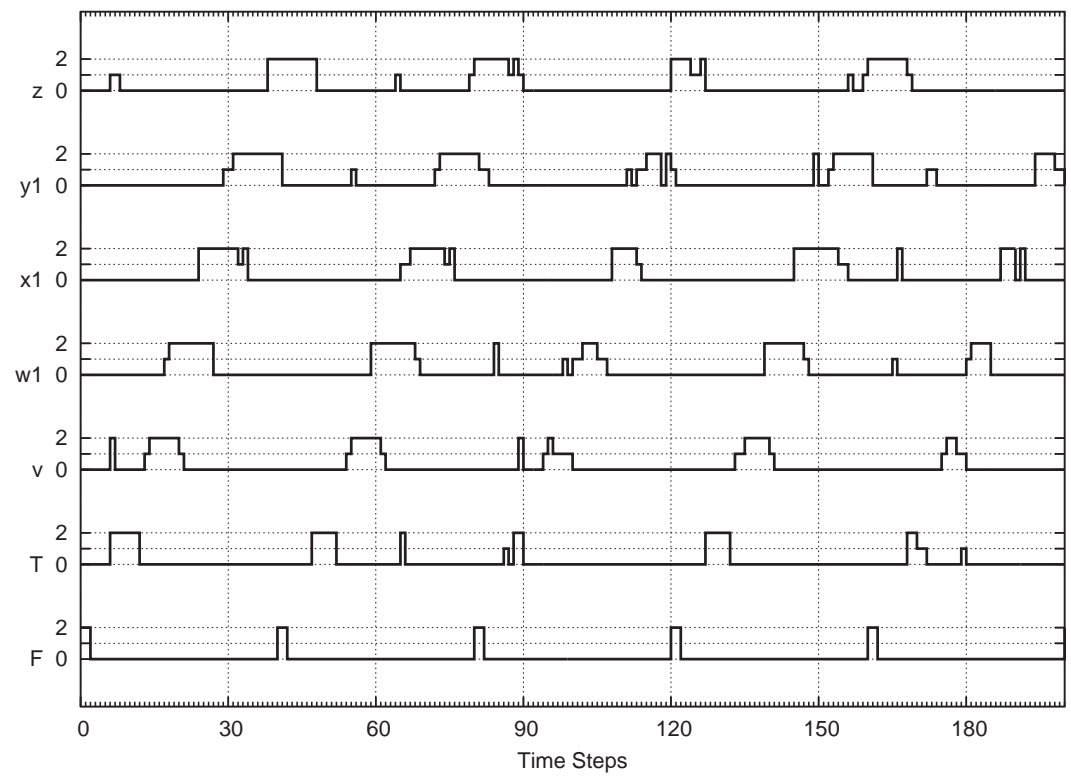

Figura A.36: Modelo PGN de três níveis do sistema de controle da progressão do ciclo celular com atrasos aleatórios, $1 \%$ de ruído (PGN com $P=0.99$ ) e ativado por $\mathbf{F}=$ oscilador de período 40 . 


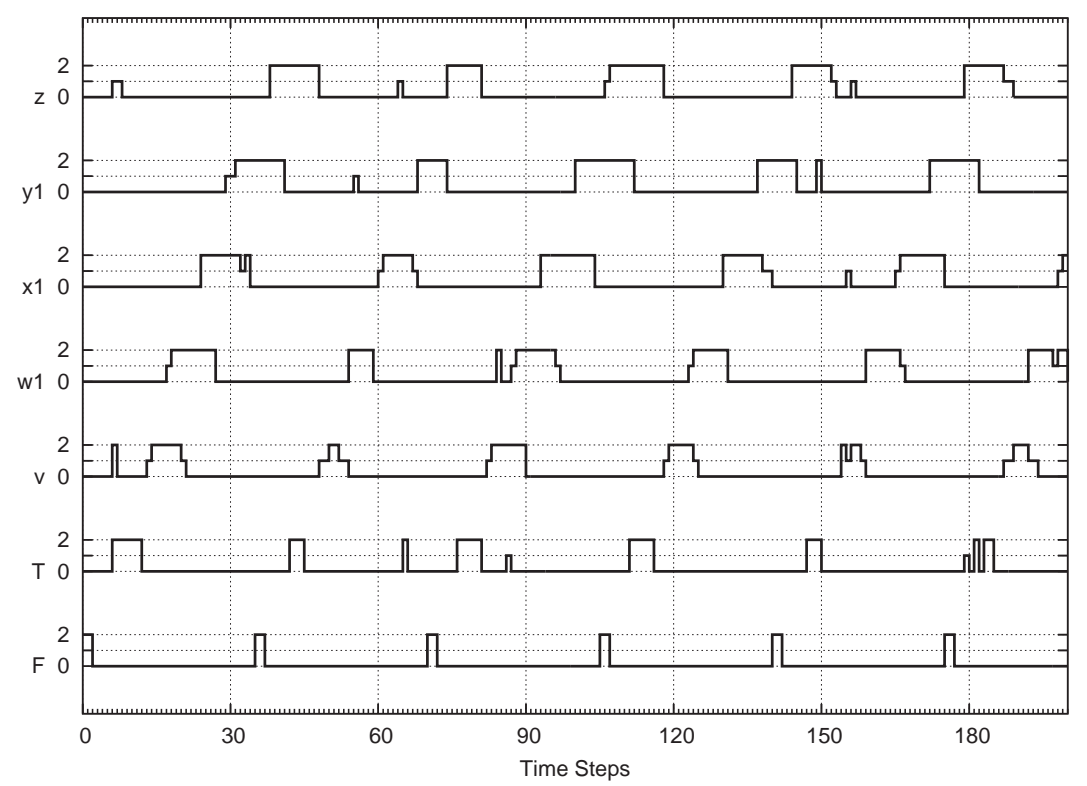

Figura A.37: Modelo PGN de três níveis do sistema de controle da progressão do ciclo celular com atrasos aleatórios, $1 \%$ de ruído (PGN com $P=0.99$ ) e ativado por $\mathbf{F}=$ oscilador de período 35 .

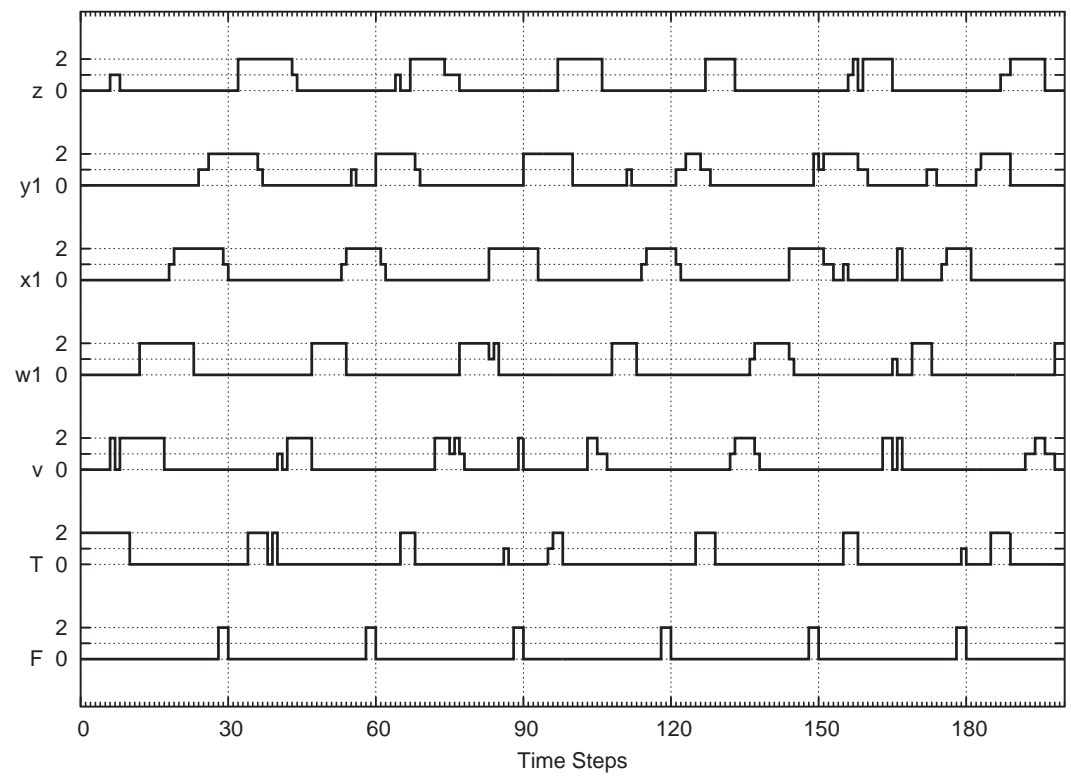

Figura A.38: Modelo PGN de três níveis do sistema de controle da progressão do ciclo celular com atrasos aleatórios, $1 \%$ de ruído (PGN com $P=0.99$ ) e ativado por $\mathbf{F}=$ oscilador de período 30 . 


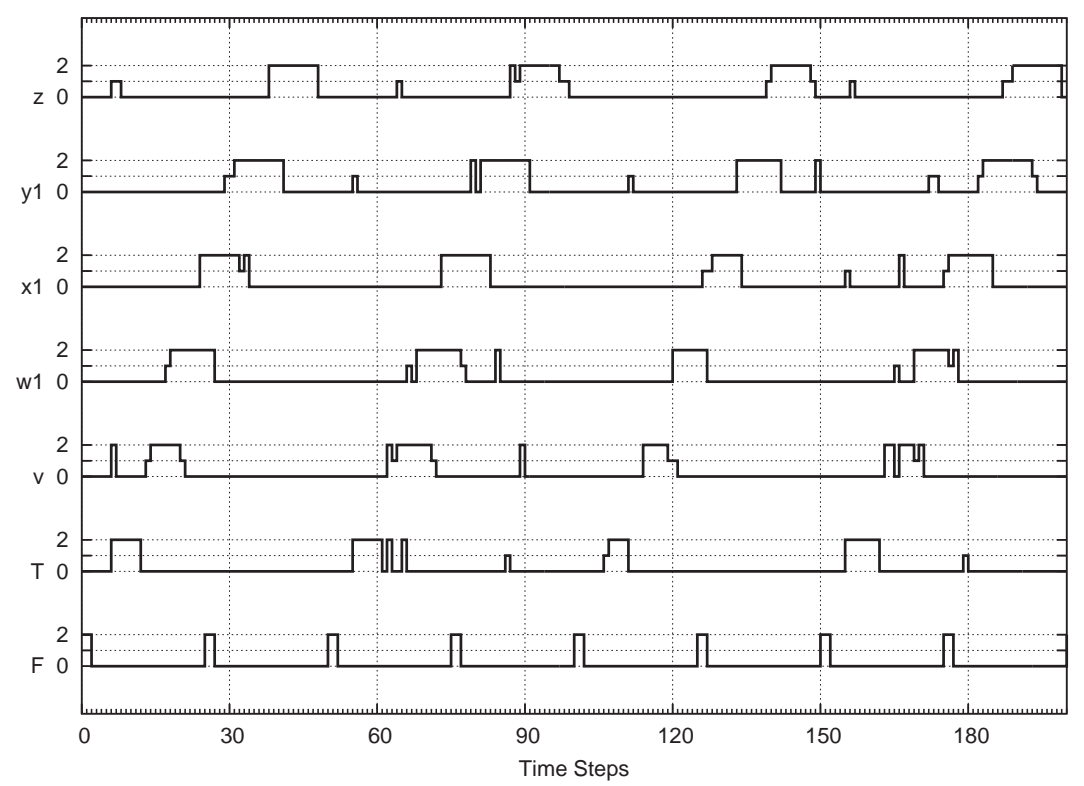

Figura A.39: Modelo PGN de três níveis do sistema de controle da progressão do ciclo celular com atrasos aleatórios, $1 \%$ de ruído (PGN com $P=0.99$ ) e ativado por $\mathbf{F}=$ oscilador de período 25 .

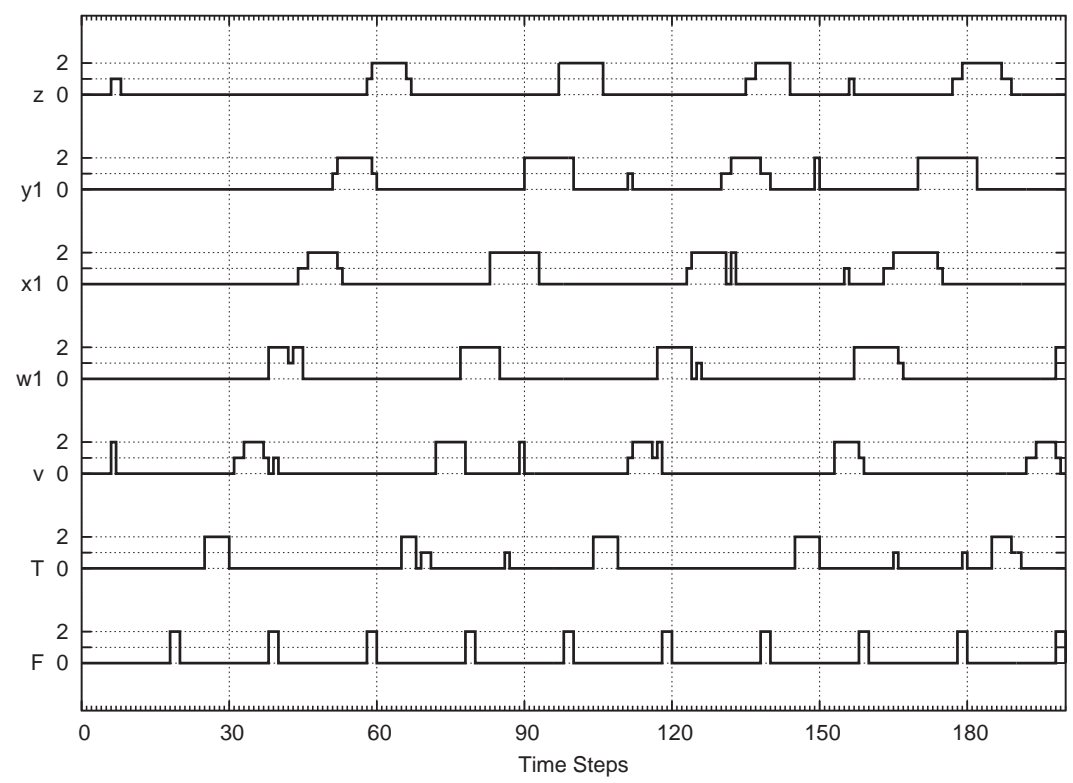

Figura A.40: Modelo PGN de três níveis do sistema de controle da progressão do ciclo celular com atrasos aleatórios, $1 \%$ de ruído (PGN com $P=0.99$ ) e ativado por $\mathbf{F}=$ oscilador de período 20 . 


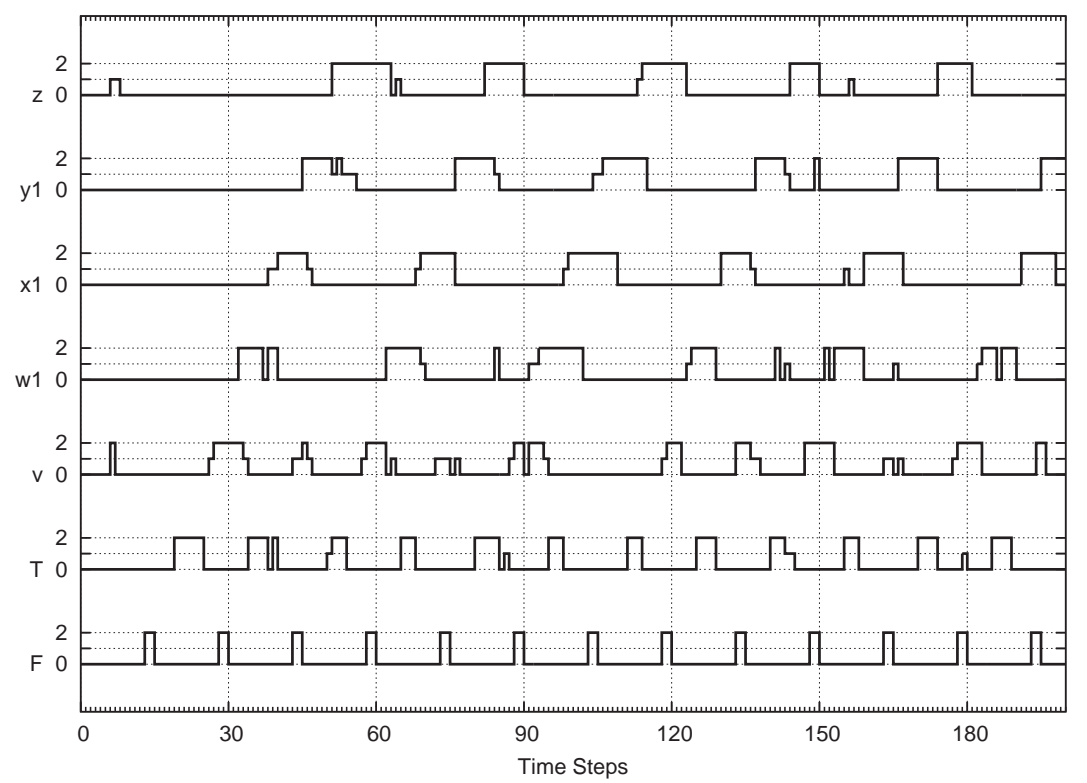

Figura A.41: Modelo PGN de três níveis do sistema de controle da progressão do ciclo celular com atrasos aleatórios, $1 \%$ de ruído (PGN com $P=0.99$ ) e ativado por $\mathbf{F}=$ oscilador de período 15 .

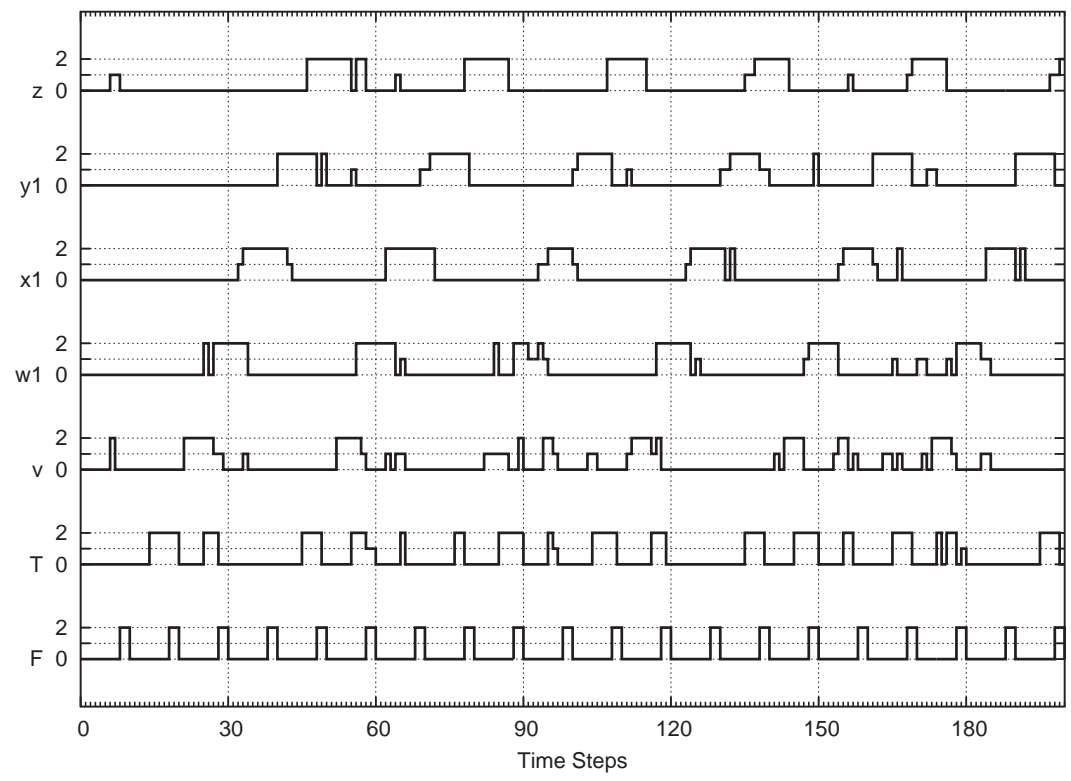

Figura A.42: Modelo PGN de três níveis do sistema de controle da progressão do ciclo celular com atrasos aleatórios, $1 \%$ de ruído (PGN com $P=0.99$ ) e ativado por $\mathbf{F}=$ oscilador de período 10 . 


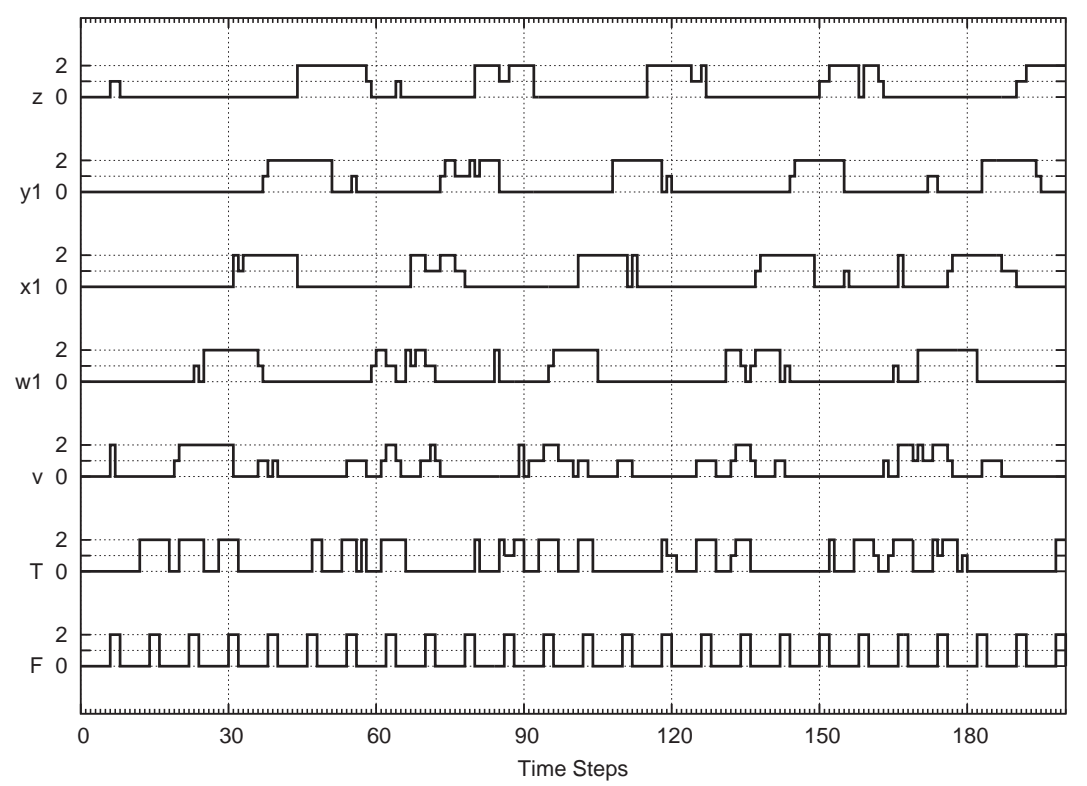

Figura A.43: Modelo PGN de três níveis do sistema de controle da progressão do ciclo celular com atrasos aleatórios, $1 \%$ de ruído (PGN com $P=0.99$ ) e ativado por $\mathbf{F}=$ oscilador de período 8 .

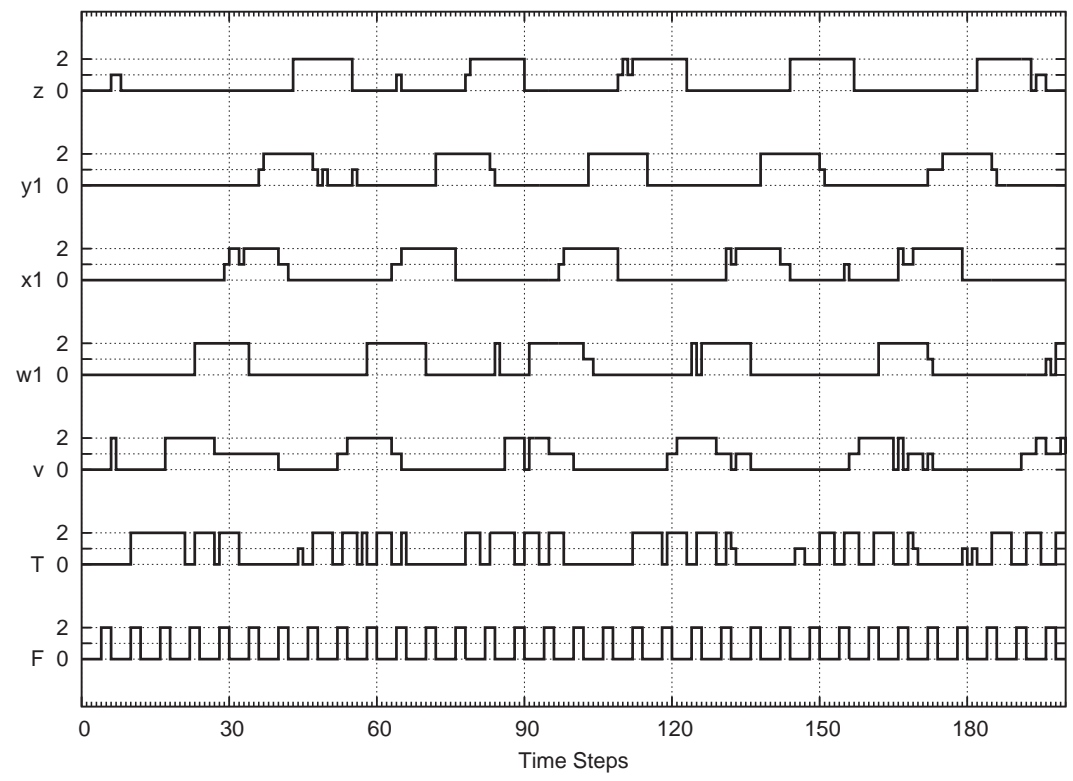

Figura A.44: Modelo PGN de três níveis do sistema de controle da progressão do ciclo celular com atrasos aleatórios, $1 \%$ de ruído (PGN com $P=0.99$ ) e ativado por $\mathbf{F}=$ oscilador de período 6 . 


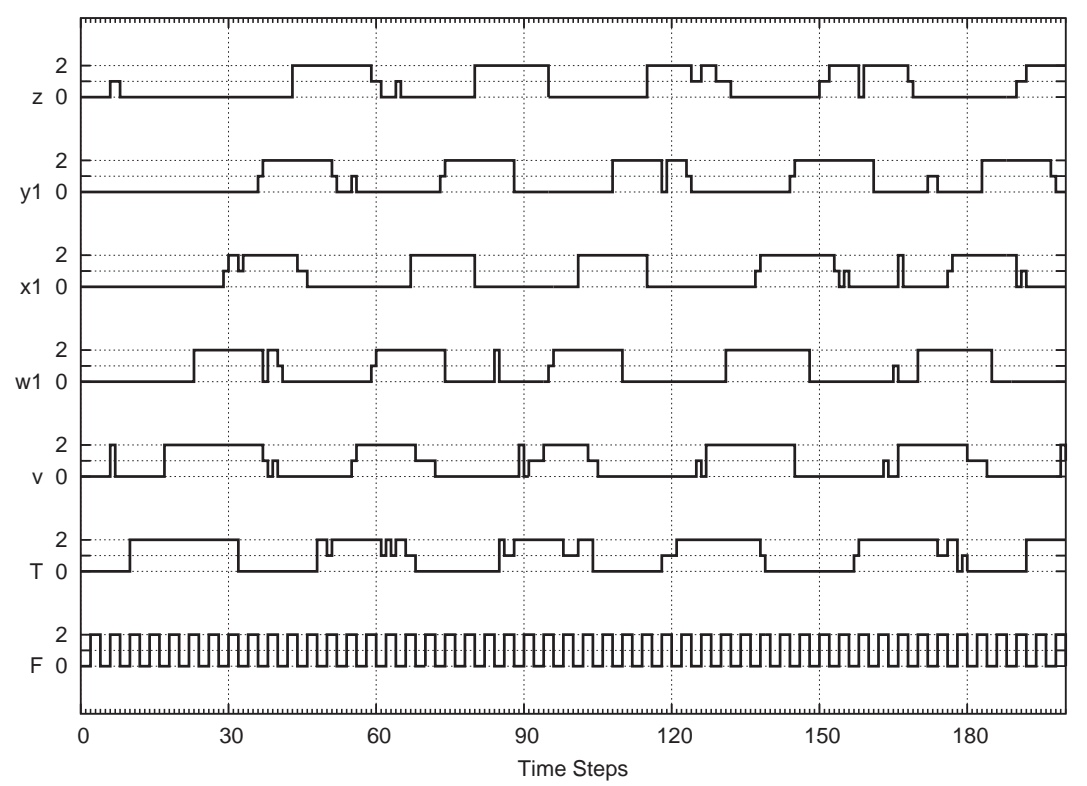

Figura A.45: Modelo PGN de três níveis do sistema de controle da progressão do ciclo celular com atrasos aleatórios, $1 \%$ de ruído (PGN com $P=0.99$ ) e ativado por $\mathbf{F}=$ oscilador de período 4 .

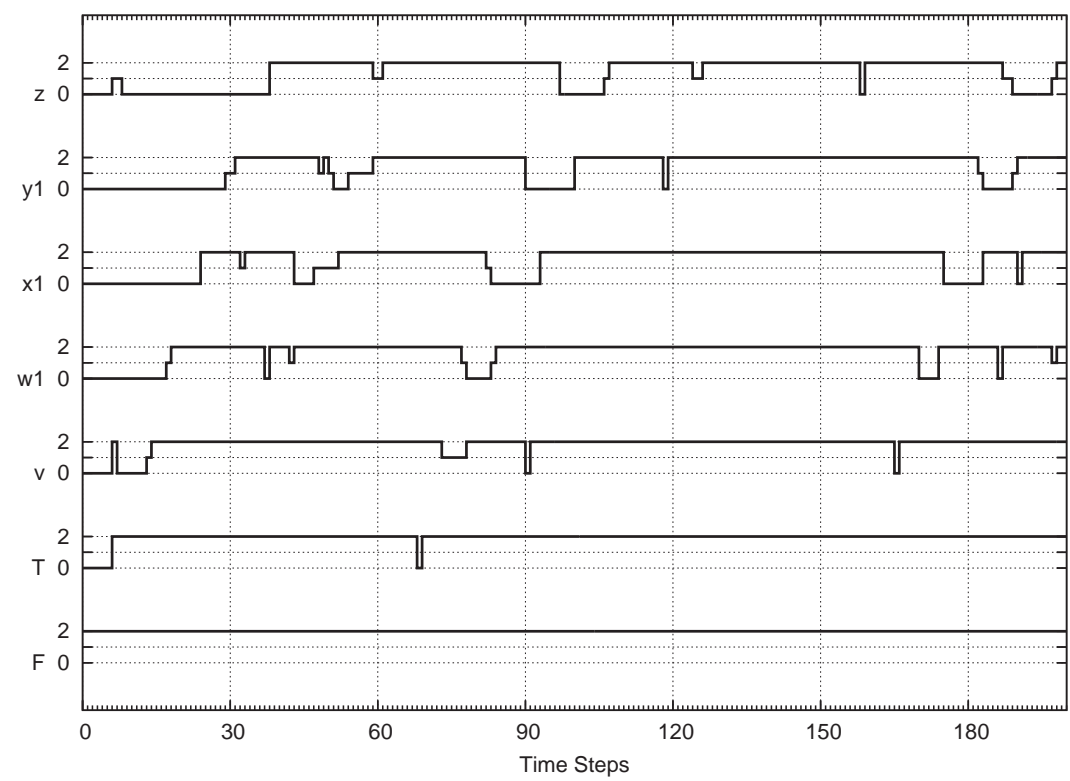

Figura A.46: Modelo PGN de três níveis do sistema de controle da progressão do ciclo celular com atrasos aleatórios, $1 \%$ de ruído (PGN com $P=0.99$ ) e ativado por um sinal constante $\mathrm{CS}=\mathbf{2}$. 


\section{A.2.4 Testes Exaustivos de Estabilidade e Robustez}

Para atingir um maior entendimento do funcionamento do modelo, seu comportamento, limites de estabilidade e robustez, e quais os efeitos produzidos por cada um dos diferentes tipos de mecanismos de controle, realizamos três series de testes exaustivos e estudos comparativos. Estes testes foram realizados nas diferentes condições de sinal de ativação — desde um único pulso inicial, aumentando a freqüência dos pulsos até chegar a um sinal constante- com o objetivo de comparar o desempenho em cada caso. Logicamente, os efeitos mais interessantes foram observados para sinais de ativação de período 25 ou menor, quando as realimentações negativas estão ativas (ciclo em andamento) no momento em que chega um novo pulso de ativação. Em tais casos foi possível observar a forma em que cada tipo de realimentação contribui a resistir o excesso de excitação.

Foram realizados três grupos de testes, nas seguintes condições:

\section{A.2.4.1 Diminuindo gradualmente a força das realimentações ${ }^{1}$}

Neste teste, o valor dos pesos da PGN correspondentes aos sinais de realimentação foram diminuídos gradualmente a passos de 5\% cada vez até chegar a um 50\% dos valores originais. Em cada caso o modelo foi simulado em todas as condições — freqüências - de sinais de ativação F. Ao variar a força das realimentações vemos, por exemplo, que com realimentações de um valor $70 \%$ do original existem algumas ondas de de sinal que conseguem se propagar apesar de que o ciclo anterior ainda não finalizou (Figura A.47(b)). Isto não acontecia com realimentações no $100 \%$ do seu valor (Figura A.47(a)).

\footnotetext{
${ }^{1}$ http://www.vision.ime.usp.br/ walter/sim/Simulacoes.html
} 


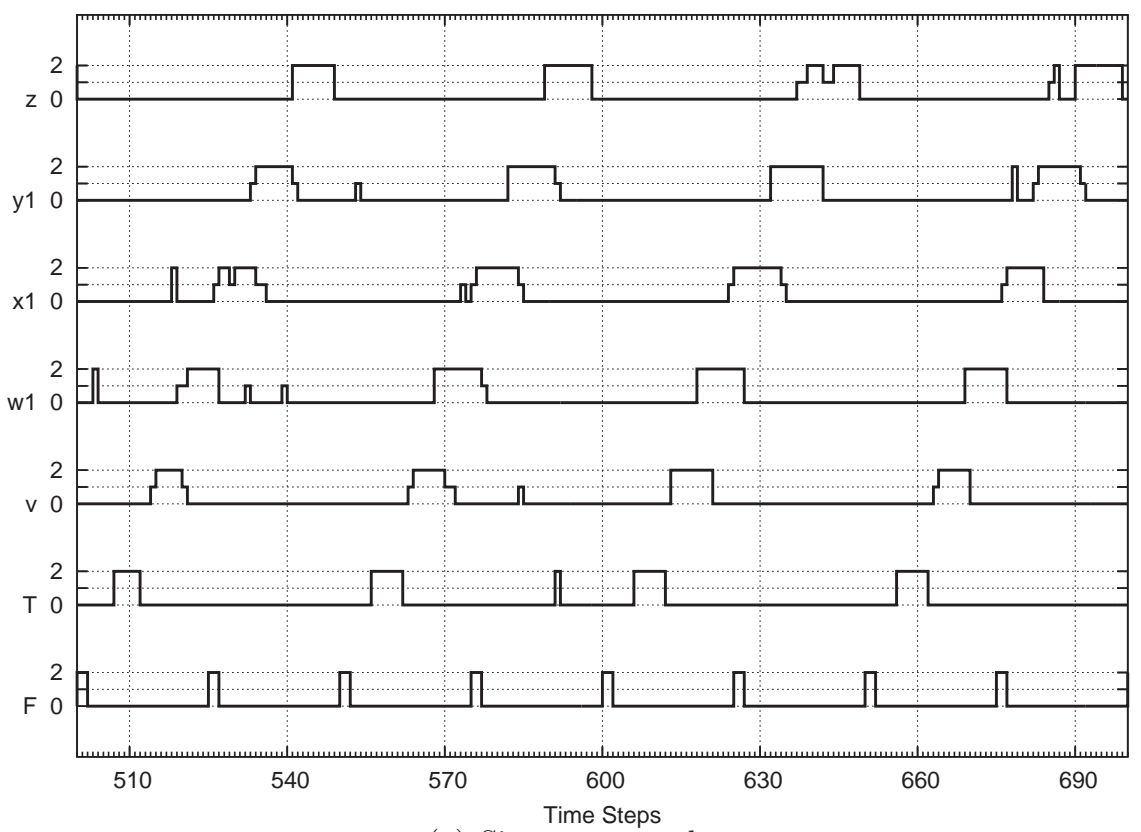

(a) Sistema normal.

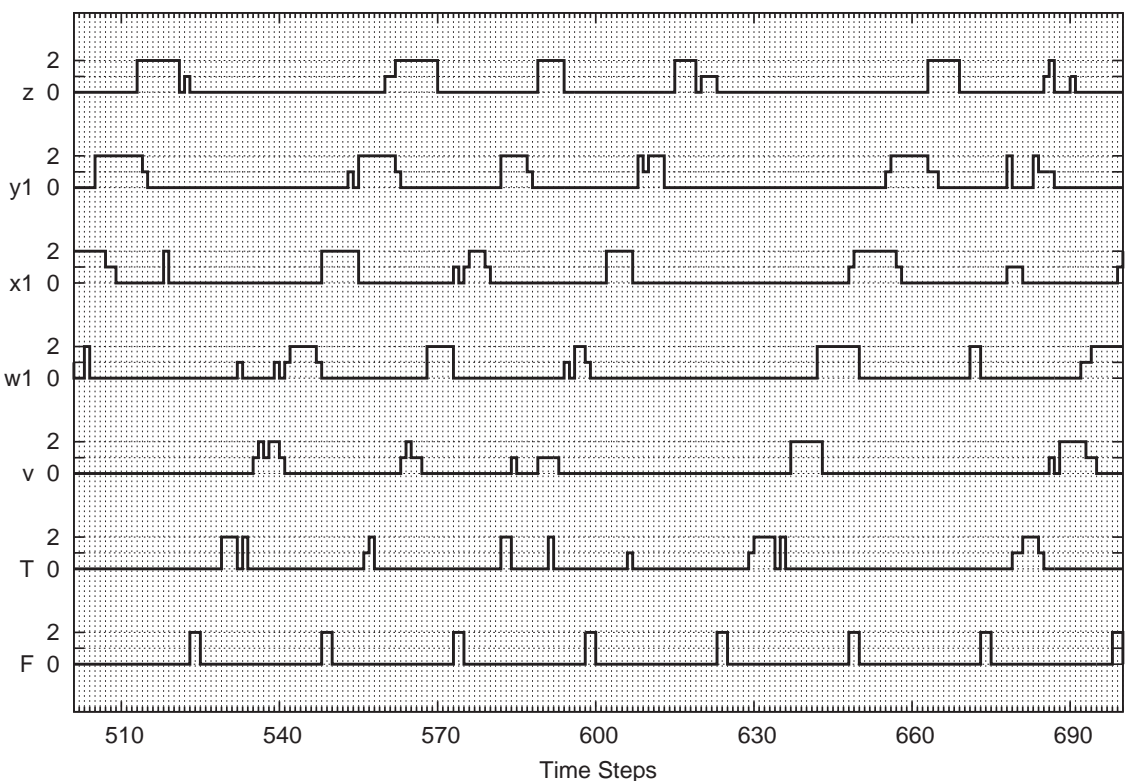

(b) Sistema com o valor do peso das realimentações negativas diminuídas a um $70 \%$ do seu valor original.

Figura A.47: Efeito da diminuição da força das realimentações no modelo PGN do sistema de controle do ciclo celular com $1 \%$ de ruído ( $F=$ oscilador de período 25$)$. Em b) uma onda de sinal consegue se propagar com o ciclo anterior ainda en andamento, devido ao enfraquecimento da força das realimentações negativas. 


\section{A.2.4.2 Eliminando algum tipo de realimentação ${ }^{2}$}

Para entender melhor qual é a contribuição de cada um dos diferentes mecanismos de regulação, foi estudado o efeito produzido no sistema pela eliminação, em cada caso, de algum tipo de realimentação: i) para a camada anterior, ou ii) para o gene disparador $T$. A comparação do comportamento em tais condições com o do modelo completo, mostrou mais claramente a ação reguladora de cada mecanismo.

\section{Sem realimentações para a camada anterior}

Em ausência de realimentações para a camada anterior, se observa um maior alargamento do pulso de sinal a medida que ele avança pelas camadas de controle na progressão do ciclo celular (Figura A.48). Este alargamento era evitado pelo efeito inibidor das realimentações aqui faltantes, as quais uma vez ativada uma camada, inibem o avanço de uma nova onda de sinal, enquanto as funções controladas pela presente camada estão sendo executadas. Estas simulações mostram a função de temporização, ou controle do tempo de execução atribuído às tarefas de cada etapa, que cumprem as realimentações para a camada anterior.

Quando a ativação $F$ resulta demasiado freqüente, se observa uma maior abundância de trens múltiplos de sinal — muito próximos no tempo- (Figura A.49(b)). No modelo completo, as realimentações para a camada anterior contribuíam a deter novos trens de sinal quando o anterior ainda está se propagando pelo ciclo (Figura A.49(a)).

Para ativação ainda mais freqüente, acontece um efeito interessante (Figura A.50(b)).

\footnotetext{
${ }^{2}$ http://www.vision.ime.usp.br/ walter/sim2/test-24.html
} 
O aumento da força das realimentações para o gene disparador $\mathrm{T}$ (as únicas atuando no sistema) produz uma modulação nos padrões de sinal com um ciclo de trabalho de aproximadamente $50 \%$. Este equilíbrio dinâmico se logra da seguinte forma. A força da onda aumenta até que as realimentações para $T$ produzidas por ela conseguem inibir $T$, então a onda cai em amplitude, o que diminui as realimentações para $T$. Como a ativação forte de $F$ continua, a onda volta a crescer em amplitude, até que a força das realimentações consegue novamente inibir $T$, e o ciclo se repete. Na Figura A.50(b), sem realimentações para a camada anterior, pode ver-se que este efeito é produzido somente pelas realimentações negativas para o gene disparador T. A Figura A.50(a) (sistema normal - completo-) mostra como este padrão é modificado pelas realimentações para a camada anterior.

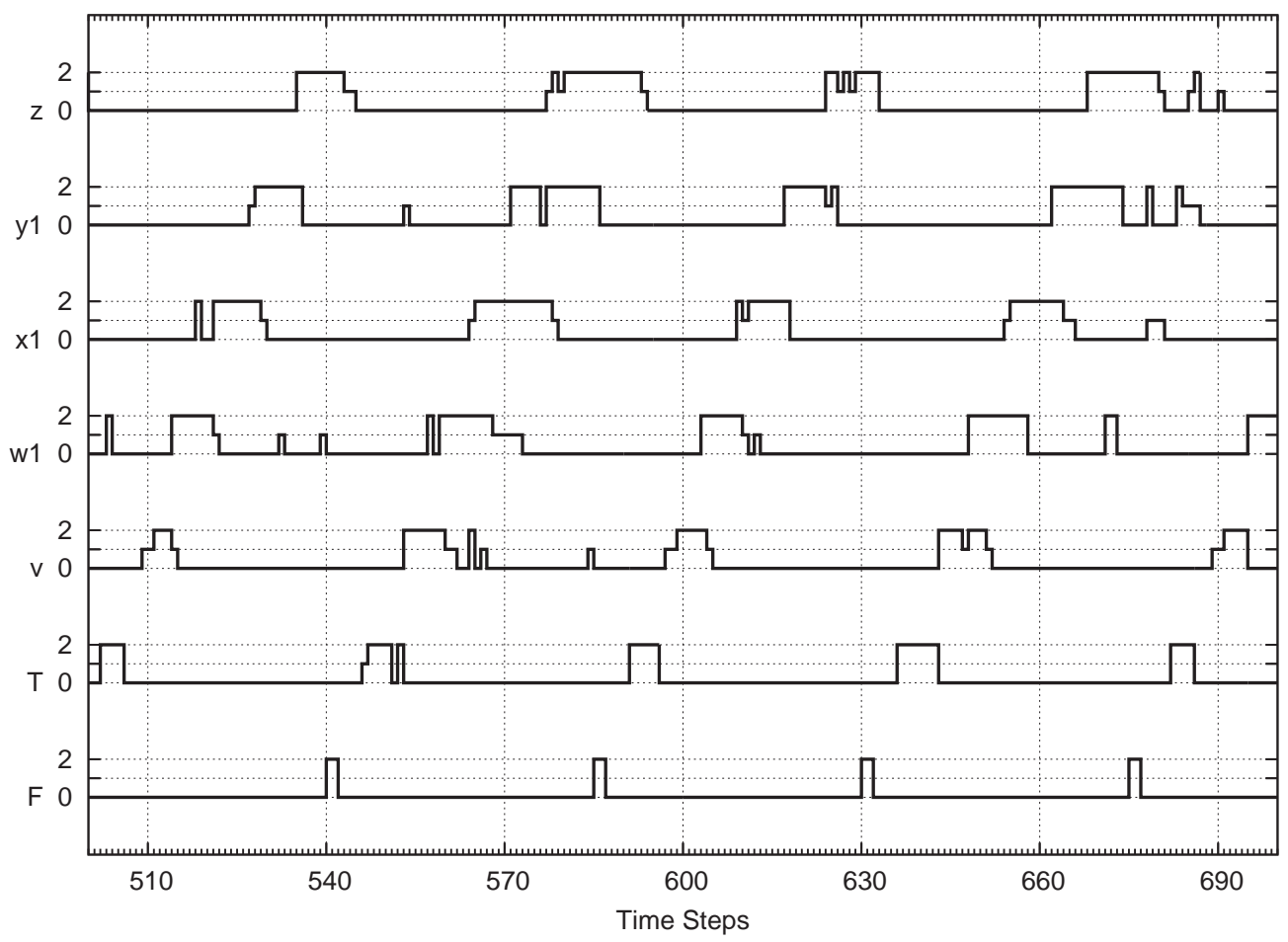

Figura A.48: Efeito de alargamento progressivo do pulso de sinal, devido à ausência de realimentações para a camada anterior no modelo PGN do sistema de controle do ciclo celular com $1 \%$ de ruído $(F=$ oscilador de período 45$)$. 


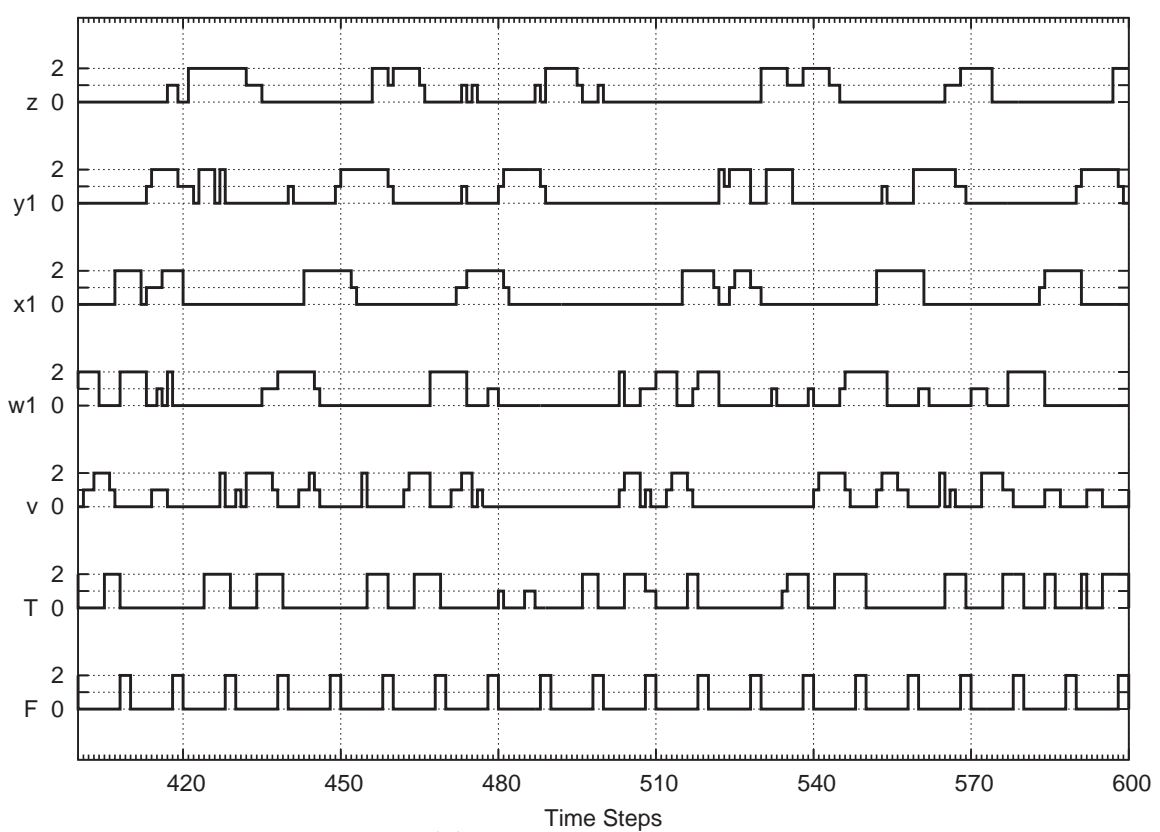

(a) Sistema normal.

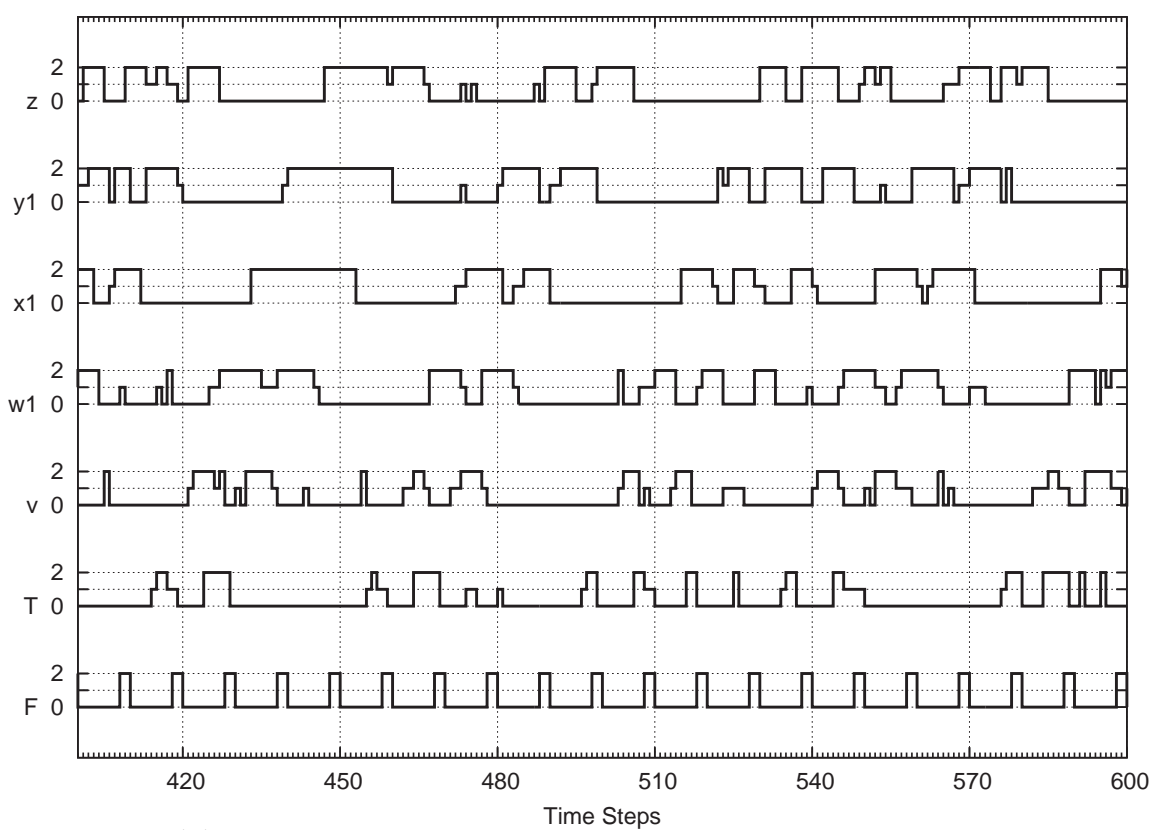

(b) Sistema sem realimentações para a camada anterior.

Figura A.49: Aumento do numero de trens múltiplos de sinal para ativação $F$ muito freqüente ( $F=$ oscilador de período 10, neste caso), no modelo PGN do sistema de controle do ciclo celular com $1 \%$ de ruído. 


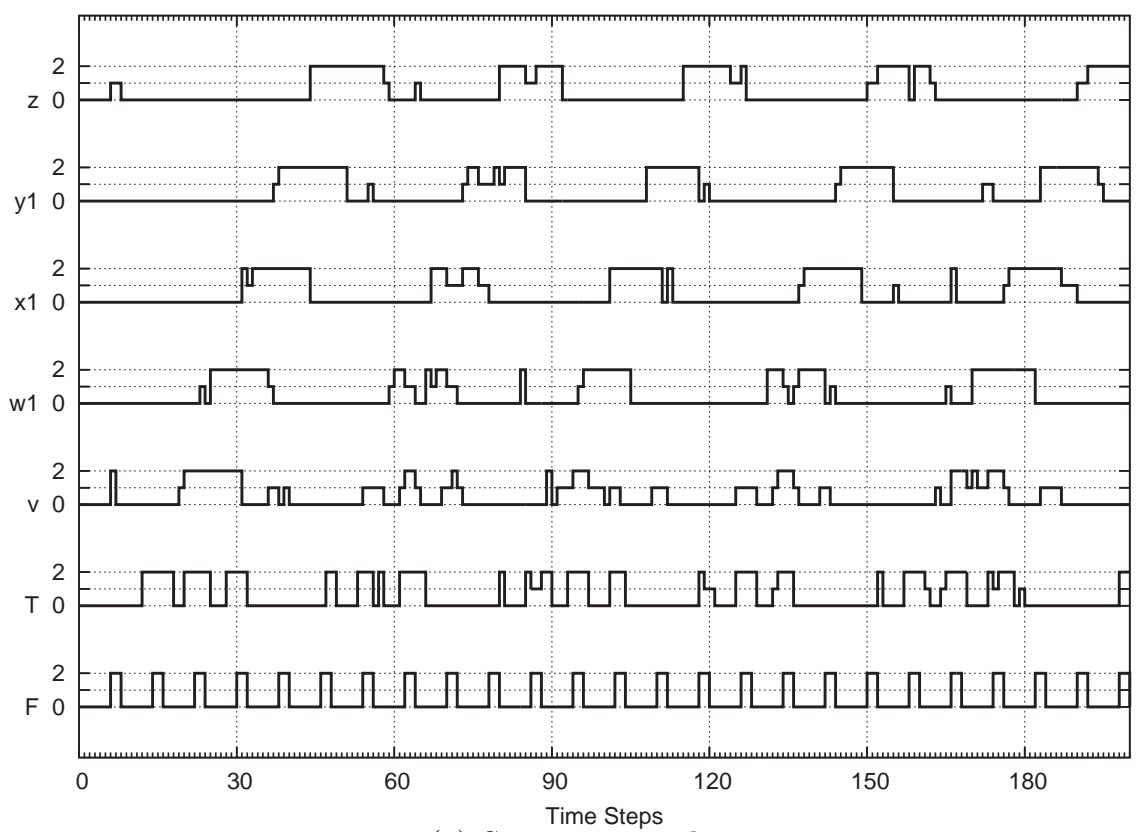

(a) Sistema normal.

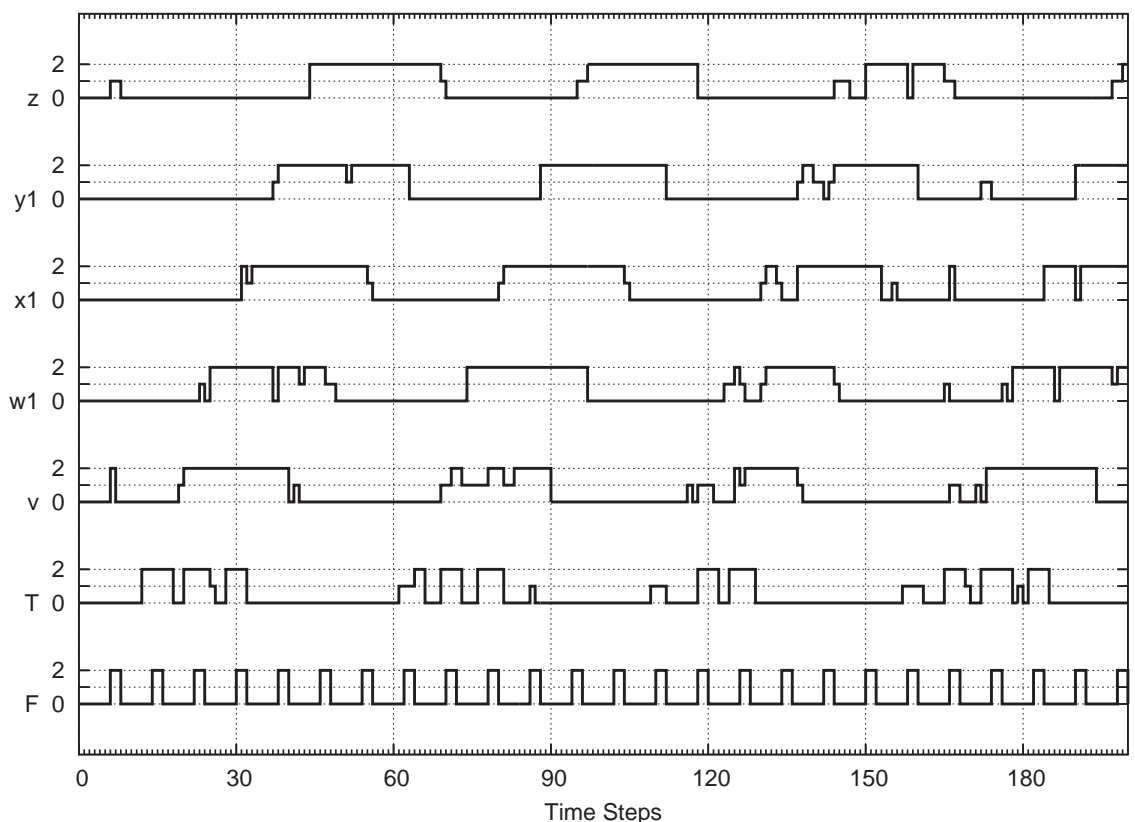

(b) Sistema sem realimentações para a camada anterior.

Figura A.50: Padrão de expressão produzido pelas realimentações para o gene disparador T quando o sinal de ativação $F$ é muito freqüente ( $F=$ oscilador de período 8 , neste caso), no modelo PGN do sistema de controle do ciclo celular com $1 \%$ de ruído. Em b) pode ver-se que este efeito é produzido inteiramente pelas realimentações negativas para o gene disparador $T$. 


\section{Sem realimentações para o gene $\mathbf{T}$}

Vemos na Figura A.51(b) que quando o sistema sem realimentações para o gene $\mathrm{T}$ é ativado por um trem de pulsos $F$ de período 25, o segundo pulso não é detido (como acontece no sistema com todas as realimentações da Figura A.51(a)), pois as realimentações entre camadas tem um efeito de curto prazo e não são efetivas quando a onda de sinal do ciclo em andamento está a mais de uma camada de distância do novo pulso. Fica claro o papel regulador das realimentações para o gene $\mathrm{T}$, de impedir o disparo de um novo ciclo de divisão celular enquanto o anterior está em andamento.

É também observada uma sobre expressão do gene T, em ausência de realimentações negativas para ele (Figura A.52(b)). As realimentações entre camadas conseguem deter parte do excesso de sinal nas camadas posteriores.

Este grupo de testes mostra que as realimentações negativas para a camada anterior tem um efeito de mais curto prazo, conseguindo evitar o alargamento sucessivo dos pulsos ou deter um novo trem de pulsos que está muito próximo — no tempo - do anterior. Não são efetivas quando a onda de sinal do ciclo em andamento está a mais de uma camada de distancia do novo sinal que tenta se propagar.

Já as realimentações negativas para o gene disparador $\mathrm{T}$, tem um efeito de mais longo prazo, pois carregam informação do que esta acontecendo em todas as camadas seguintes. Elas conseguem deter um novo pulso de $F$ bastante distante do anterior e tendem a inibir o disparo de T sempre que um ciclo esteja em andamento. 


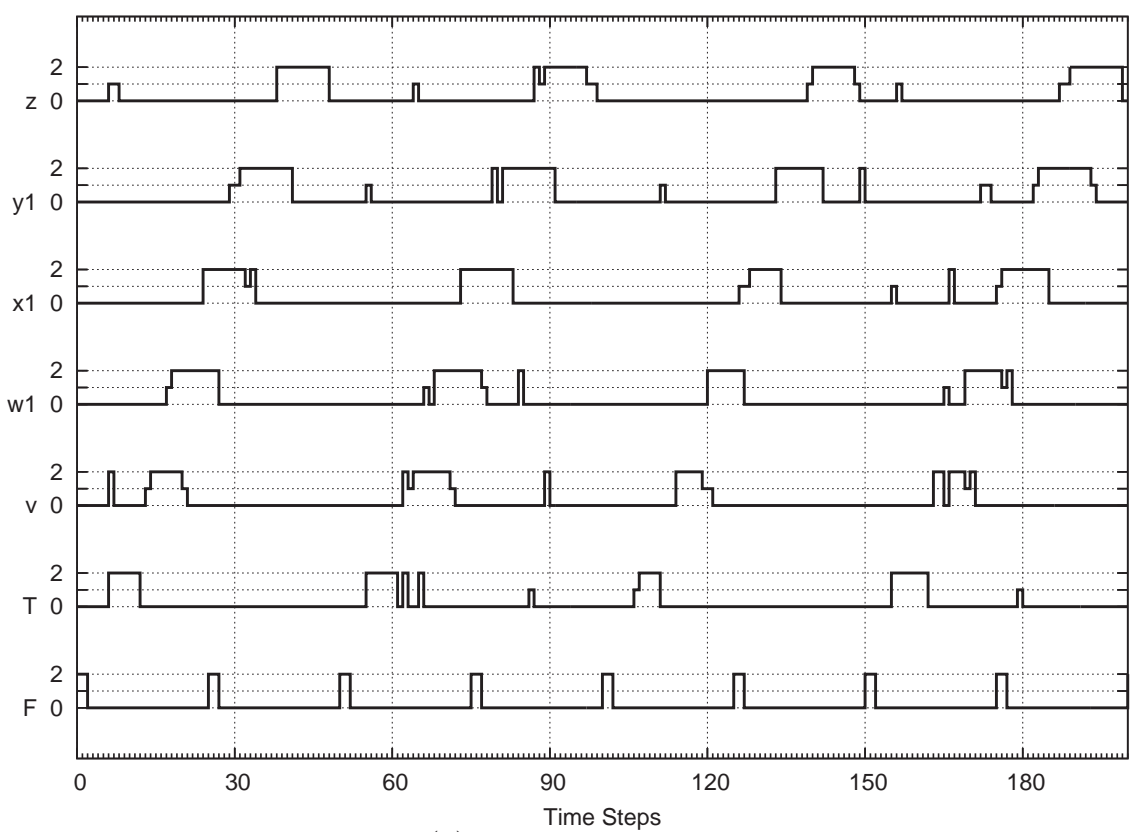

(a) Sistema normal.

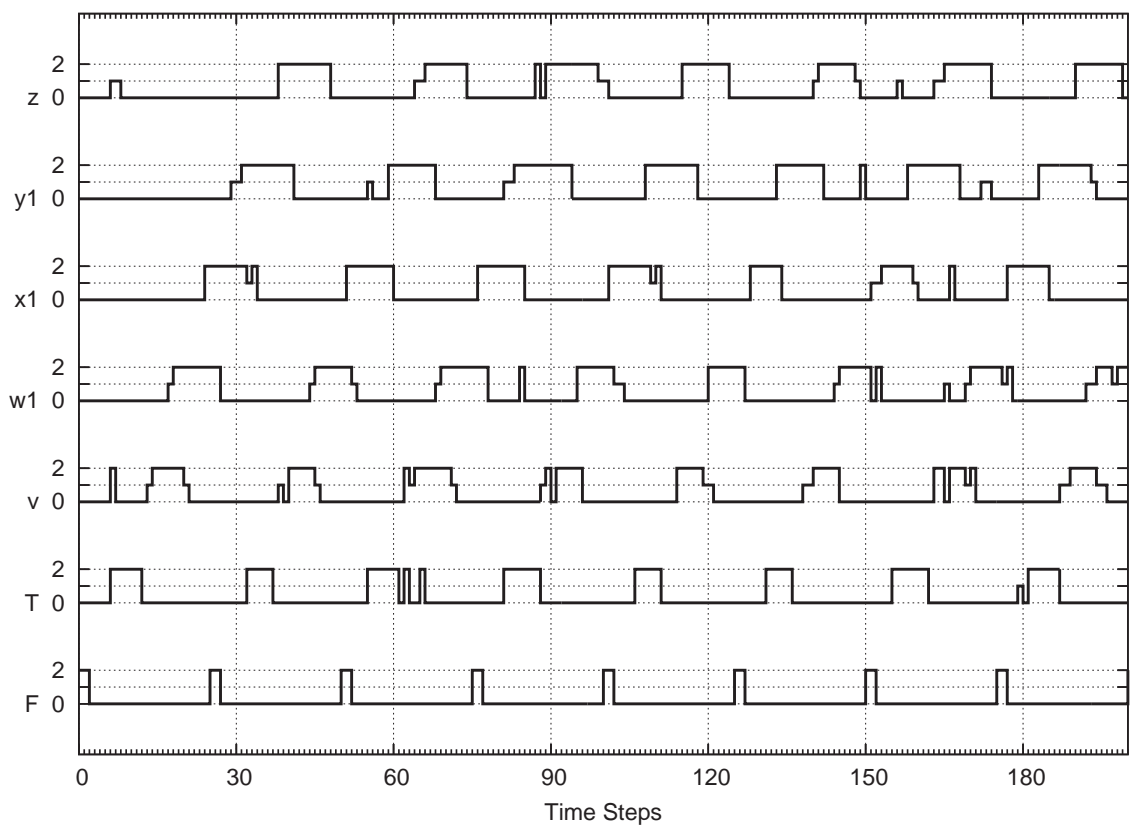

(b) Sistema sem realimentações negativas para o gente disparador $\mathrm{T}$.

Figura A.51: Efeito regulador das realimentações para o gene disparador T: em a) elas inibem disparo de um novo ciclo de divisão celular enquanto o anterior está em andamento, sem elas, em b), estes disparos não desejados acontecem (Modelo PGN do sistema de controle do ciclo celular com $1 \%$ de ruído ativado com $F=$ oscilador de período 25$)$. 


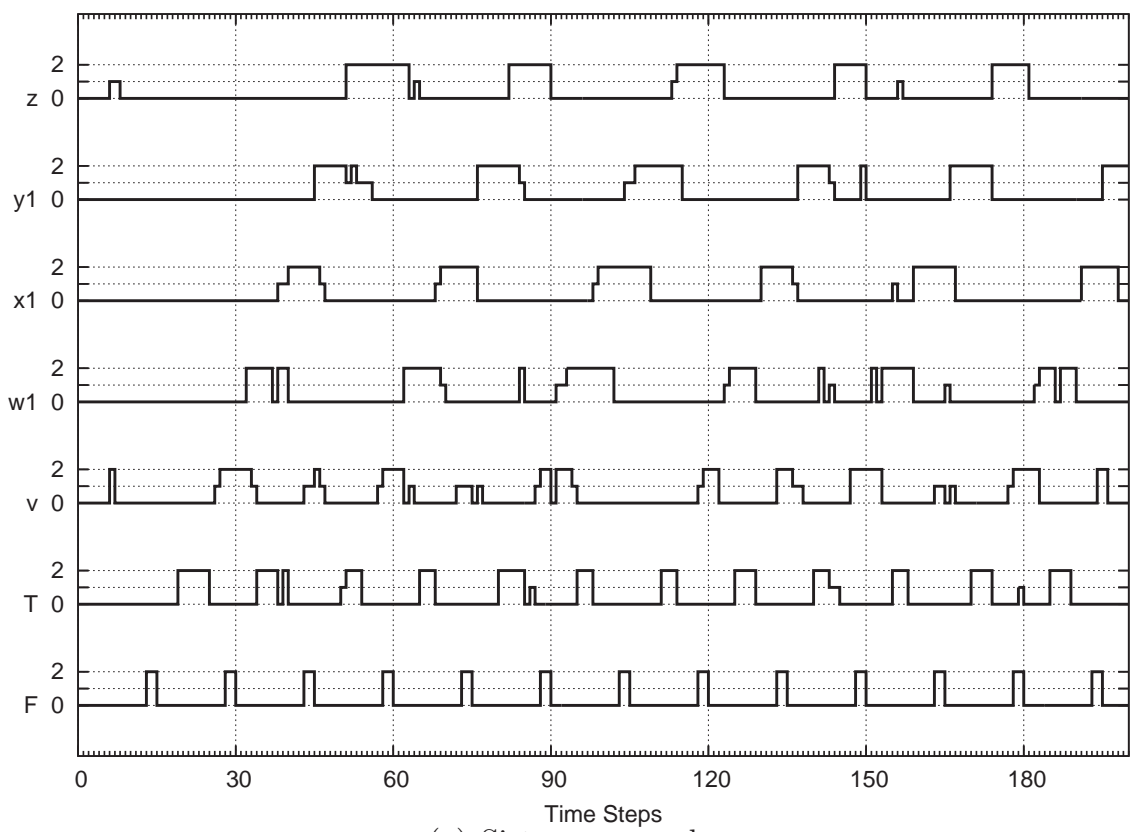

(a) Sistema normal.

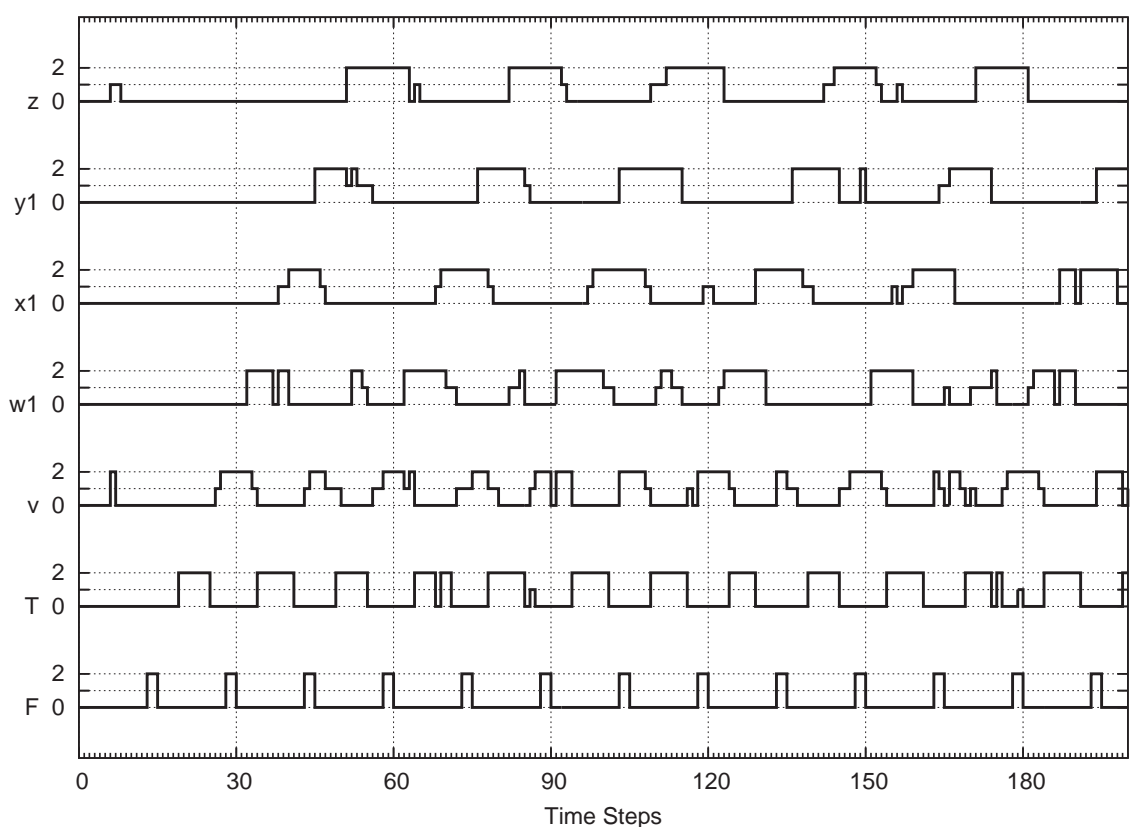

(b) Sistema sem realimentações negativas para o gene disparador $\mathrm{T}$.

Figura A.52: Sobre-expressão relativa do gene T em ausência de realimentações negativas para ele (Modelo PGN do sistema de controle do ciclo celular com $1 \%$ de ruído ativado com $F=$ oscilador de período 15). 


\section{A.2.4.3 Aumentando gradualmente o nível de ruído presente no sistema ${ }^{3}$}

Neste grupo de testes aumentamos gradualmente — a passos de 0,5\% - o nível de ruído no sistema, partindo de $0 \%(P=1)$ até um $5 \%(P=0.95)$. Observamos que um ruído acima de $3 \%$ causa alguns problemas no sistema, por exemplo na Figura A.53(b) vemos que um trem intermédio - entre dois ciclos consecutivos - de sinal é gerado por ruído originado na camada v. Um 5\% de ruído causa sérios problemas no funcionamento do sistema, como: i) ondas de propagação geradas pelo ruído quando não existe sinal de ativação (Figura A.54(b)), ii) o ruído impede o disparo ou a propagação de uma onda apesar de existir o sinal de ativação necessário (Figura A.55(b)) ou iii) até um sinal de ativação constante $(F=2)$ não consegue impor seu padrão de saturação no sistema (Figura A.56(b)).

\footnotetext{
${ }^{3}$ http://www.vision.ime.usp.br/ walter/sim3/Simulacoes.html
} 


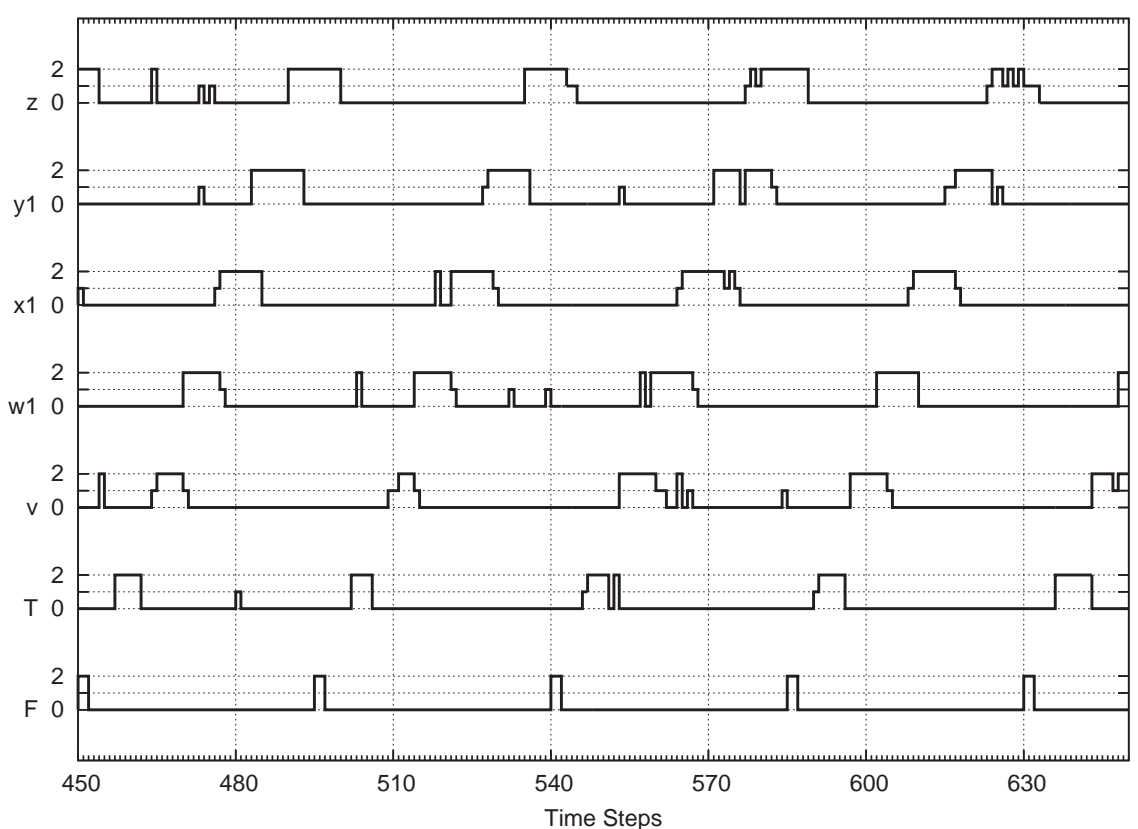

(a) $1 \%$ de ruído no sistema.

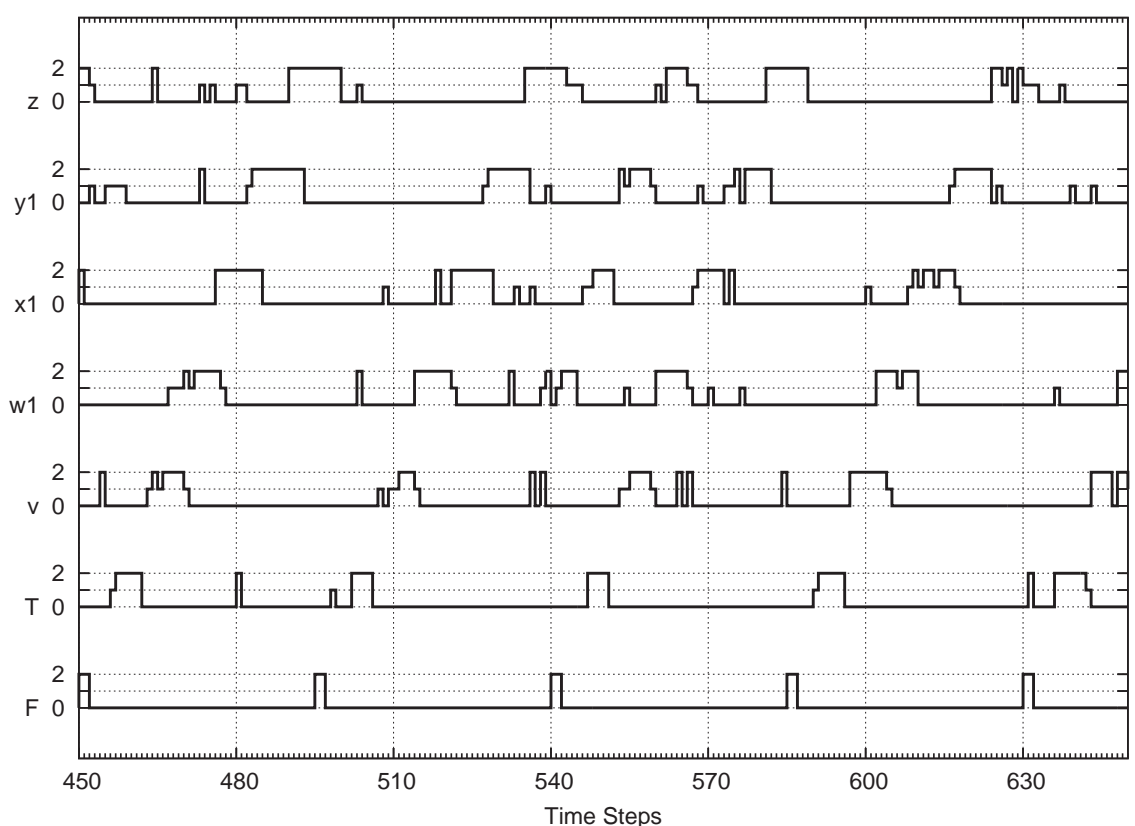

(b) $3 \%$ de ruído no sistema. Uma onda de sinal, gerada por ruído na camada $v$, consegue se propagar pelo sistema.

Figura A.53: Onda de sinal gerada pelo ruído. Modelo PGN do sistema de controle do ciclo celular ativado com $F=$ oscilador de período 45 . 


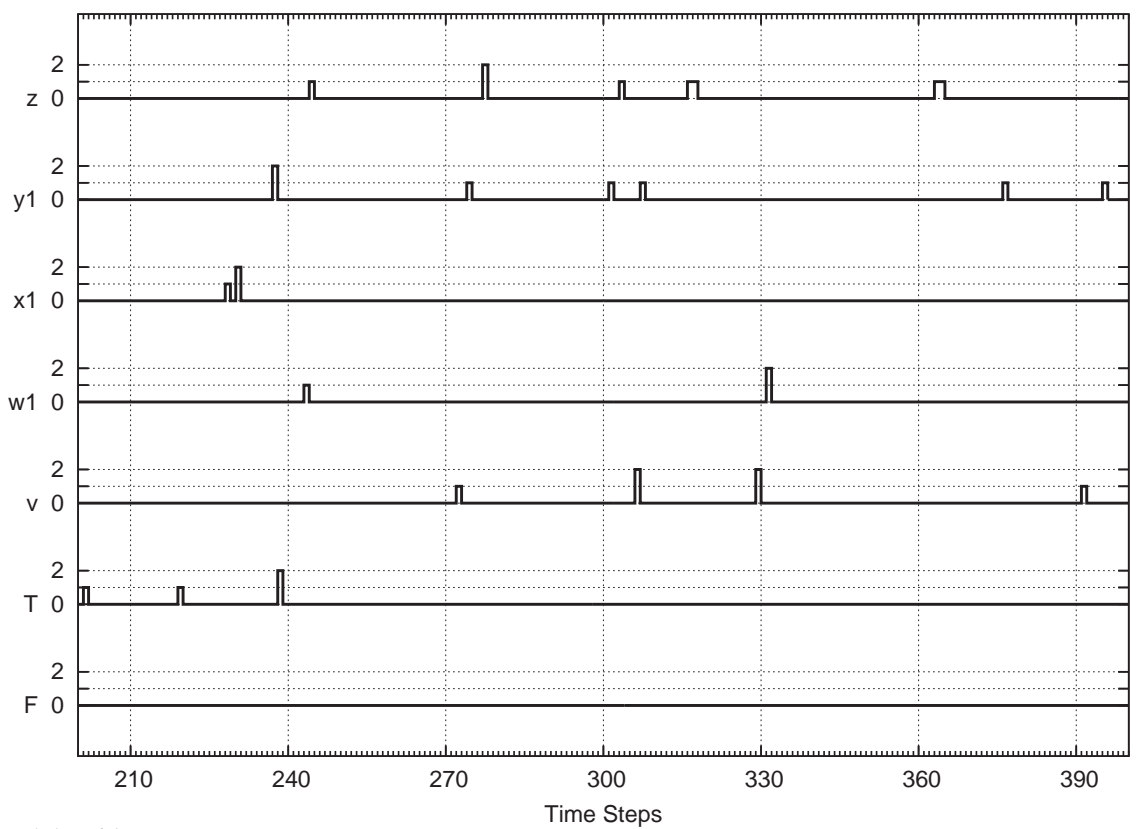

(a) $1 \%$ de ruído no sistema. Não há ondas de propagação geradas pelo ruído.

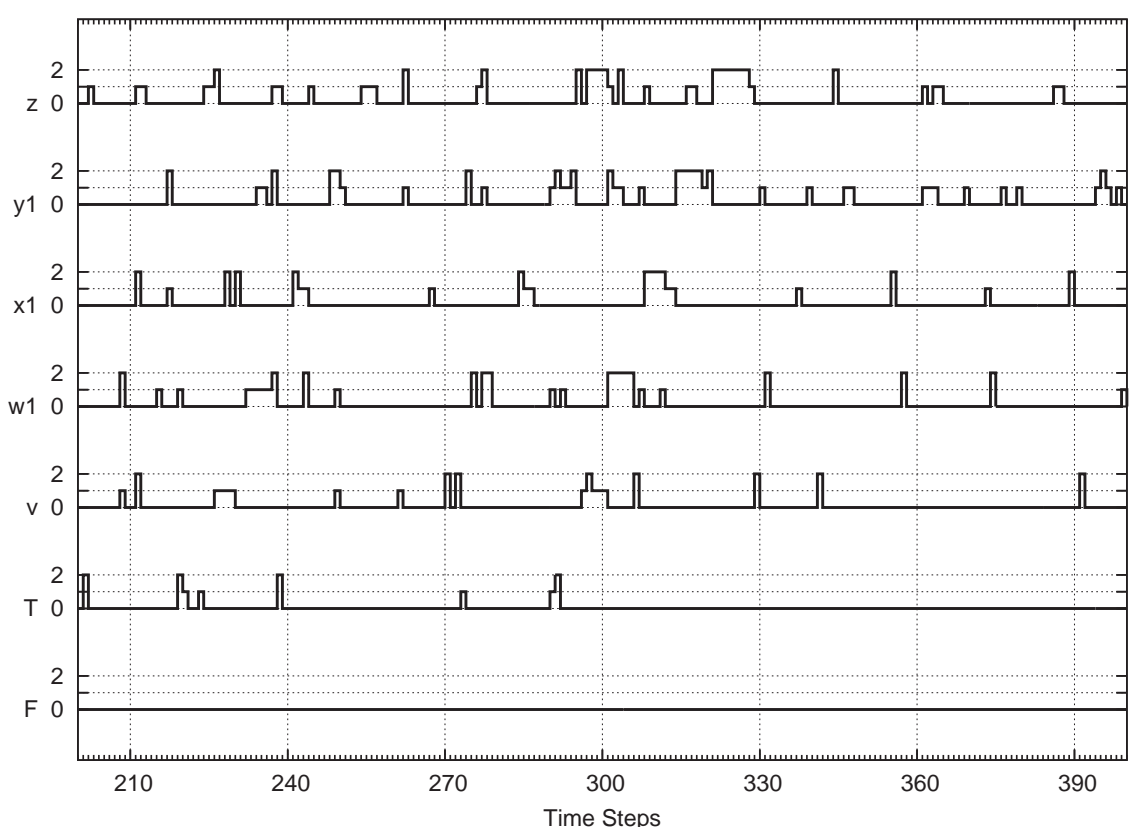

(b) $5 \%$ de ruído no sistema. Ondas de propagação são geradas pelo ruído (sem sinal $F$ de ativação).

Figura A.54: Ondas de sinal geradas pelo ruído em ausência de sinal $F$ de ativação. 


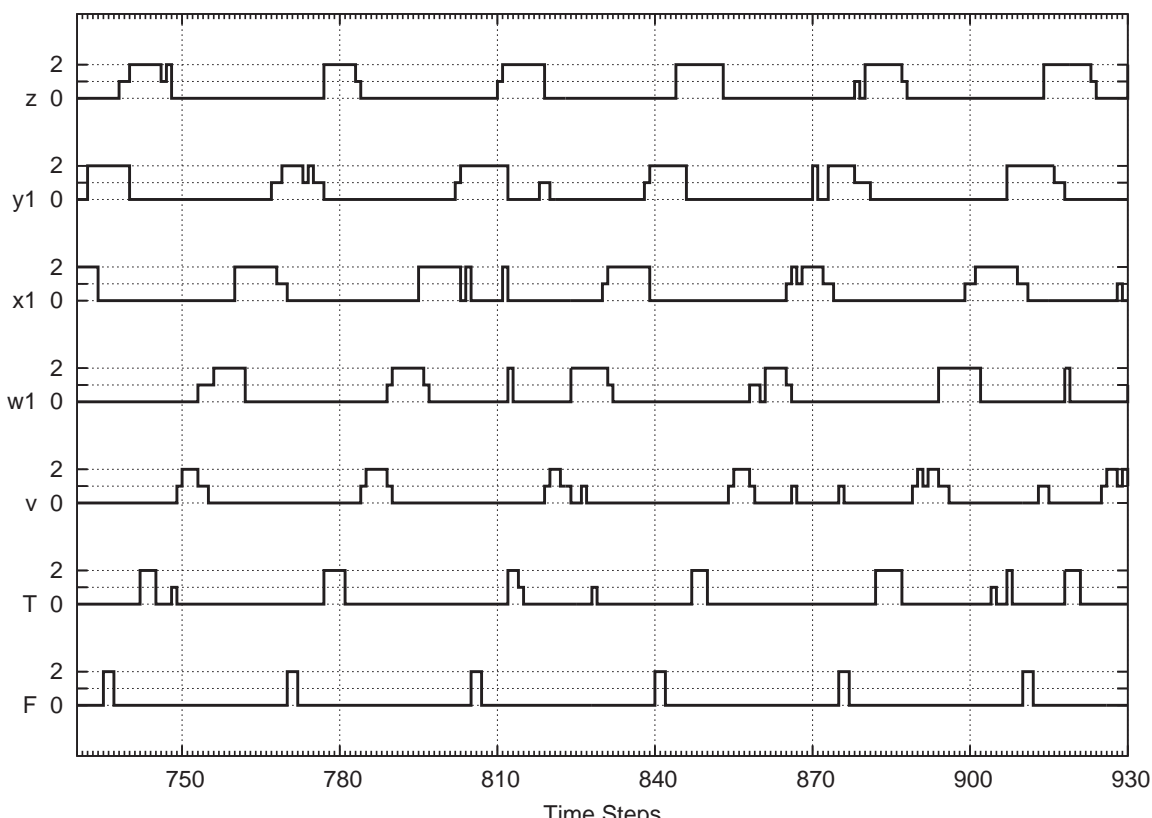

(a) $1 \%$ de ruído no sistema. Todos os ciclos são iniciados e acabam normalmente.

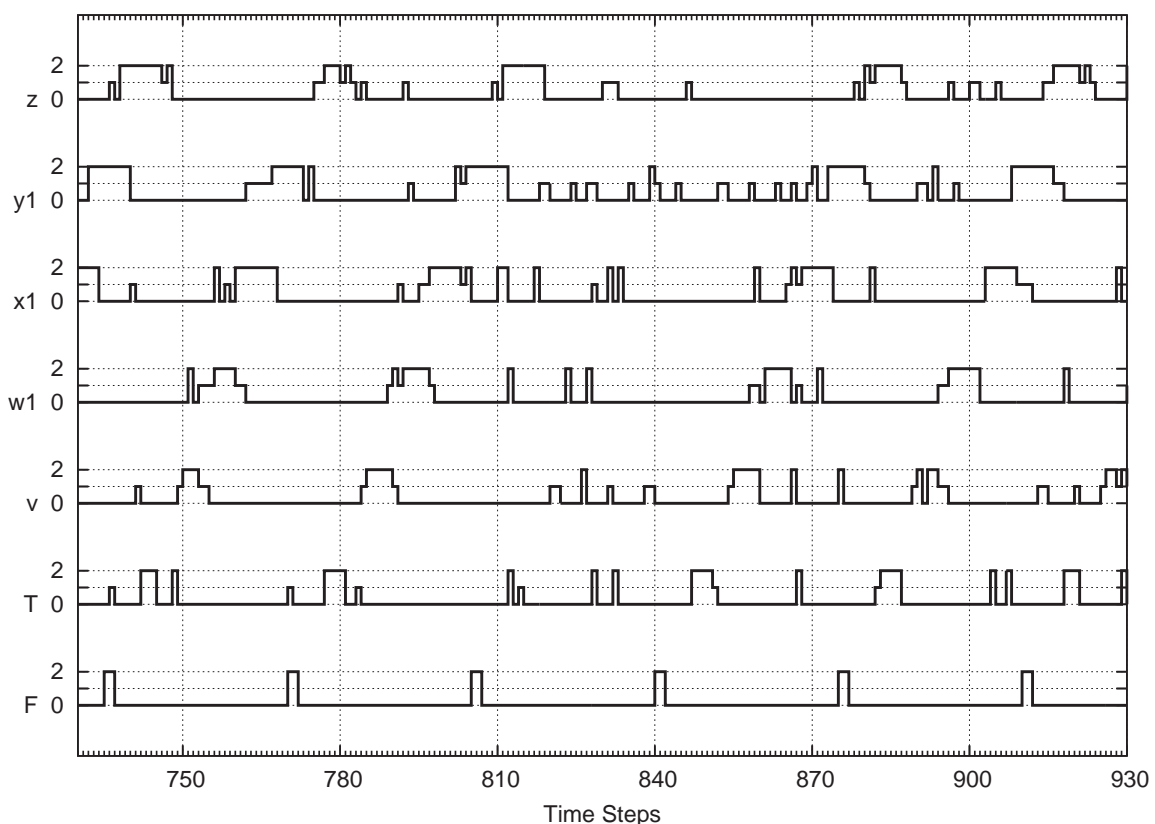

(b) $5 \%$ de ruído no sistema. O terceiro ciclo não consegue se executar por causa do ruído, apesar de existir o sinal $F$ de ativação necessário.

Figura A.55: O ruído impede a geração e propagação de uma onda de sinal, existindo o sinal $F$ de ativação necessário. Modelo PGN do sistema de controle do ciclo celular ativado com $F=$ oscilador de período 35. 


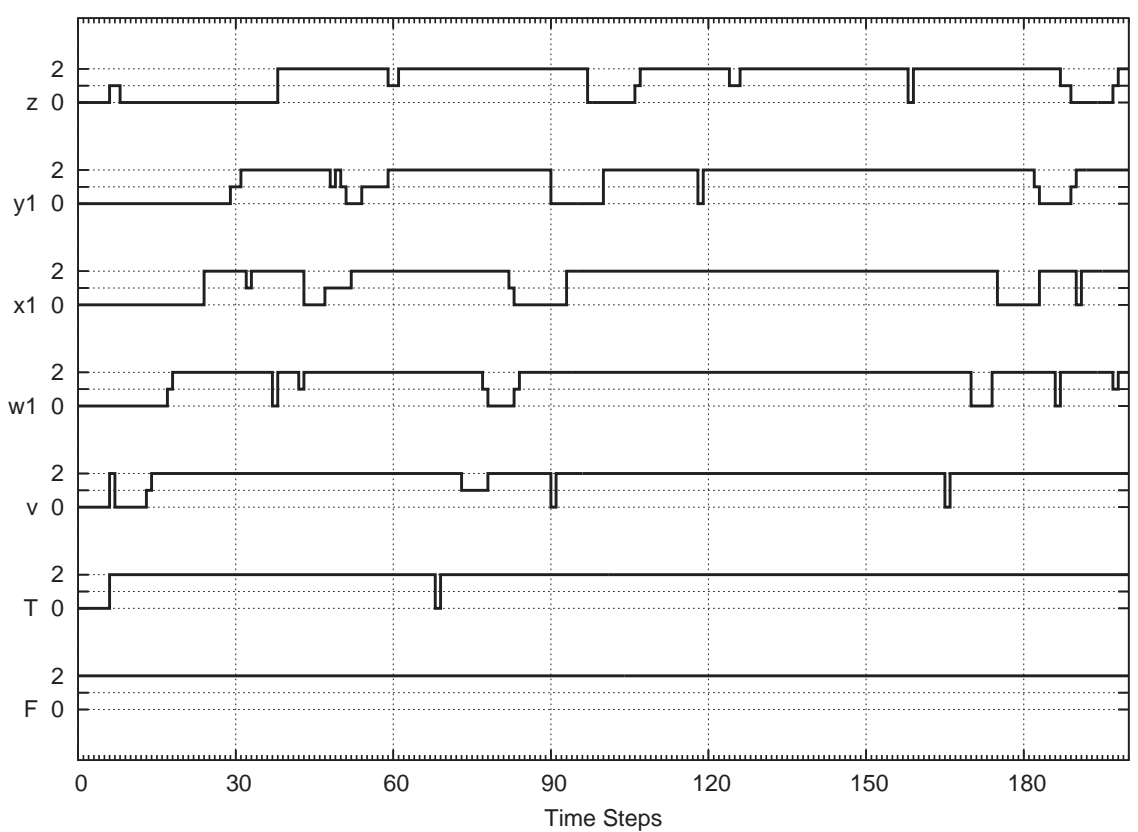

(a) $1 \%$ de ruído no sistema.

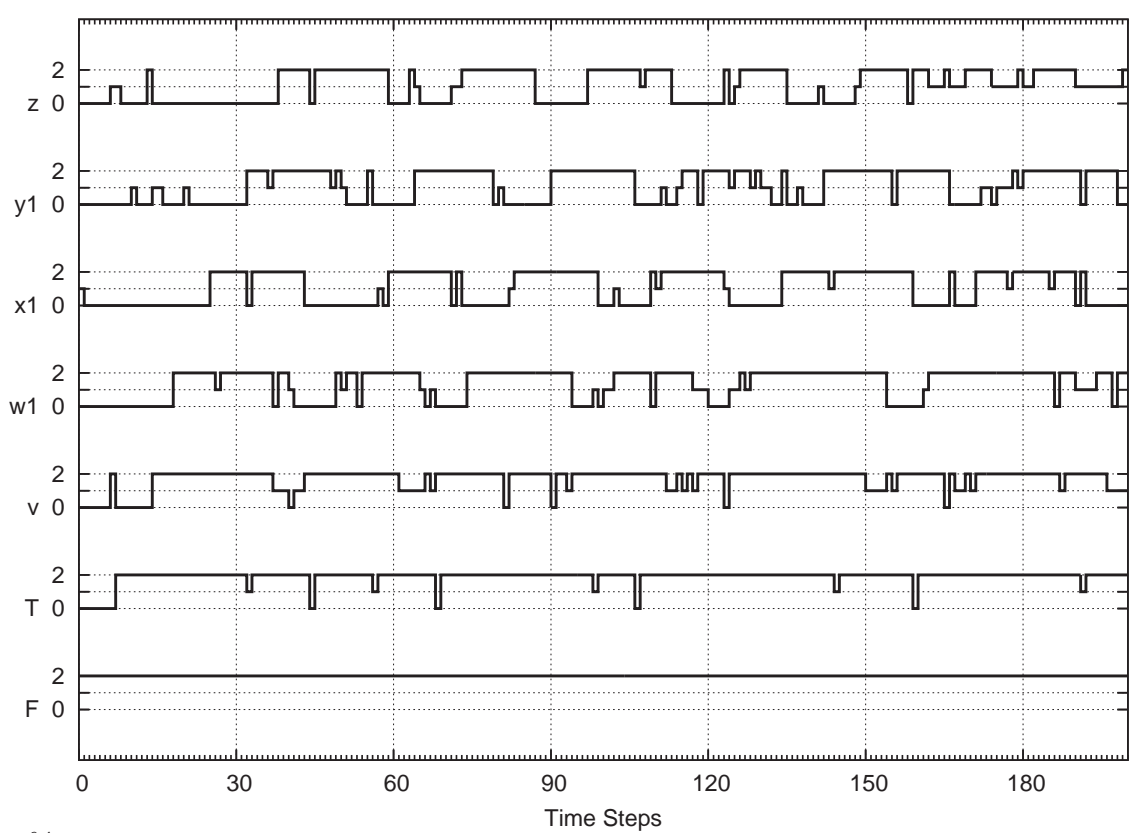

(b) $5 \%$ de ruído no sistema. Um sinal constante $F=2$ não consegue impor seu padrão de saturação no sistema por causa do ruido.

Figura A.56: Modelo PGN do sistema de controle do ciclo celular ativado com sinal constante $F=2$. 
Apêndice B

Publicações e Apresentações em

Eventos Científicos 
. 


\section{Lista de Trabalhos}

Os seguintes trabalhos foram publicados ou apresentados em eventos científicos durante o curso de doutorado:

"Identification of Input-free Finite Lattice Dynamical Systems under Envelope Constraints" Junior Barrera, Paulo A. Martin, Edward R. Dougherty, Marco D. Gubitoso, Nina S. T. Hirata and Nestor W. Trepode. Artigo em: International Symposium on Mathematical Morphology (ISMM) and its Applications to Image and Signal Processing, Sydney, Australia, 2002.

"From Microarray Images to Biological Knowledge" Junior Barrera, Roberto M. Cesar Jr, Daniel O. Dantas, David C. Martins and Nestor W. Trepode. Artigo em: II Simpósio Brasileiro de Biologia Matemática e Computacional, Río de Janeiro, Setembro de 2002.

"An Approach for Studying Genetic Networks: Discrete Dynamical System Simulation. A Case Study: The Cell Cycle." Nestor Walter Trepode, Hugo Aguirre Armelin, Michael Bittner, Junior Barrera and Marco Dimas Gubitoso. Pôster apresentado em: ICoBiCoBi: 1st. International Conference on Bioinformatics and Computational Biology, Maio de 2003, Riberão Preto, São Paulo, Brasil.

"Envelope and Multi-resolution Constraints in Genetic Network Identification" Nestor Walter Trepode, Junior Barrera, Ronaldo Fumio Hashimoto and Paulo Agozzini Martin. Pôster apresentado em: ICoBiCoBi: 1st. International Conference on Bioinformatics and Computational Biology, Maio de 2003, Riberão Preto, São Paulo, Brasil. 
"Discrete Dynamical System Simulation for the Study of Genetic Netwoks" Walter Trepode, Hugo Aguirre Armelin, Michael Bittner, Junior Barrera, Marco D. Gubitoso and Ronaldo F. Hashimoto. Pôster apresentado em: ICoBiCoBi II: 2nd. International Conference on Bioinformatics and Computational Biology, Outubro de 2004, Angra dos Reis, Rio de Janeiro.

"Modeling Cell Cycle Regulation by Discrete Dynamical Systems" Nestor Walter Trepode, Hugo Aguirre Armelin, Michael Bittner, Junior Barrera, Marco Dimas Gubitoso and Ronaldo Fumio Hashimoto". Publicação de resumo e apresentação oral em: GENSIPS 2005: IEEE International Workshop on Genomic Signal Processing and Statistics 2005.

“Cell-Cycle Control System Modeling and Simulation" Nestor Walter Trepode, Hugo Aguirre Armelin, Michael Bittner and Junior Barrera. Pôster apresentado em: X-Meeting 1st. International Conference of the AB3C (Associação Brasileira de Bioinformática e Biologia Computacional) Outubro de 2005, Caxambu, MG, Brasil.

"Modelagem e Simulação do Sistema de Controle do Ciclo Celular" Nestor Walter Trepode. Publicação de resumo e apresentação oral em: I Simpósio de Iniciação Científica e Pós-Graduação do IME-USP Outubro de 2005.

\footnotetext{
"A Robust Structural PGN Model for Control of Cell-Cycle Progression Stabilized by Negative Feedbacks" Nestor Walter Trepode, Hugo Aguirre Armelin, Michael Bittner, Junior Barrera, Marco Dimas Gubitoso and Ronaldo Fumio Hashimoto. Submetido para: EURASIP Journal on Bioinformatics and Systems Biology - Special Issue on Genetic Regulatory Networks - Publication: 1st Quarter, 2007.

En fase final de revisão, como dois de três árbitros recomendando: "Publish Unaltered".
} 


\section{Lista de Figuras}

2.1 Rede de regulação gênica . . . . . . . . . . . . . . . . . . . . 10

2.2 Sistema típico de controle. . . . . . . . . . . . . . . . . . . . 11

2.3 Modelo PGN de um gene. . . . . . . . . . . . . . . . . . . 16

2.4 Fases do Ciclo Celular . . . . . . . . . . . . . . . . . . . . . . . . . 19

2.5 Arquitetura do modelo de Li et al. do ciclo celular da levedura . . . . . . . . . . 24

3.1 Simulação do modelo do ciclo celular da levedura de três níveis determinístico, ativado por um único pulso de $C S=2$ em $t=-1 \ldots \ldots \ldots \ldots$

3.2 Simulação do modelo PGN de três níveis do ciclo celular da levedura com $1 \%$ de ruído (PGN com $P=0.99$ ) ativado por um único pulsos de $C S=2$ em $t=-1$. . 31

3.3 Simulação do modelo PGN de três níveis do ciclo celular da levedura com $1 \%$ de ruído (PGN com $P=0.99$ ) ativado por pulsos de $C S$ de freqüência crescente. . . 33

3.4 Arquitetura do nosso modelo de controle da progressão do ciclo celular. . . . . . 35

3.5 Exemplo de sinais regulatórios típicos em nosso modelo. . . . . . . . . . . . . . 37

3.6 Simulação de nosso modelo PGN de três níveis do sistema de controle da progressão do ciclo celular, com $1 \%$ de ruído (PGN com $P=0.99$ ) e novos pulsos de ativação de $F$ ocorrendo depois de que o ciclo anterior finalizou. . . . . . . . . . . .

3.7 Simulação de nosso modelo PGN de três níveis do sistema de controle da progressão do ciclo celular, com $1 \%$ de ruído (PGN com $P=0.99$ ) e pulsos ativadores de $F$ que arribam eventualmente antes do que o ciclo prévio termine. . . . . . . . . .

3.8 Simulação de nosso modelo PGN de três níveis do sistema de controle da progressão do ciclo celular com atrasos aleatórios e $1 \%$ de ruído (PGN com $P=0.99$ ), quando os pulsos ativadores de $F$ chegam depois de que o ciclo anterior finalizou. . . . .

3.9 Simulação de nosso modelo PGN de três níveis do sistema de controle da progressão do ciclo celular com atrasos aleatórios, $1 \%$ de ruído (PGN com $P=0.99$ ), quando os pulsos ativadores de $F$ chegam antes de que o ciclo anterior termine e com ativação constante $F=2 \ldots \ldots \ldots \ldots \ldots$

3.10 Modelo de controle da progressão do ciclo celular com atrasos aleatórios e realimentação positiva do gene $z$ para o gene disparador $T\left(a_{z T}^{k}=7, k=5+t_{d}\right), 1 \%$ de ruído e um único pulso ativador inicial $F=2$ em $t=-1,-2 . \ldots \ldots$. . . 
A.1 Modelo PGN de três níveis do ciclo celular da levedura com $1 \%$ de ruido (PGN com $P=0.99)$ ativado por $\mathbf{C S}=$ oscilador de período $20 . \ldots \ldots$. . .

A.2 Modelo PGN de três níveis do ciclo celular da levedura com $1 \%$ de ruido (PGN com $P=0.99)$ ativado por $\mathbf{C S}=$ oscilador de período 20 (100 primeiros

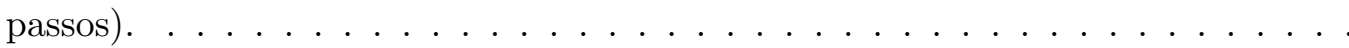

A.3 Modelo PGN de três níveis do ciclo celular da levedura com $1 \%$ de ruido (PGN com $P=0.99$ ) ativado por $\mathbf{C S}=$ oscilador de período $15 \ldots \ldots \ldots$

A.4 Modelo PGN de três níveis do ciclo celular da levedura com $1 \%$ de ruido (PGN com $P=0.99)$ ativado por $\mathbf{C S}=$ oscilador de período $10 . \ldots$. . . . . .

A.5 Modelo PGN de três níveis do ciclo celular da levedura com $1 \%$ de ruido (PGN com $P=0.99$ ) ativado por $\mathbf{C S}=$ oscilador de período $6 . \ldots \ldots$

A.6 Modelo PGN de três níveis do ciclo celular da levedura com $1 \%$ de ruido (PGN com $P=0.99)$ ativado por $\mathbf{C S}=$ oscilador de período $4 . \ldots \ldots$. . . .

A.7 Modelo PGN de três níveis do ciclo celular da levedura com $1 \%$ de ruido (PGN com $P=0.99$ ) ativado por $\mathbf{C S}=$ oscilador de período $3 . \ldots \ldots \ldots$

A.8 Modelo PGN de três níveis do ciclo celular da levedura com $1 \%$ de ruido (PGN com $P=0.99)$ ativado por $\mathbf{C S}=$ oscilador de período $2 . \ldots \ldots$. . . .

A.9 Modelo PGN de três níveis do ciclo celular da levedura com $1 \%$ de ruido (PGN com $P=0.99$ ) ativado por um sinal constante $\mathbf{C S}=\mathbf{2} \ldots \ldots \ldots \ldots$

A.10 Modelo PGN de três níveis do ciclo celular da levedura com $\mathbf{1 \%}$ de ruido (PGN com $P=0.99)$ ativado por um único pulso de $C S=2$ em $t=-1$. . . . . . . .

A.11 Modelo PGN de três níveis do ciclo celular da levedura com $\mathbf{0 , 5 \%}$ de ruido (PGN com $P=0.995$ ) ativado por um único pulso de $C S=2$ em $t=-1 . \quad$. .

A.12 Modelo PGN de três níveis do ciclo celular da levedura com $\mathbf{0 , 4 \%}$ de ruido (PGN com $P=0.996$ ) ativado por um único pulso de $C S=2$ em $t=-1$. . .

A.13 Modelo PGN de três níveis do ciclo celular da levedura com $\mathbf{0}, \mathbf{3 \%}$ de ruido (PGN com $P=0.997$ ) ativado por um único pulso de $C S=2 \mathrm{em} t=-1$. . . .

A.14 Modelo PGN de três níveis do ciclo celular da levedura com $\mathbf{0 , 2 \%}$ de ruido (PGN com $P=0.998$ ) ativado por um único pulso de $C S=2$ em $t=-1$. . . .

A.15 Modelo PGN de três níveis do ciclo celular da levedura com $\mathbf{0 , 1 \%}$ de ruido (PGN com $P=0.999$ ) ativado por um único pulso de $C S=2 \mathrm{em} t=-1$. . . .

A.16 Modelo PGN de três níveis do ciclo celular da levedura com $\mathbf{0 , 0 5 \%}$ de ruido (PGN com $P=0.9995)$ ativado por um único pulso de $C S=2$ em $t=-1$. . .

A.17 Modelo PGN de três níveis do ciclo celular da levedura com $\mathbf{0 \%}$ de ruido (PGN com $P \rightarrow 1$, sistema determinístico) ativado por um único pulso de $C S=2 \mathrm{em}$ $t=-1 \ldots \ldots \ldots \ldots \ldots \ldots \ldots \ldots \ldots \ldots \ldots \ldots \ldots \ldots \ldots \ldots \ldots \ldots$

A.18 Modelo PGN de três níveis do sistema de controle da progressão do ciclo celular, com $1 \%$ de ruído (PGN com $P=0.99$ ) ativado por um único pulso de $\mathbf{F}=\mathbf{2}$ em $\mathbf{t}=-1$. 
A.19 Modelo PGN de três níveis do sistema de controle da progressão do ciclo celular, com $1 \%$ de ruído (PGN com $P=0.99$ ) ativado por $\mathbf{F}=$ oscilador de período 50 .

A.20 Modelo PGN de três níveis do sistema de controle da progressão do ciclo celular, com $1 \%$ de ruído (PGN com $P=0.99$ ) ativado por $\mathbf{F}=$ oscilador de período 30 .

A.21 Modelo PGN de três níveis do sistema de controle da progressão do ciclo celular, com $1 \%$ de ruído (PGN com $P=0.99$ ) ativado por $\mathbf{F}=$ oscilador de período 20 .

A.22 Modelo PGN de três níveis do sistema de controle da progressão do ciclo celular, com $1 \%$ de ruído (PGN com $P=0.99$ ) ativado por $\mathbf{F}=$ oscilador de período 10 .

A.23 Modelo PGN de três níveis do sistema de controle da progressão do ciclo celular, com $1 \%$ de ruído (PGN com $P=0.99$ ) ativado por $\mathbf{F}=$ oscilador de período 5 .

A.24 Modelo PGN de três níveis do sistema de controle da progressão do ciclo celular, com $1 \%$ de ruído (PGN com $P=0.99$ ) ativado por $\mathbf{F}=$ oscilador de período 3 .

A.25 Modelo PGN de três níveis do sistema de controle da progressão do ciclo celular, com $1 \%$ de ruído (PGN com $P=0.99$ ) ativado por $\mathbf{F}=$ oscilador de período 2 .

A.26 Modelo PGN de três níveis do sistema de controle da progressão do ciclo celular, com $1 \%$ de ruído (PGN com $P=0.99$ ) ativado por um sinal constante $\mathbf{F}=\mathbf{2}$.

A.27 Modelo PGN de três níveis do sistema de controle da progressão do ciclo celular com $\mathbf{0 \%}$ de ruido (PGN com $P \rightarrow 1$, sistema determinístico) ativado por um único pulso de $F=2$ em $t=-1$.

A.28 Modelo PGN de três níveis do sistema de controle da progressão do ciclo celular com 1\% de ruido (PGN com $P=0.99$ ) ativado por um único pulso de $F=2$ em $t=-1 . \ldots \ldots \ldots \ldots \ldots \ldots$

A.29 Modelo PGN de três níveis do sistema de controle da progressão do ciclo celular com $2 \%$ de ruido (PGN com $P=0.98$ ) ativado por um único pulso de $F=2$ em $t=-1 . \ldots \ldots \ldots \ldots \ldots \ldots \ldots \ldots \ldots \ldots \ldots \ldots \ldots \ldots \ldots \ldots \ldots$

A.30 Modelo PGN de três níveis do sistema de controle da progressão do ciclo celular com 3\% de ruido (PGN com $P=0.97$ ) ativado por um único pulso de $F=2$ em $t=-1 . \ldots \ldots \ldots \ldots \ldots \ldots$

A.31 Modelo PGN de três níveis do sistema de controle da progressão do ciclo celular com 4\% de ruido (PGN com $P=0.96$ ) ativado por um único pulso de $F=2$ em $t=-1 . \ldots \ldots \ldots \ldots \ldots \ldots$

A.32 Modelo PGN de três níveis do sistema de controle da progressão do ciclo celular com $\mathbf{5 \%}$ de ruido (PGN com $P=0.95$ ) ativado por um único pulso de $F=2$ em $t=-1$. 
A.33 Modelo PGN de três níveis do sistema de controle da progressão do ciclo celular com atrasos aleatórios, $1 \%$ de ruído (PGN com $P=0.99$ ) e ativado por um único pulso de $\mathrm{F}=2 \mathrm{em} \mathrm{t}=-1,-2$.

A.34 Modelo PGN de três níveis do sistema de controle da progressão do ciclo celular com atrasos aleatórios, $1 \%$ de ruído (PGN com $P=0.99$ ) e ativado por $\mathbf{F}=$ oscilador de período $60 \ldots \ldots \ldots \ldots \ldots$

A.35 Modelo PGN de três níveis do sistema de controle da progressão do ciclo celular com atrasos aleatórios, $1 \%$ de ruído (PGN com $P=0.99$ ) e ativado por $\mathbf{F}=$ oscilador de período 45 .

A.36 Modelo PGN de três níveis do sistema de controle da progressão do ciclo celular com atrasos aleatórios, $1 \%$ de ruído (PGN com $P=0.99$ ) e ativado por $\mathbf{F}=$ oscilador de período 40 .

A.37 Modelo PGN de três níveis do sistema de controle da progressão do ciclo celular com atrasos aleatórios, $1 \%$ de ruído $(\mathrm{PGN}$ com $P=0.99)$ e ativado por $\mathbf{F}=$ oscilador de período 35 .

A.38 Modelo PGN de três níveis do sistema de controle da progressão do ciclo celular com atrasos aleatórios, $1 \%$ de ruído (PGN com $P=0.99$ ) e ativado por $\mathbf{F}=$ oscilador de período 30 .

A.39 Modelo PGN de três níveis do sistema de controle da progressão do ciclo celular com atrasos aleatórios, $1 \%$ de ruído (PGN com $P=0.99$ ) e ativado por $\mathbf{F}=$ oscilador de período $25 \ldots \ldots \ldots \ldots$

A.40 Modelo PGN de três níveis do sistema de controle da progressão do ciclo celular com atrasos aleatórios, $1 \%$ de ruído $(\mathrm{PGN}$ com $P=0.99$ ) e ativado por $\mathbf{F}=$ oscilador de período 20 .

A.41 Modelo PGN de três níveis do sistema de controle da progressão do ciclo celular com atrasos aleatórios, $1 \%$ de ruído (PGN com $P=0.99$ ) e ativado por $\mathbf{F}=$ oscilador de período $15 \ldots \ldots \ldots \ldots$

A.42 Modelo PGN de três níveis do sistema de controle da progressão do ciclo celular com atrasos aleatórios, $1 \%$ de ruído $(\mathrm{PGN}$ com $P=0.99$ ) e ativado por $\mathbf{F}=$ oscilador de período 10 .

A.43 Modelo PGN de três níveis do sistema de controle da progressão do ciclo celular com atrasos aleatórios, $1 \%$ de ruído (PGN com $P=0.99$ ) e ativado por $\mathbf{F}=$ oscilador de período 8

A.44 Modelo PGN de três níveis do sistema de controle da progressão do ciclo celular com atrasos aleatórios, $1 \%$ de ruído (PGN com $P=0.99$ ) e ativado por $\mathbf{F}=$ oscilador de período 6 .

A.45 Modelo PGN de três níveis do sistema de controle da progressão do ciclo celular com atrasos aleatórios, $1 \%$ de ruído (PGN com $P=0.99$ ) e ativado por $\mathbf{F}=$ oscilador de período 4 . 
A.46 Modelo PGN de três níveis do sistema de controle da progressão do ciclo celular com atrasos aleatórios, $1 \%$ de ruído (PGN com $P=0.99$ ) e ativado por um sinal constante $\mathbf{C S}=\mathbf{2} \ldots \ldots \ldots \ldots \ldots \ldots \ldots$

A.47 Efeito da diminuição da força das realimentações no modelo PGN do sistema de controle do ciclo celular com $1 \%$ de ruído $(F=$ oscilador de período 25$)$. Em b) uma onda de sinal consegue se propagar com o ciclo anterior ainda en andamento, devido ao enfraquecimento da força das realimentações negativas. . . . . . . . .

A.48 Efeito de alargamento progressivo do pulso de sinal, devido à ausência de realimentações para a camada anterior no modelo PGN do sistema de controle do ciclo celular com $1 \%$ de ruído $(F=$ oscilador de período 45$)$. . . . . . . . . .

A.49 Aumento do numero de trens múltiplos de sinal para ativação $F$ muito freqüente ( $F=$ oscilador de período 10, neste caso), no modelo PGN do sistema de controle do ciclo celular com $1 \%$ de ruído. . . . . . . . . . . . . .

A.50 Padrão de expressão produzido pelas realimentações para o gene disparador $\mathrm{T}$ quando o sinal de ativação $F$ é muito freqüente $(F=$ oscilador de período 8 , neste caso), no modelo PGN do sistema de controle do ciclo celular com $1 \%$ de ruído. Em b) pode ver-se que este efeito é produzido inteiramente pelas realimentações negativas para o gene disparador $T \ldots \ldots \ldots \ldots$

A.51 Efeito regulador das realimentações para o gene disparador T: em a) elas inibem disparo de um novo ciclo de divisão celular enquanto o anterior está em andamento, sem elas, em b), estes disparos não desejados acontecem (Modelo PGN do sistema de controle do ciclo celular com $1 \%$ de ruído ativado com $F=$ oscilador de período 25)

A.52 Sobre-expressão relativa do gene T em ausência de realimentações negativas para ele (Modelo PGN do sistema de controle do ciclo celular com 1\% de ruído ativado com $F=$ oscilador de período 15$). \ldots \ldots \ldots \ldots$

A.53 Onda de sinal gerada pelo ruído. Modelo PGN do sistema de controle do ciclo celular ativado com $F=$ oscilador de período $45 . \ldots \ldots \ldots$. . . . . 97

A.54 Ondas de sinal geradas pelo ruído em ausência de sinal $F$ de ativação. . . . . 98

A.55 O ruído impede a geração e propagação de uma onda de sinal, existindo o sinal $F$ de ativação necessário. Modelo PGN do sistema de controle do ciclo celular ativado com $F=$ oscilador de período $35 \ldots \ldots \ldots \ldots$

A.56 Modelo PGN do sistema de controle do ciclo celular ativado com sinal constante $F=2$. 


\section{Lista de Tabelas}

2.1 Lista simplificada de estados da via biológica. As variáveis de estado são indicadas nesta ordem: Cln3, MBF, SBF, Cln12, Cdh1, Swi5, Cdc20Cdc14, Clb56, Sic1, Clb12, Mcm1SFF. . . . . . . . . . . . . . . . . .

3.1 Mapeamento do modelo binário determinístico no modelo de três níveis determinístico do ciclo celular da levedura. Para as variáveis com a propriedade de auto degradação, o valor de $x_{i}(t)$ é aquele da coluna de $x_{i}(t-1)=0$, independentemente do valor $x_{i}(t-1) \ldots \ldots \ldots \ldots \ldots \ldots \ldots$

3.2 Valores dos pesos da PGN e limiares da função de transição. . . . . . . . . . . . 39

3.3 Probabilidades dos atrasos $\mathbf{t}_{\mathbf{d}} \ldots \ldots \ldots \ldots \ldots \ldots \ldots \ldots$

3.4 Valores dos pesos da PGN e limiares da função de transição no modelo com atrasos aleatórios nos sinais de regulação. . . . . . . . . . . . . . . . . 46 



\section{Referências Bibliográficas}

[1] Katherine C. Chen, Laurence Calzone, Attila Csikasz-Nagy, Frederick R. Cross, Bela Novak, and John J. Tyson. Integrative analysis of cell cycle control in budding yeast. Molecular Biology of the Cell, 15:3841-3862, 2004.

[2] Stefan Bornholdt. Less is more in modeling large genetic networks. Science, 310:449-450, 2005 .

[3] Fangting Li, Tao Long, Ying Lu, Qi Ouyang, and Chao Tang. The yeast cell-cycle network is robustly designed. PNAS, 101:4781-4786, 2004.

[4] Reka Albert and Hans G. Othmer. The topology of the regulatory interactions predicts the expression pattern of the segment polarity genes in drosophila melanogaster. Journal of Theoretical Biology, 223:1-18, 2003.

[5] Ivan Ivanov and Edward R. Dougherty. Modeling genetic regulatory networks: Continuous or discrete? Journal of Biological Systems, 14, No. 2:219-229, 2006.

[6] Andreas Wagner. Circuit topology and the evolution of robustness in two-gene circadian oscillators. Proceedings of the National Academy of Sciences, 102:11775-11780, 2005.

[7] Andrew Murray and Tim Hunt. The Cell Cycle: An Introduction. Oxford University Press, New York, 1993.

[8] Bruce Alberts, Alexander Johnson, Julian Lewis, Martin Raff, Keith Roberts, and Peter Walter. Molecular Biology of the Cell. Garland Science Publishing, New York, 4th. edition, 2002 .

[9] Mike Tyers. Cell cycle goes global. Current Opinion in Cell Biology, 16:602-613, 2004.

[10] Joseph R. Pomerening, Sun Y. Kim, and James E. Ferrell Jr. Systems-level dissection of the cell-cycle oscillator: Bypassing positive feedback produces damped oscillations. Cell, 122:565-578, 2005.

[11] Junior Barrera, Roberto M. Cesar Jr, David C. Martins Jr, Emilio F. Merino, Ricardo Z. N. Vêncio, Florencia G. Leonardi, Márcio M. Yamamoto, Carlos A. de B. Pereira, and Hernando A. del Portillo. A new annotation tool for malaria based on inference of probabilistic genetic networks. In $C A M D A$, pages 36-40, 2004. 
[12] Junior Barrera, Roberto M. Cesar Jr, David C. Martins Jr, Ricardo Z. N. Vêncio, Emilio F. Merino, Márcio M. Yamamoto, Florencia G. Leonardi, Carlos A. de B. Pereira, and Hernando A. del Portillo. Methods of Microarray Data Analysis V, chapter 2: Constructing Probabilistic Genetic Networks of Plasmodium falciparum from Dynamical Expression Signals of the Intraerythrocytic Developement Cycle. Springer Science, New York, 2007.

[13] Nestor W. Trepode, Hugo A. Armelin, Michael Bittner, Junior Barrera, Marco D. Gubitoso, and Ronaldo F. Hashimoto. Modeling cell cycle regulation by discrete dynamical systems. In GENSIPS 2005: IEEE International Workshop on Genomic Signal Processing and Statistics 2005, 2005.

[14] Nestor W. Trepode, Hugo A. Armelin, Michael Bittner, Junior Barrera, Marco D. Gubitoso, and Ronaldo F. Hashimoto. A robust structural PGN model for control of cell-cycle progression stabilized by negative feedbacks. EURASIP Journal on Bioinformatics and Systems Biology - Special Issue on Genetic Regulatory Networks, vol. 2007:Article ID 73109, 11 pages, 2007.

[15] http://genome-www.stanford.edu/cellcycle/.

[16] Paul T. Spellman, Gavin Sherlock, Michael Q. Zhang, Vishwanath R. Iyer, Kirk Anders, Michael B. Eisen, Patrick O. Brown, David Botstein, and Bruce FutcherDagger. Comprehensive identification of cell cycle-regulated genes of the yeast saccharomyces cerevisiae by microarray hybridization. Mol. Biol. Cell, 9:3273-3297, 1998. Identification of the 800 cell-cycle regulated genes.

[17] Shoudan Liang, Stefanie Furhman, and Roland Somogyi. Reveal, a general reverse engineering algorithm for inference of genetic network architectures. Pacific Symposium on Biocomputing, 3:18-29, 1998.

[18] Tatsuya Akutsu, Satoru Miyano, and Satoru Kuhara. Identification of genetic networks from a small number of gene expression patterns under the boolean network model. Pacific Symposium on Biocomputing, 4:17-28, 1999.

[19] Roland Somogyi and Carol A. Sniegoski. Modeling the complexity of genetic networks: understanding multigenic and pleiotropic regulation. Complexity, 1:45-63, 1996.

[20] Hugo A. Armelin, Junior Barrera, Edward R. Dougherty, João E. Ferreira, Marco D. Gubitoso, and Eduardo J. Neves. Simulator for gene expression networks. Microarrays: Optical Technologies and Informatics, Proc. SPIE, 4266:248-259, 2001.

[21] Stuart A. Kauffman. The Origins of Order. Self-Organization and Selection in Evolution. Oxford University Press, New York, 1993.

[22] Ilya Shmulevich, Edward R. Dougherty, Seungchan Kim, and Wei Zhang. Probabilistic boolean networks: a rule-based uncertainty model for gene regulatory networks. Bioinformatics, 18 (2):261-273, 2002. 
[23] Mattias Wahde and John Hertz. Coarse-grained reversed engineering of genetic regulatory networks. BioSystems, 55:129-136, 2000.

[24] Nir Friedman, Michal Linial, Iftach Nachman, and Dana Peer. Using bayesian networks to analyze expression data. Journal of Computational Biology, 7:601-620, 2000.

[25] Hidde de Jong. Modeling and simulation of regulatory systems: A literature review. Journal of Computational Biology, 9:67-103, 2002.

[26] John Goutsias and Seungchan Kim. A nonlinear discrete dynamical model for transcriptional regulation: Construction and properties. Biophyscal Journal, 86:1922-1945, 2004.

[27] Hiroaki Kitano. Biological robustness. Nature Reviews Genetics, 5:826-837, 2004.

[28] Katherine C. Chen, Attila Csikasz-Nagy, Bela Gyorffy, John Val, Bela Novak, and John J. Tyson. Kinetic analysis of a molecular model of the budding yeast cell cycle. Molecular Biology of the Cell, 11:369-391, 2000.

[29] John J. Tyson, Attila Csikasz-Nagy, and Bela Novak. The dynamics of cell cycle regulation. BioEssays, 24:1095-1109, 2002.

[30] Bela Novak and John J. Tyson. Modelling the controls of the eukaryotic cell cycle. Biochemical Society Transactions (2003) Volume 31, part 6, 31, part 6:1526-1529, 2003.

[31] Akos Sveiczer, John J. Tyson, and Bela Novak. A stochastic, molecular model of the fission yeast cell cycle: role of the nucleocytoplasmic ratio in cycle time regulation. Biophysical Chemistry, 92:1-15, 2001.

[32] Hiroaki Kitano. Systems biology: A brief overview. Science, 295. no. 5560:1662-1664, 2002. 